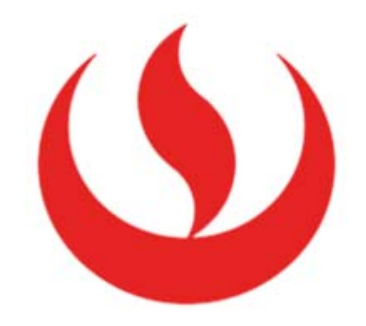

UNIVERSIDAD PERUANA DE CIENCIAS APLICADAS

FACULTAD DE ARQUITECTURA

PROGRAMA ACADÉMICO DE ARQUITECTURA

\title{
ESCUELA DE TEATRO EXPERIMENTAL EN COMAS
}

\author{
TESIS \\ Para optar el Título Profesional de Arquitecto \\ Autor \\ Ximena Segura Zúñiga (0000-0001-9921-4700) \\ Asesor de Tesis \\ Arq. Francisco Javier Elice Navarro (000-0002-0368-8344)
}

Lima, 20 de Setiembre de 2018 
A city has to take the long view, the view for the common good. Una ciudad debe tomar la visión de largo plazo, la visión para el bien común.

Amanda Burden Urban Planner 


\section{TABLA DE CONTENIDO}

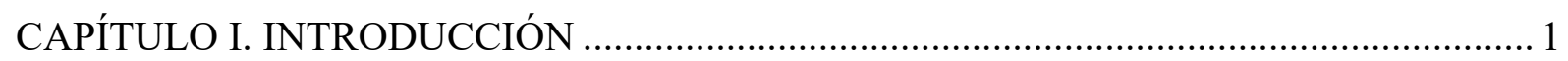

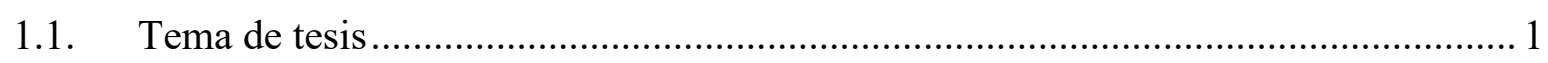

1.1.1. El lugar: Comas distrito Cultural ............................................................... 1

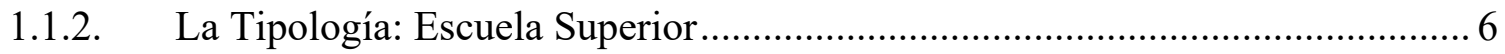

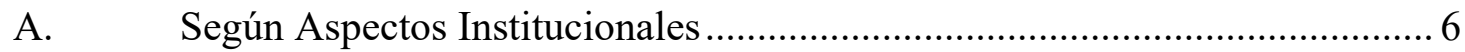

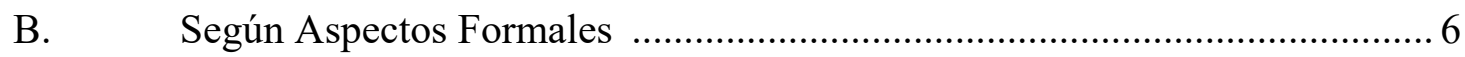

1.1.3. Objetivos Generales y Específicos para el diseño......................................... 8

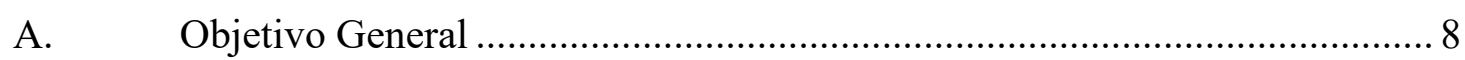

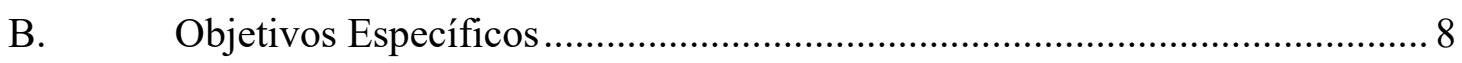

CAPÍtUlO II: CONCEPTOS APLICADOS AL DISEÑO DE LA ESCUELA

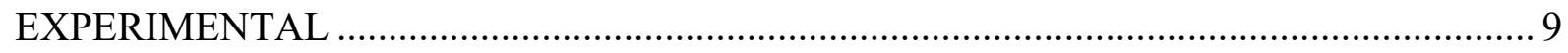

2.1. Selección y Sustentación de fuentes...................................................................... 9

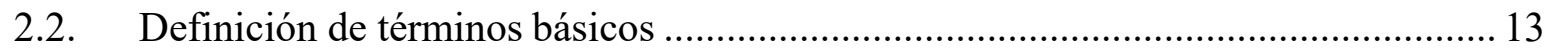

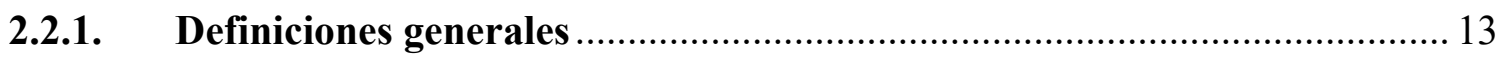

2.2.2. Espacios componentes de una escuela de Teatro ........................................... 15

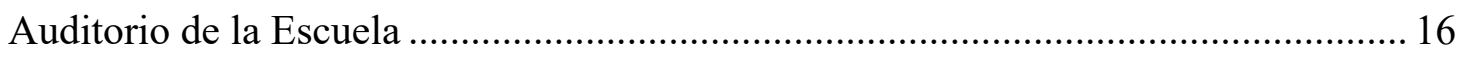

Black box Theater o Teatro de caja negra................................................................ 17

CAPÍTULO III: HISTORIA DE LA ENSEÑANZA TEATRAL SUPERIOR -

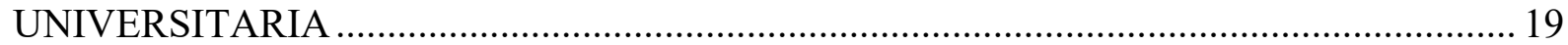

3.1. Historia de la enseñanza Superior/ Universitaria del teatro .................................... 19

3.2. Enseñanza Básica / Superior teatral en el Perú ................................................... 22

3.2.1. Facultad de Artes Escénicas - Teatro de la Universidad Católica del Perú........... 22

3.2.2. Escuela Nacional Superior de Arte Dramático ENSAD ........................................ 25

3.3. La Educación Tradicional y Nueva en el Mundo.................................................... 27

3.4. Educación y Espacios Experimentales en el Teatro .............................................. 28

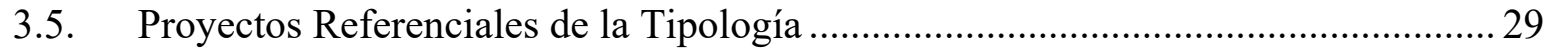

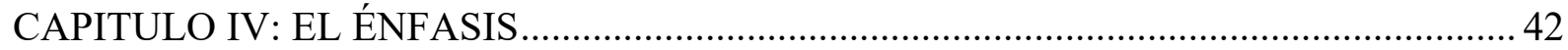

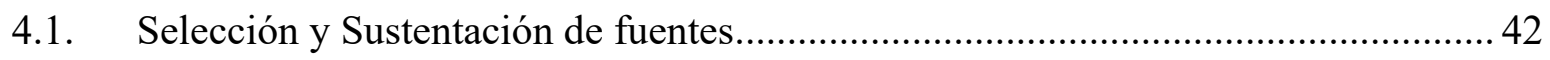

4.2. Espacios Experimentales de Enseñanza .......................................................... 45

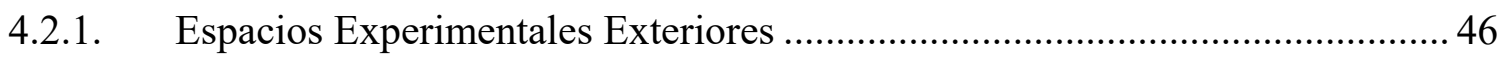

4.2.1.1. Espacios Experimentales en el Teatro ................................................... 49 


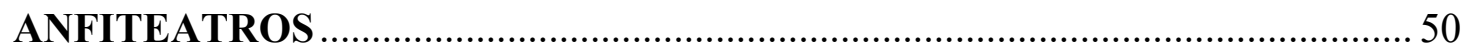

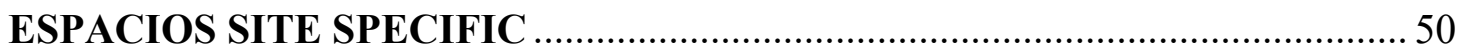

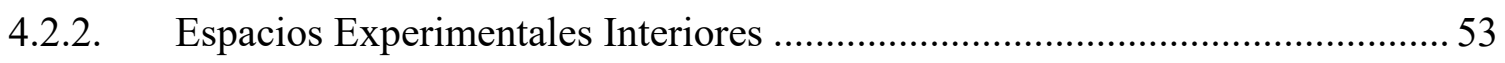

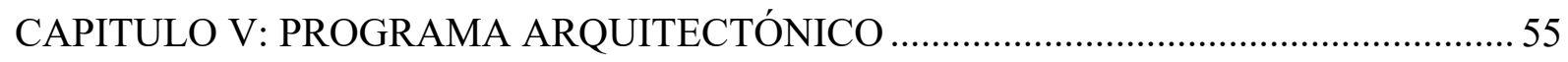

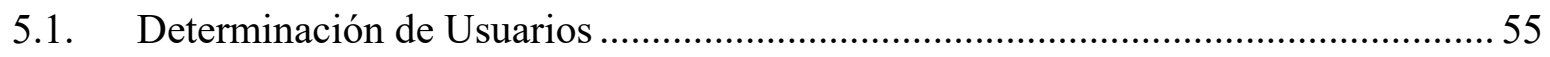

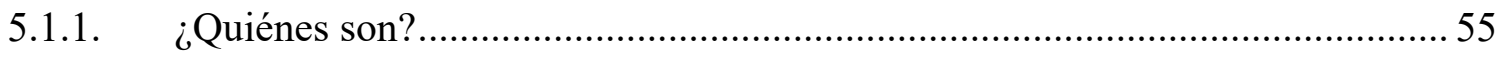

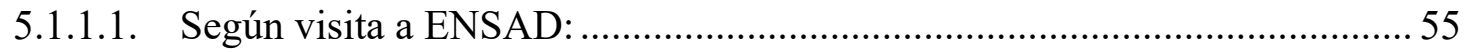

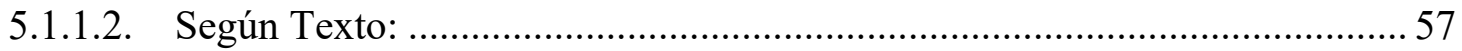

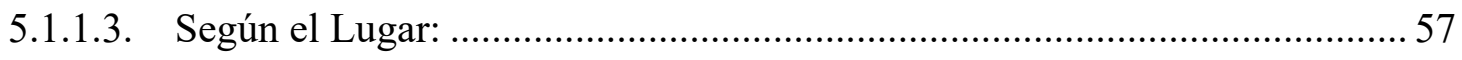

5.1.1.4. Conclusión de Organigrama Tipo de Usuarios: .......................................... 57

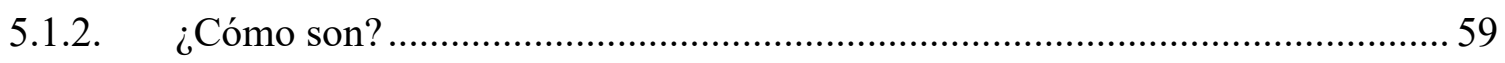

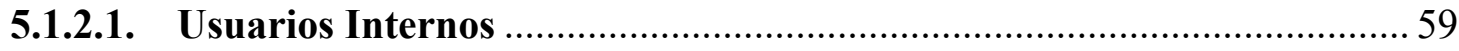

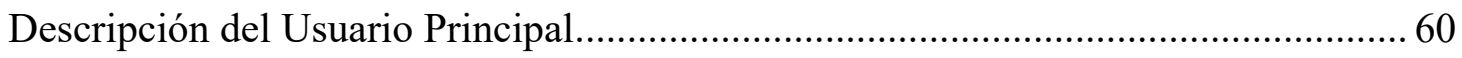

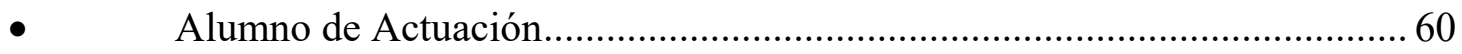

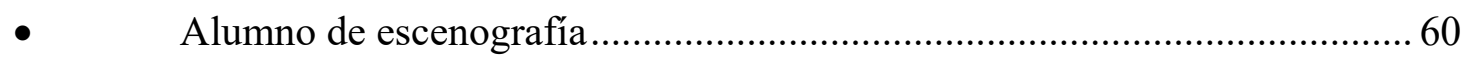

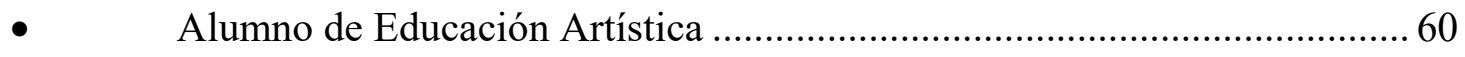

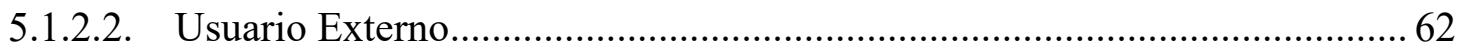

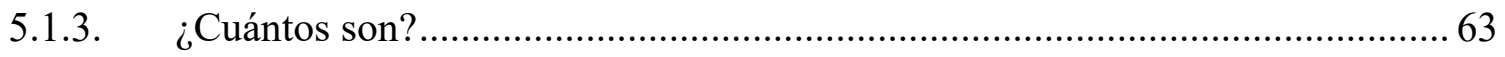

El análisis del número de usuarios se dio en base al siguiente cálculo:.......................... 63

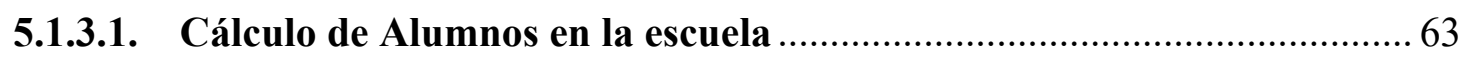

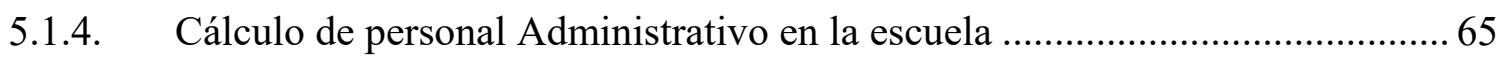

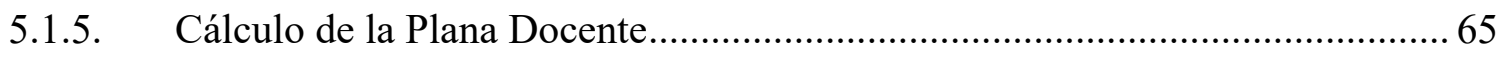

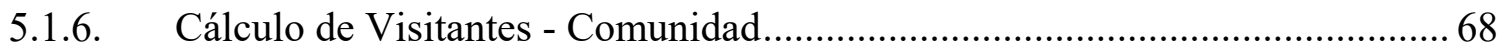

5.1.7. Conclusión número de Usuarios Total en la Escuela.......................................69

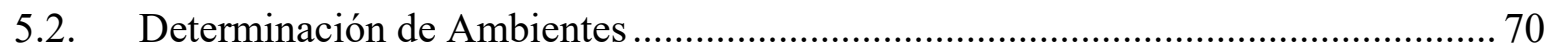

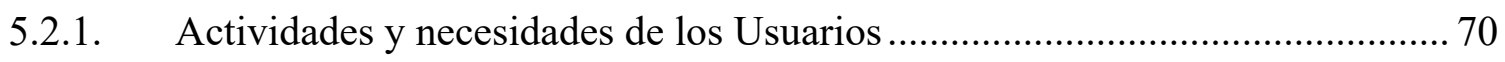

5.3. Determinación de Aspectos Cualitativos y Cuantitativos ....................................... 77

5.3.1. Determinación de ambientes y elección de 5 ambientes más importantes a

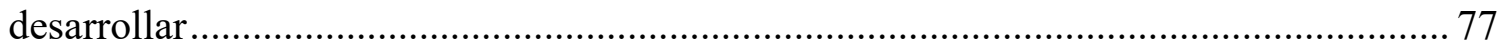

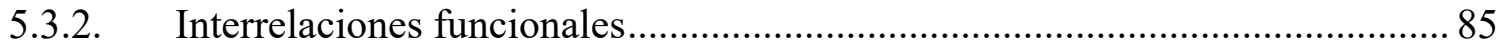

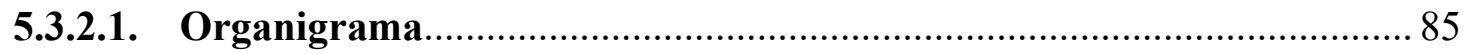

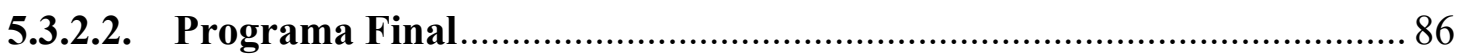


6.1. Las nuevas centralidades en Lima, Lima Norte y Comas ..................................... 92

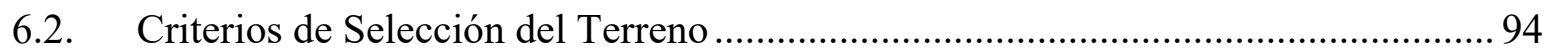

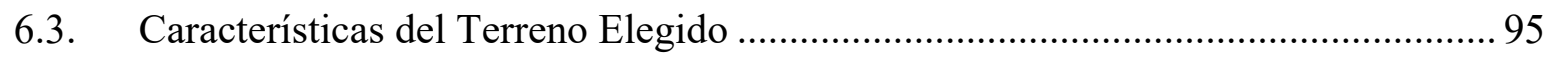

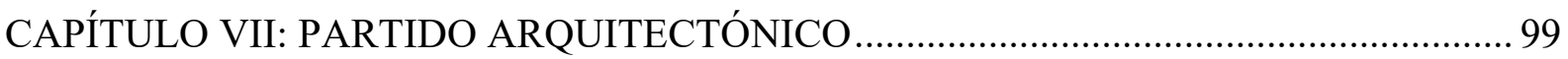

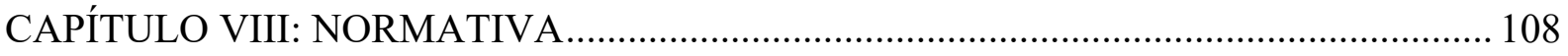

8.1. Reglamento Nacional de Edificaciones - Norma A040 Educación........................ 108

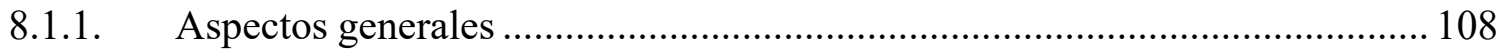

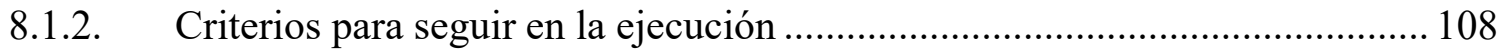

8.1.3. Criterios de ubicación en el Plan Urbano ......................................................... 108

8.1.4. Criterios para crear ambientes propicios para el proceso de aprendizaje ...... 109

8.1.5. Circulaciones: las circulaciones verticales deben estar techadas .................... 109

8.1.6. Características de los componentes.............................................................. 109

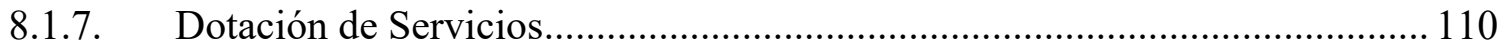

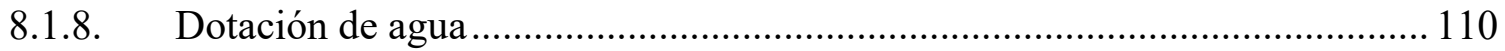

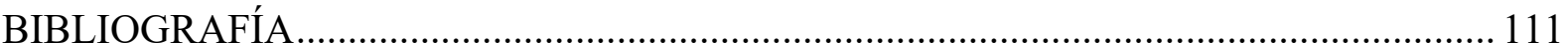




\section{ÍNDICE DE CUADROS}

Cuadro 1. Puntos de Cultura en Comas.................................................................. 3

Cuadro 2. Eventos y Festividades participativas de Teatro en Comas ........................ 4

Cuadro 3. Escuela de Artes Dramáticas en Lima Metropolitana ..........................................63 


\section{ÍNDICE DE FIGURAS}

Figura 1. Línea del Tiempo de la Historia de la Enseñanza Superior del Teatro .................. 5

Figura 2. Puesta en Escena "Adiós Ayacucho" interpretada por el Grupo Yuyachkani, obra que hace referencia a la violencia de los años 80 vivida en Ayacucho, Perú. ................. 20

Figura 3. Línea del Tiempo de la Historia de la Enseñanza Superior del Teatro ................ 21

Figura 4. Facultad de Artes Escénicas de la Pontificia Universidad Católica del Perú....... 23

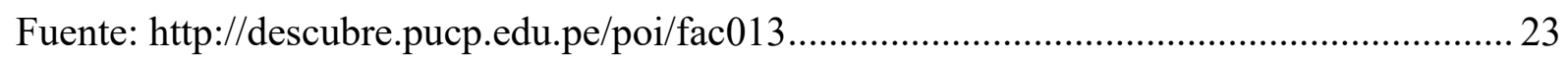

Figura 5. Plan de estudios de la especialidad de teatro desde el 2016 - 1.......................... 24

Figura 6. Plan de estudios de la carrera de formación artística desde el 2010 ENSAD ...... 26

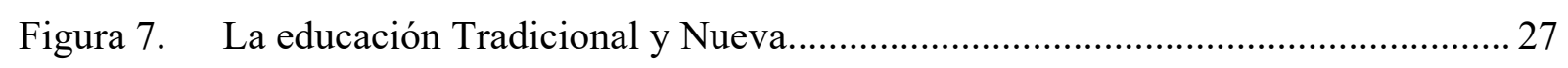

Figura 8. Educación y Espacios Experimentales en el Teatro ........................................... 28

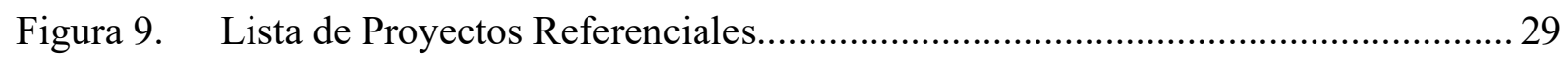
30

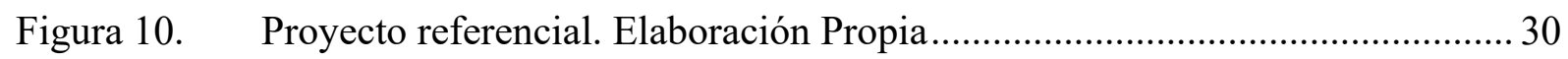

Figura 11. Proyecto referencial. Elaboración Propia .................................................... 31

Figura 12. Proyecto referencial. Elaboración Propia ................................................... 32

Figura 13. Proyecto referencial. Elaboración Propia ..................................................... 33

Figura 14. Proyecto referencial. Elaboración Propia ..................................................... 34

Figura 15. Proyecto referencial. Elaboración Propia ..................................................... 35

Figura 16. Proyecto referencial. Elaboración Propia .................................................... 36

Figura 17. Proyecto referencial. Elaboración Propia .................................................... 37

Figura 18. Proyecto referencial. Elaboración Propia .................................................... 38

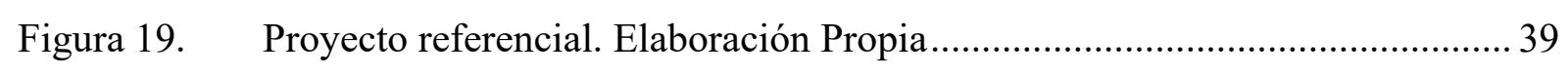

Figura 20. Proyecto referencial. Elaboración Propia ..................................................... 40

Figura 21. Proyecto referencial. Elaboración Propia ..................................................... 41

Figura 22. Espacios Experimentales de enseñanza.................................................. 45

Figura 23. Espacios Experimentales Exteriores …................................................... 48

Figura 24. Plataforma a aire libre del teatro de Monterrey, México ................................ 49

Figura 25. Actividades realizadas en Site Specific en el Distrito de Miraflores ............... 50

Figura 26. Instalación Site-specific en Noemie Lafrance por Marcy Schlissel................. 51

Figura 27. Espacios Experimentales Interiores. Elaboración Propia................................. 52

Figura 28. Espacios Experimentales Interiores. Elaboración Propia ................................. 53 
Figura 29. Espacios Experimentales Interiores. Elaboración Propia..................................54

Figura 30. Esquema de Organización de Usuarios de ENSAD 2014 ...............................55

Fuente: Elaboración propia en base a visita realizada a la Escuela Nacional Superior de Arte Dramático ENSAD y entrevista realizada al director de la ENSAD Jorge Sarmiento, 2014.

Figura 31. Esquema Conceptual de Organización Administrativa de ENSAD.................56

Fuente: Página web de ENSAD. https://www.ensad.edu.pe/transparencia/organigrama/.......56

Figura 32. Esquema Conceptual de Organización de Usuarios en una Escuela Superior. 57 Fuente: Elaboración propia en base a el Proyecto de Ley, MINEDU, Ley de Institutos y Escuelas de educación Superior y la Carrera Pública. .57

http://www.minedu.gob.pe/minedu/archivos/proyecto_de_ley_institutos_escuelas.pdf.........57

Figura 33. Esquema Final de Organización de Usuarios.................................................. 58

Fuente: Elaboración propia en base las tres fuentes de los puntos 6.1.1.1, 6.1.1.2 y 6.1.1.3.. 58

Figura 34. Cuadro de Usuarios Internos y descripción.....................................................59

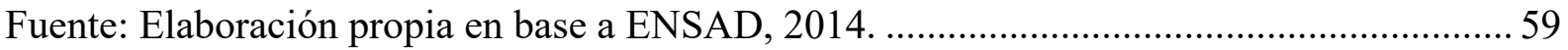

Figura 35. Cuadro Resumen del alumno estudiante de teatro ......................................... 61

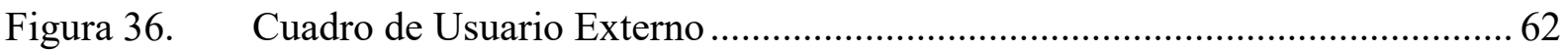

Figura 37. Cuadro de Uso de la Fórmula de Población a Futuro ........................................ 64

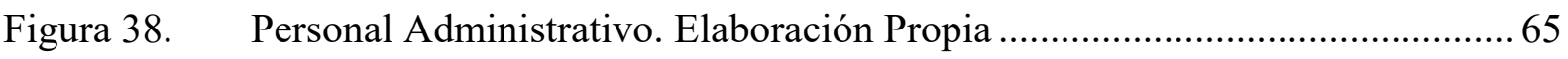

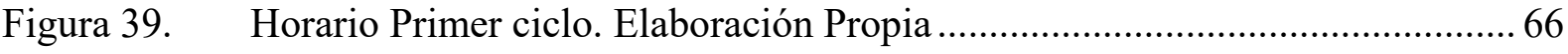

Figura 40. Horario Segundo Ciclo. Elaboración Propia .................................................... 66

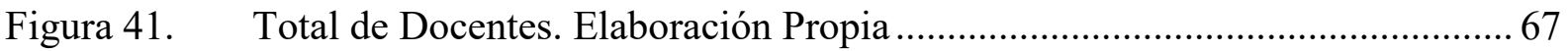

Figura 42. Cálculo Número de Usuarios. Elaboración Propia............................................ 68

Figura 43. Total Número de Usuarios. Elaboración Propia................................................ 69

Figura 44. Actividades y Necesidades del Alumno ........................................................ 70

Figura 45. Actividades y Necesidades del Profesor ...................................................... 71

Figura 46. Actividades y Necesidades del Personal Admirativo...................................... 72

Figura 47. Actividades y Necesidades del Visitante -Padre de Familia ........................... 73

Figura 48. Actividades y Necesidades del Visitante - Espectador................................. 74

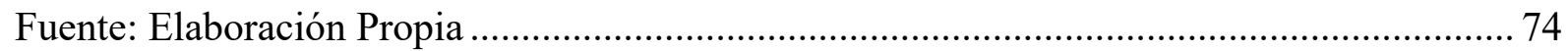

Figura 49. Actividades y Necesidades de Asociaciones de la Comunidad ....................... 75

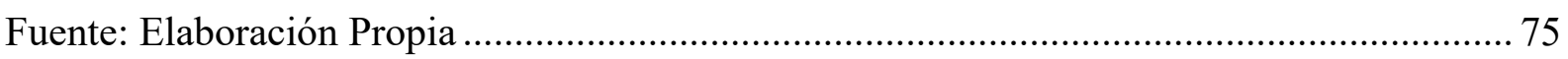

Figura 50. Actividades y Necesidades de Personal de Servicio y Apoyo Técnico ........... 76

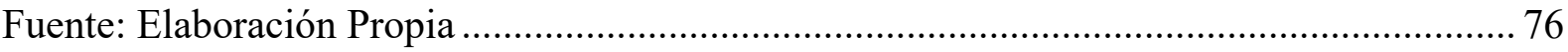


Figura 51. Cuadro de Ambientes. Elaboración Propia ....................................................... 77

Figura 52. Hall de Ingreso. Elaboración Propia …........................................................... 78

Figura 53. Hall de Ingreso. Elaboración Propia ............................................................... 79

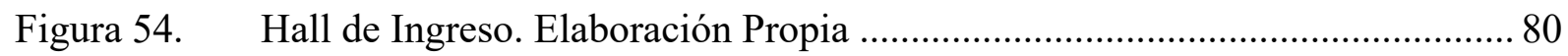

Figura 55. Auditorio Escolar. Elaboración Propia....................................................... 81

Figura 56. Taller de Teatro. Elaboración Propia ............................................................ 82

Figura 57. Teatro Black Box. Elaboración Propia........................................................... 83

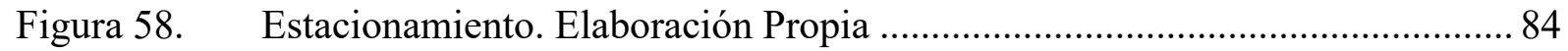

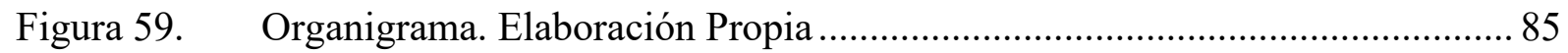

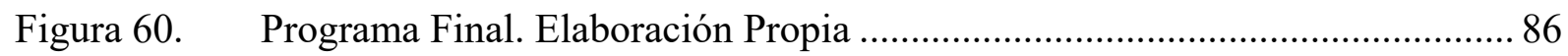

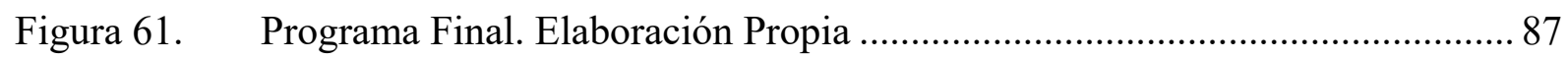

Figura 62. Programa Final. Elaboración Propia ............................................................. 88

Figura 63. Programa Final. Elaboración Propia ............................................................ 89

Figura 64. Programa Final. Elaboración Propia …............................................................ 90

Figura 65. Programa Final. Elaboración Propia .............................................................. 91

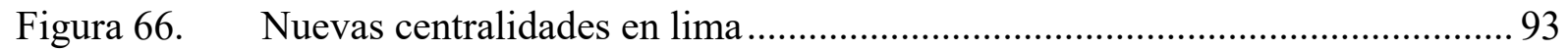

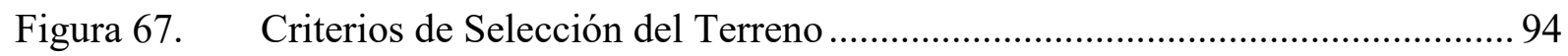

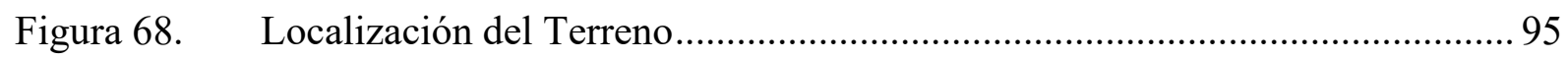

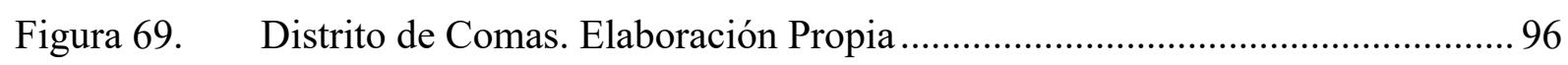

Figura 70. Tipo de Suelo. Elaboración Propia................................................................ 97

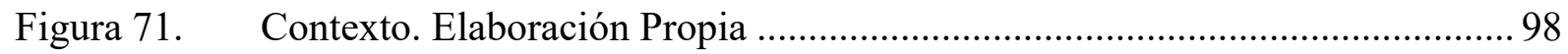

Figura 72. Partido Arquitectónico. Elaboración Propia.................................................... 99

Figura 73. Partido Arquitectónico. Elaboración Propia................................................... 100

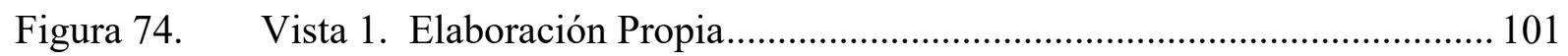

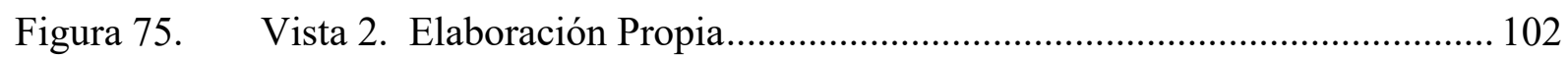

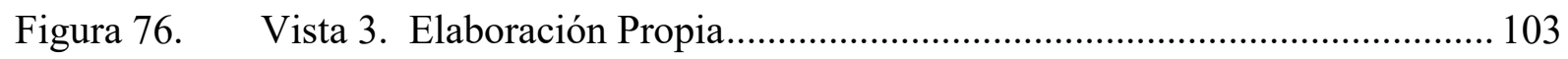

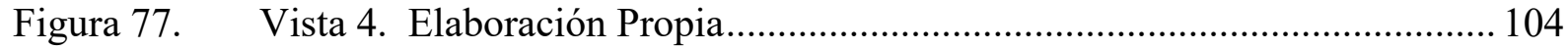

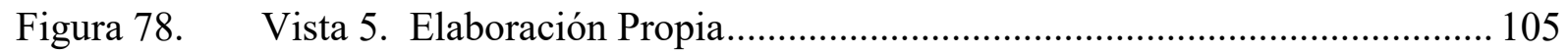

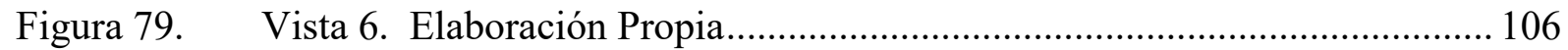

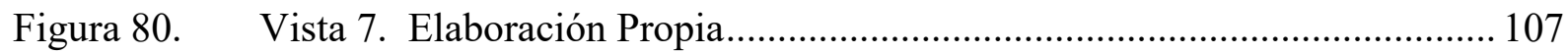




\section{CAPÍTULO I. INTRODUCCIÓN}

\subsection{Tema de tesis}

\subsubsection{El lugar: Comas distrito Cultural}

Más allá de su geografía Comas es un laboratorio social del Perú actual, es una reproducción en pequeño de lo que es la nueva Lima, cada vez más mestiza, llena de contrastes, miserias y grandezas con la ventaja de tener una identidad singular y rasgos de integración que no se ven en otros distritos, arte y cultura ligado a lo nacional, deporte en efervescencia no obstante la crisis... (Municipalidad Distrital de Comas, 2010 p. 10)

Comas es el distrito con mayor número de habitantes y mayor extensión geográfica del Cono Norte de Lima según el último censo del Instituto Nacional de Estadística e Informática del 2005. Su población es de 486,977 habitantes y en su mayoría está representada por jóvenes de 14 a 25 años (INEI 2007).

El Distrito está compuesto en su mayoría de migrantes de distintas partes del país que trajeron sus costumbres, tradiciones, lenguas e idiosincrasia dando un carácter heterogéneo a la cultura actual del distrito. ${ }^{1}$ Actualmente, Comas es considerado un distrito con una gran tradición cultural en expresión del arte popular. Los ciudadanos, asociaciones culturales, colectivos y municipalidad en conjunto realizan eventos, actividades y festivales de teatro internacional y nacional, danza, folclore, marionetas, circo, entre otros a lo largo del año para promover el desarrollo de la cultura en Lima.

Sin embargo, la carencia de infraestructura para el desarrollo de estas actividades obliga a la improvisación de lugares donde desarrollarse, optando por cerrar calles en días festivos para el uso del espacio público como pistas y veredas, canchas de futbol comunales, parques y descampados para la estructuración de arquitectura efímera: como circos, graderías, escenarios, etc.

\footnotetext{
${ }^{1}$ Diagnóstico Local Participativo del Distrito de Comas, 2006. Municipalidad de Comas pág. 4.
} 
En Lima existen 115 Puntos de Cultura (Asociaciones, Grupos de Arte Comunitario, Colectivos de artistas e iniciativas sostenibles de cultura) de los cuales 20 están registradas en el distrito de Comas relacionadas a la cultura y expresión teatral, Según el Sistema de Registro On-Line de Puntos de Cultura del Ministerio de Cultura. (Ver Cuadro 1)

Estas asociaciones socioculturales imparten cultura a niños, jóvenes, adultos y ancianos y participan en las actividades culturales del calendario anual de cultura de Comas, difundiendo así el arte y la cultura con vecinos y turistas limeños.

Actualmente el distrito de Comas cuenta con una Agenda cultural amplia, en donde con respecto al teatro destacan eventos y festividades Internacionales y Nacionales. (Ver cuadro 2) 


\section{Cuadro 1. Puntos de Cultura en Comas}

\begin{tabular}{|c|c|c|c|}
\hline \multicolumn{4}{|c|}{ Organizaciones Culturales y/o Asociaciones de expresión artística teatral en Comas } \\
\hline & Asociaciones y Colectivos culturales & Tipo & Público \\
\hline 1 & Es- Cultura Asociación Cultural & Teatro, Danza, Pintura, Música & $\begin{array}{l}\text { Niños, adolescentes, } \\
\text { Jóvenes y adultos }\end{array}$ \\
\hline 2 & $\begin{array}{l}\text { Semillas- Movimiento Artístico para los } \\
\text { valores y el liderazgo infantil }\end{array}$ & Teatro y Canto & Infantes y niños \\
\hline 3 & Colectivo Río Danza Comunitaria & Teatro, danza y Folclore & Jóvenes y adultos \\
\hline 4 & Kilombo Artes Escénicas & Teatro de la Calle y Danza & Jóvenes y adultos \\
\hline 5 & $\begin{array}{l}\text { Espacio Libre - Grupo de teatro } \\
\text { Independiente }\end{array}$ & Teatro Experimental & Jóvenes y adultos \\
\hline 6 & ValidArte Asociación Cultural & Teatro y danza & Jóvenes y adultos \\
\hline 7 & Escuela Experimental de Mimo y Títeres & Teatro, Improvisación y Mimo & Jóvenes y adultos \\
\hline 8 & $\begin{array}{l}\text { Asociación Cultural y educativa Sol de } \\
\text { Medianoche }\end{array}$ & Teatro Universitario & Jóvenes Estudiantes \\
\hline 9 & $\begin{array}{l}\text { Centro de Investigación Formación y } \\
\text { Difusión Cultural "La gran Marcha de los } \\
\text { muñecones" }\end{array}$ & Teatro Comunitario & Jóvenes y Estudiantes \\
\hline 10 & Asociación Talentos & Teatro educativo & $\begin{array}{l}\text { Niños, adolescentes, } \\
\text { Jóvenes y adultos }\end{array}$ \\
\hline 11 & Lunasol & Arte Dramático & $\begin{array}{l}\text { Jóvenes y Adultos de } \\
\text { ENSAD }\end{array}$ \\
\hline 12 & Colectivo C.H.O.L.O & Bellas Artes & Jóvenes y adultos \\
\hline 13 & Centro de Dia Pedro Jose Triest & Teatro Religioso & $\begin{array}{l}\text { Niños, adolescentes, } \\
\text { Jóvenes y adultos }\end{array}$ \\
\hline 14 & Iglesia de Cristo en San Borja & Teatro y Canto religioso & $\begin{array}{l}\text { Niños, adolescentes, } \\
\text { Jóvenes y adultos }\end{array}$ \\
\hline 15 & $\begin{array}{l}\text { Asociación Iglesia Cristiana los } \\
\text { maravillosos colaboradores }\end{array}$ & Teatro, mimo, canto y danza & $\begin{array}{l}\text { Niños, adolescentes, } \\
\text { Jóvenes y adultos }\end{array}$ \\
\hline 16 & $\begin{array}{l}\text { Asociación Ángel de la guarda para niños y } \\
\text { ancianos }\end{array}$ & Improvisación, Arte y Teatro & Niños y Adulto mayor \\
\hline 17 & Asociación Cultural San Jerónimo & Teatro, mimo, canto y danza & Jóvenes y adultos \\
\hline 18 & Centro Cultural COLLI & Todas las artes & $\begin{array}{l}\text { Niños, adolescentes, } \\
\text { Jóvenes y adultos }\end{array}$ \\
\hline 19 & YachayPucllayPacha & Canto y Danza & Niños \\
\hline 20 & $\begin{array}{l}\text { Asociación cultural Artística y educativa } \\
\text { "Haciendo Pueblo" }\end{array}$ & Teatro y Danza & $\begin{array}{l}\text { Niños, adolescentes, } \\
\text { Jóvenes y adultos }\end{array}$ \\
\hline
\end{tabular}

Fuente: Elaboración Propia con datos del Sistema de Registro On-Line de Puntos de Cultura del Ministerio de Cultura del Perú. 


\section{Cuadro 2. Eventos y Festividades participativas de Teatro en Comas}

\begin{tabular}{|c|c|c|c|}
\hline \multicolumn{4}{|c|}{ Eventos y Festividades Participativas de Teatro en Comas } \\
\hline & Nombre & Descripción & $\begin{array}{l}\text { Mes en } \\
\text { que se } \\
\text { realiza }\end{array}$ \\
\hline 1 & FITECA & Fiesta Internacional de Teatro en Calles Abiertas & Mayo \\
\hline 2 & Festival Nacional de Cultura Urbana & Todas las artes & Mayo \\
\hline 3 & $\begin{array}{l}\text { Festival Internacional de danza "En } \\
\text { Movimiento" }\end{array}$ & Expresión corporal, danza e impro & Junio \\
\hline 4 & FIETPO & Festival Itinerante y encuentro de teatro popular & Julio \\
\hline 5 & FICCA & Festival Internacional de Cultura del Carmen & Julio \\
\hline 6 & FIAE & Festival Internacional de artes escénicas & $\begin{array}{l}\text { Septiemb } \\
\text { re }\end{array}$ \\
\hline 7 & $\begin{array}{l}\text { Festival de arte Total de Comas para el } \\
\text { mundo }\end{array}$ & Todas las artes & Octubre \\
\hline 8 & Festimuñecomas & Circo, teatro, danza y música & Octubre \\
\hline 9 & Viacrucis tradicional de Lima & $\begin{array}{l}\text { Representación teatral de la vida, pasión y muerte } \\
\text { de Jesús }\end{array}$ & Abril \\
\hline
\end{tabular}

Fuente: Elaboración Propia con datos del diagnóstico participativo del Distrito de Comas 2015 - Municipalidad de Comas

En todo este marco cultural, se propone el diseño de una institución que forme artistas en la especialidad del Teatro, y que el distrito de Comas y Lima Norte pueda contar con un equipamiento educativo para el desarrollo profesional de los ciudadanos. 


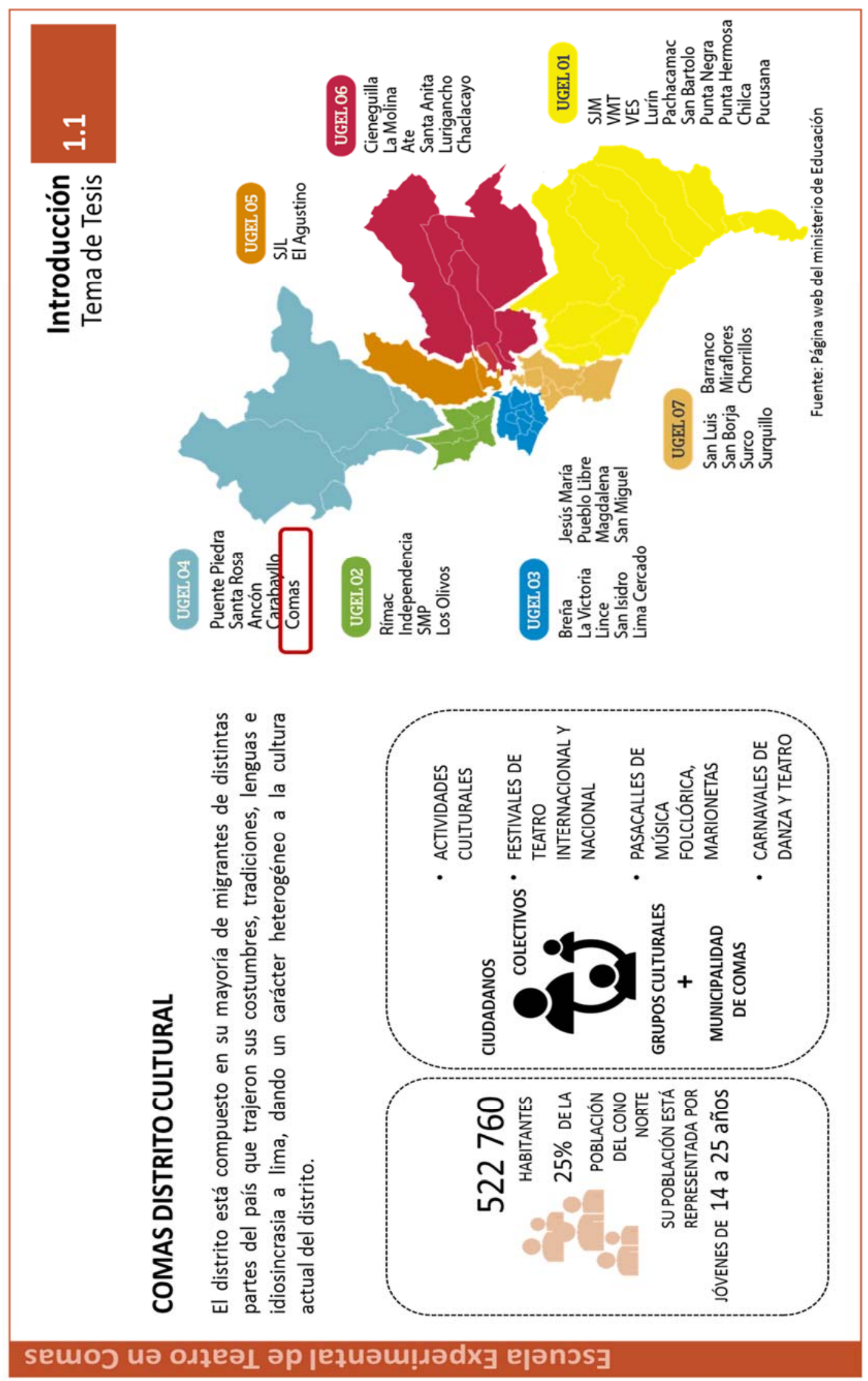

Figura 1. Línea del Tiempo de la Historia de la Enseñanza Superior del Teatro Fuente: Elaboración propia 


\subsubsection{La Tipología: Escuela Superior}

Se propone una Escuela Superior para la formación Teatral en todas las disciplinas artísticas: Actuación, Diseño (decorado, vestuario, proyección y sonido), dirección, producción y gestión del teatro.

La escuela contempla:

- Espacios fundamentales para el aprendizaje del alumno actor y su formación teatral profesional global (que abarca desde los textos clásicos de Shakespeare hasta Chekhov para nuevas obras)

- Espacios de experimentación que se adaptan al contexto cultural de Comas: Un Teatro tipo "Black-box" por su característica experimental y una Sala polivalente de doble altura para el ensayo de diferentes disciplinas juntas.

- Espacios extraescénicos interiores (espacios en área libre, espacios entre pabellones) y exteriores (espacios urbanos) dentro del terreno de la escuela.

Las características Tipológicas de la Escuela Experimental de Teatro en Comas son:

\section{A. Según Aspectos Institucionales}

Según la Ley General de educación 28044, Capítulo V, Educación Superior - MINEDU (Ministerio de educación del Perú) la Escuela de Teatro es una Institución Educativa Superior de Formación Artística cuyo objetivo es formar personas en los campos de la ciencia, la tecnología y las artes, para contribuir con su desarrollo individual, social inclusivo y su adecuado desenvolvimiento en el entorno laboral nacional y global.

\section{B. Según Aspectos Formales ${ }^{2}$}

Es un proyecto arquitectónico cuya escala se adapta al entorno urbano de Comas, sin embargo busca destacarse por su plástica optando por formas curvas y texturas no convencionales. Se

\footnotetext{
${ }^{2}$ Plazola, A.C. (2001), RNE (Reglamento Nacional de Edificación - Perú) y Proyectos Referenciales estudiados en la presente Tesis.
} 
emplaza en un terreno que ocupa toda una cuadra del distrito, frente a una avenida principal para así destacar el proyecto y sea una referencia cultural o hito urbano en Comas.

\section{Según Aspectos Funcionales ${ }^{3}$}

Es un proyecto arquitectónico que responde a los siguientes paquetes funcionales cuya organización, conexión e interrelación logra un buen funcionamiento del edificio con los usuarios de la escuela:

- Unidad Educativa

- Teatro Black Box

- Administración

- Servicio

- Áreas Comunes

Funcionalmente también responde a su entorno urbano y socio cultural adaptando la arquitectura para el uso comunitario del Teatro Black Box.

\section{Según Aspectos Tecnológicos ${ }^{4}$}

Los espacios cuentan con las siguientes características tecnológicas:

- Ventilación Natural y Artificial

- Manejo eficiente de la iluminación natural y Artificial

- Aislamiento Acústico y Control de Sonido

- Sistema constructivo Aporticado: placas, vigas y columnas de concreto armado. Circulaciones metálicas ancladas a estructura de concreto. Grandes luces con vigas metálicas. Losas aligeradas en dos direcciones.

\footnotetext{
${ }^{3}$ Plazola, A.C. (2001), RNE (Reglamento Nacional de Edificación - Perú) y Proyectos Referenciales estudiados en la presente Tesis.

${ }^{4}$ RNE (Reglamento Nacional de Edificación - Perú) y Proyectos Referenciales estudiados en la presente Tesis.
} 
- Elección de materiales y acabados de acuerdo a su función, durabilidad, calidad y seguridad.

\subsubsection{Objetivos Generales y Específicos para el diseño}

\section{A. Objetivo General}

Diseñar una Escuela Experimental de teatro en el distrito de Comas cuya arquitectura responda al estándar global y a su entorno cultural.

\section{B. Objetivos Específicos}

- Conceptos Experimentales de enseñanza: Diseñar una Escuela de teatro teniendo en cuenta las nuevas prácticas y métodos en la enseñanza del teatro experimental con espacios que permitan la formación de profesionales competentes en el arte, que respondan de manera exitosa a los desafíos actuales en esta disciplina.

- Conceptos comunitarios y culturales: Diseñar una Escuela de teatro que contemple espacios comunitarios para la adaptación, realización e incorporación de eventos culturales que se realizan en Comas y así formar parte del circuito social - cultural del distrito. 


\section{CAPÍTULO II: CONCEPTOS APLICADOS AL DISEÑO DE LA ESCUELA EXPERIMENTAL}

\subsection{Selección y Sustentación de fuentes}

\section{TEXTO 1}

Libro: Enciclopedia de Arquitectura Plazola

Autor: Arq. Ing. Alfredo Plazola Cisneros

Editorial: Plazola Editores, edición 2

Volumen: 10, pág. $200-221$

Año y Lugar de Publicación: 1994, México

Contenido: El Contenido General de la Obra, que abarca 10 volúmenes, estructura las definiciones arquitectónicas generales y específicas por Temas y Tipologías en donde el autor no solo brinda conceptos sino que también ejemplifica con proyectos referenciales reales cuyo funcionamiento y forma ayudan al mejor entendimiento de conceptos arquitectónicos.

Aspectos Importantes extraídos: En el Volumen 10 en donde el autor abarca la tipología de Teatro / Auditorio, se utilizan los conceptos generales y definiciones de esta especialidad así como también se estudia su clasificación y sus requerimientos especiales como acústica, isóptica, paquetes funcionales y programa arquitectónico. De los Proyectos Referenciales que brinda el libro, se toma como ejemplo el Teatro de la ciudad, en Monterrey- México y se estudian conceptos de teatros universitarios, comunitarios y experimentales.

El estudio de las áreas de un teatro para menos de 400 personas brindado por este libro sirvió como punto de comparación con otras áreas obtenidas de proyectos Actuales y contemporáneos.

Los requerimientos de espacio para un teatro de escuela y auditorio escolar expuestos en el libro fueron de vital importancia para entender la escala del proyecto, su magnitud, su composición y la dificultad requerida para la tesis. 


\section{TEXTO 2}

Decreto: Real Decreto 389/1992. Título II: Capítulo II. De los Centros de Enseñanza de Educación Artística

Autor: Ministerio de Educación y Ciencia de España

Tipo: Boletín Oficial del Estado

Capítulo: II, Artículo 21 AL 31

Año y Lugar de Publicación: 1992, España

Contenido: El Contenido General del decreto es establecer los requisitos mínimos de los centros que impartan enseñanzas artísticas. Programa Arquitectónico, medidas, dimensiones, áreas, características, aforo y plana docente se describen y se cuantifican para regular la Arquitectura de los centros de Enseñanza.

Aspectos Importantes extraídos: Los requisitos referidos a las instalaciones y condiciones materiales como institucionales en los centros elementales de enseñanza artística son detallados ambiente por ambiente.

El programa Arquitectónico discriminado por uso en la escuela está descrito en características cualitativas y cuantitativas, brindando información importante para contrastar con los Proyectos Referenciales y los otros Textos de la Tesis.

Ejemplo: "El número de aulas destinadas a clases de danza, con una superficie mínima de 70 metros cuadrados, que se precise para que, de acuerdo con el horario de funcionamiento del centro, el número de puestos escolares y la relación numérica profesor-alumno pueda garantizarse el horario lectivo que se establezca en el plan de estudios. Dichas aulas tendrán una altura mínima de tres metros y pavimento flotante"

De donde se extrae: Aula de Danza

Área: Min. $70 \mathrm{~m} 2$

Alt. Min: $3.00 \mathrm{~m}$

Característica: Pavimento Flotante 


\section{TEXTO 3}

Libro: Reglamento Nacional de Edificaciones del Perú

Publicación: Diario el Peruano (2006)

Año y Lugar de Publicación: 2015, (incluye modificaciones del 2012, 2014, 2015) Perú

Capítulo: Título III Arquitectura: Norma A010 Condiciones Generales de diseño, A040 Educación

Contenido: El Objetivo del Reglamento Nacional de Edificaciones es normar los criterios y requisitos mínimos para el diseño y la edificación de Habilitaciones Urbanas y edificaciones.

Aspectos Importantes extraídos: Las características y requisitos para lograr las condiciones de habitabilidad y seguridad se han extraído de este libro con el objetivo de cumplir con las normas regidas en el Perú. Aspectos como usos del espacio, características espaciales de una escuela, cuadro de áreas, circulación, accesos, sistemas de ventilación e iluminación, seguridad, entre otros fueron tomados como referencias mínimas (base) a cumplir, de donde partió el diseño y para luego aplicar el criterio profesional a los ambientes, utilizando las medidas mínimas o ampliándolas por aspectos espaciales y de armonía. 


\section{TEXTO 4}

Revista: Diseño Armónico de un Teatro Auditorio

Autor: VI Congreso Internacional de Ergonomía

Editorial: Universidad de Guanajuato

Páginas: pág. 191-202

Año y Lugar de Publicación: 2004, México

Contenido: El Objetivo del VI Congreso Internacional de Ergonomía fue investigar, analizar y explicar la relación de todo con respecto al cuerpo humano sobre diversos temas relacionados al espacio, entre ellos el Teatro/ Auditorio. En la Publicación destacan medidas, reglas y características espaciales necesarias para el buen funcionamiento de esta tipología.

Aspectos Importantes extraídos: Las características físicas, espaciales y tecnológicas de un Teatro/ Auditorio responden a 2 necesidades importantes para esta tipología: La comunicación y la expresión artística. Estas necesidades se dan a través del fenómeno sonoro en donde debe haber una fuente de emisión, un medio de propagación y un receptor de audición que junto a un espacio bien diseñado debe cumplir con los requisitos acústicos y las tendencias actuales como integrar varias funciones en un mismo teatro, entre otras. 


\subsection{Definición de términos básicos}

\subsubsection{Definiciones generales}

Escuela de Educación Superior : "Los Institutos de Educación Superior y las escuelas de Educación Superior son instituciones educativas de la segunda etapa del sistema educativo nacional, que forman personas en los campos de la ciencia, la tecnología y las artes, con énfasis en una formación aplicada. " - Ley N²9394, Ley de Institutos y Escuelas de Educación Superior.

Escuela Experimental: Las escuelas experimentales constituyen una propuesta innovadora y alternativa al sistema educativo tradicional, cuya propuesta pedagógica nunca antepone la teoría a la práctica. (Cutillas, V. 2005). El sistema de enseñanza de una Escuela Experimental de Teatro no está enfocado en la ecuación tradicional de arte dramático, sino más bien en la libertad para modificar, desde la experiencia, una escuela nueva en formación por el entorno social en el que se desarrolla.

Escuela de Teatro: Institución en la que se forman profesionales competentes en el arte dramático capaces de desarrollar eficazmente actividades en actuación, diseño escenográfico y producción de obras teatrales promoviendo su compromiso en el arte teatral, la investigación artística y la educación. (ENSAD, 2014)

Teatro: Según la Real Academia Española (RAE), teatro es Conjunto de todas las producciones dramáticas de un pueblo, de una época o de un autor; como también es el edificio o sitio destinado a la representación de obras dramáticas o a otros espectáculos públicos propios de la escena. Según la Enciclopedia de Arquitectura Plazola la clasificación de los teatros se da por: 5

Por el edificio con respecto al entorno: Existen dos tipos entre los que se encuentran:

- Teatro Abierto. El que se construye al aire libre (plaza o parque) Se utilizan por actos públicos propios y de grupos de teatro experimental de la localidad.

\footnotetext{
${ }^{5}$ Plazola, A.C. (2001)
} 
- Teatro Cerrado. El que agrupa los espacios en un edificio cerrado de volúmenes simétricos con las instalaciones necesarias para realizar un espectáculo teatral.

Por su concepto: Se diferencian por el tipo de producción.

- Teatro Contemporáneo. Requiere de un espacio propio y organizado para su fin específico.

- Teatro De Masas. Edificio destinado a albergar una cantidad considerable de público de diversos estratos sociales que gustan de las representaciones populares.

- Teatro Experimental. Son necesarios en áreas de estudio, se utilizan para realizar investigaciones del sonido, del espacio, del cine, del color, etc. Cuyos resultados dejarán sentir su influencia sobre los diseños de teatros nuevos. En estos locales no existe una separación clara entre la escena y la zona de espectadores y la representación se dirige a todos los puntos del reciento.

- Teatro Polivalente. Edificio acondicionado para todo tipo de representaciones por lo general es una zona alargada con escenario al frente.

- Teatro Municipal, estatal, nacional. Son los que diseña el estado para cumplir con las demandas sociales de proporcionar cultura.

- Teatro Universitario. Se lleva a cabo en una institución educativa, contribuye a la vida social y cultural de la universidad que subsidia y mantiene con sus propios recursos desarrollando producciones de tipo estudiantil y profesional.

Actor - Actriz. El que representa uno de los personajes en una obra escénica cinematográfica. Personaje de una acción o de una obra literaria, encargado crear, interpretar y representar una acción dramática basándose en textos, estímulos visuales, sonoros y otros, previamente concebidos o improvisados, de manera individual o colectiva. El artista transmite emociones, valores y sentimientos al público, debe ser capaz de enfrentar cualquier disciplina sobre un escenario. (Zafra, 2013)

Escena. Caracterización del escenario para que represente el lugar donde se supone ocurre la acción. 
Escenografía. Estudio y practica de toda forma de expresión capaz de inscribirse en el universo del teatro, el espectáculo y la organización espacial.

Foro. Espacio destinado para la presentación del espectáculo ante el público; las áreas adyacentes en el mismo nivel denominadas alas para maniobras de escenografía.

Parilla del telar. Armazón de madera o metal que debe ocupar toda la caja del telar, en ella se alojan sistemas de elementos teatrales que bajan y suben.

Paso de gato. (Catwalk) Pasillo o puente estrecho, exclusivo para peatones que manejan los proyectores del teatro.

Platea. Parte baja de los Teatros.

Proscenio. Parte del escenario más inmediato al público, que viene a ser la que media entre el borde del escenario mismo y el primer orden de bastidores.

Puente de Iluminación. Elemento estructural que sostiene los sistemas de iluminación frontales o cenitales del escenario.

Sala de ensayos. Local con un área mínima de $144 \mathrm{~m}^{2}(12 \times 12)$ piso de madera, barra para ballet, espejos en los muros, intercomunicación al puesto de traspunte y aislado de sonidos del exterior.

Visual Teatral. Línea recta tirada desde el ojo dl espectador hasta el objetivo, persona o zona de actuación.

\subsubsection{Espacios componentes de una escuela de Teatro}

Según la Enciclopedia de Arquitectura Plazola (2001) los espacios componentes que se requieren en una escuela de teatro son los siguientes:

Aulas prácticas. Espacio para el aprendizaje del movimiento corporal, técnicas de expresión, vocalización y mímica. Son grandes espacios ambientados con instalaciones de iluminación, sonido, cortinajes. Debe ser ventilado y también contar con iluminación natural amplia.

Aulas teóricas. Aulas para clases del tipo teórico, apuntes, exposiciones. Estos ambientes cuentan con facilidades tecnológicas y multimedia. 
Sala de ensayos. Espacio para la práctica, el repaso y el ensayo de presentaciones. Debe tener instalaciones de audio y sonido adecuados. También se utilizan para Audiciones.

Camerinos. Ubicados aledaño a los servicios higiénicos, Sirven para el cambio de vestuario de los alumnos antes y después de las clases prácticas

Sala de maquillaje. Sala donde se transforman los estudiantes, se arreglan, se maquillan y se meten físicamente dentro del personaje.

Biblioteca/ mediateca. Con áreas de lectura, audio y video, internet y espacios para la revisión de material físico para el conocimiento e inspiración.

Sala de estar. Sala dedicada la espera, entremés, y relajación y pausa en la rutina del alumno. Área administrativa. Corresponde a las oficinas para el personal docente y administrativo.

Bodega de utilería. Donde se almacenan todo tipo de objetos, artefactos y útiles para el desarrollo de las clases prácticas y representaciones.

Almacén de vestuario. Ropa, máscaras, sombreros, disfraces se almacenan en buen estado para su reutilización.

Cafetería. Establecimiento de hostelería donde se ofrecen los aperitivos y comidas a los estudiantes, personal administrativo y al visitante.

\section{Auditorio de la Escuela}

Espacio de representación flexible acondicionado para llevar a cabo diferentes actividades culturales, festivas, musicales, conferencias, debates y montajes de obras teatrales en la escuela. En ellos deben existir 3 elementos asociados llamados cadena acústica: Fuente (emisión), Medio (propagación) y el receptor (audición).

Los auditorios cuentan con ambientes anexos para su buen funcionamiento:

Vestíbulo. Área de descanso para los espectadores, especialmente antes de la función y durante los descansos, pero también como lugar de reunión después de la función.

Escenario. El escenario está compuesto por el área de transición de actores, tramoya, boca de escena y vestimenta del escenario. 
Área de artistas. Cuentan con un acceso separado del público, un vestíbulo, sala de descanso, oficinas, camerinos individuales o colectivos (en caso de escuela colectiva), salas de ensayos.

Sala de ensayos. Sala de tamaño idéntico al escenario o proporcional.

Sala de espectadores. Espacio compuesto por butacas orientadas hacia el escenario. Para su buen funcionamiento el ángulo horizontal al eje central de la sala en donde los objetos atrás del telón del escenario dejan de tener la relación con los otros y con el fondo es de $60^{\circ}$. Además, el ángulo horizontal de visión sin movimiento del ojo es aproximadamente de $40^{\circ}$ y el asiento más alto en el anfiteatro debe estar en una línea que no tenga más de $30^{\circ}$ a la horizontal al frente del telón en el piso del escenario, de lo contrario estará más allá del límite de distancia.

Servicios generales. Servicios sanitarios, casilleros, cuartos de instalaciones.

Cabina control de luces y sonido. Está generalmente situado en una posición central, en la parte trasera del auditorio, desde donde el operador tiene una visión sin interferencias de la escena. Debería ser un espacio cerrado con una ventana de observación. Necesita espacio para una consola de control de la iluminación y el operador que ha de sentarse delante. También se requiere espacio adicional para un asistente y un espacio para el trabajo con los guiones. Ha de contar con ventilación mecánica independiente. (Appleton, 1996)

\section{Black box Theater o Teatro de caja negra ${ }^{6}$}

Consiste en un espacio de actuación simple, sin adornos, que generalmente se da en una sala cuadrada con paredes negras y un piso plano. En esta tipología de teatro la relación pública artista se pierde, convirtiendo al público en parte de la obra y fomentando su participación en una locación flexible, multifuncional y lúdica. Su finalidad es explorar un teatro más 'puro' con los elementos más humanos y menos técnicos. ${ }^{7}$

\footnotetext{
${ }^{6}$ Según Plazola, A.C. (2001), RNE (Reglamento Nacional de Edificación - Perú) y Proyectos Referenciales estudiados en la presente Tesis.

7 "What is a Black Box Theater?". Wisegeek.com. Obtenido el 2018-04-04
} 
Los Teatros Black Box cuentan con ambientes anexos para su buen funcionamiento:

\section{Espacios Exteriores al Black Box}

- Plaza de acceso. conectada al ingreso peatonal y vehicular del público y del estudiante.

- Estacionamientos. Para estudiantes, personal administrativo y público espectador.

- Acceso. Para el público que asiste a la función, personal administrativo y trabajadores, alumnos y actores.

- Salidas de emergencia.

\section{Espacios Previos al Black Box}

- Ingreso. Entrada al teatro debe ser legible a diferentes distancias

- Taquilla. Ubicada en el pórtico de ingreso,

- Vestíbulo o Foyer. Espera llegada y salida del teatro.

- Cafetería. Concesionarios para el consumo de alimentos de paso.

- Servicios de guardarropa y Teléfonos públicos.

- Servicios sanitarios. Baños mujer, hombre y discapacitados.

- Cabina. Acceso a la cabina de control de sonido, luces y proyecciones.

- Ingreso al escenario. Acceso a la Sala de espectadores

\section{Espacios al Interior del Black Box}

- Escenario. Contiene en espacios no delimitados y a creatividad del autor de la obra, contiene la sala de espectadores.

- Vestíbulo. De acceso de actores, directores y colaboradores.

- Backstage o Trascenio. Área de transición anterior a la escena.

- Sala de ensayos.

- Área de artistas. Cuentan con un acceso separado del público, un vestíbulo, sala de descanso, oficinas, camerinos individuales o colectivos.

- Servicios generales. Servicios sanitarios, casilleros, cuartos de instalaciones. 


\section{CAPÍTULO III: HISTORIA DE LA ENSEÑANZA TEATRAL SUPERIOR -UNIVERSITARIA}

\subsection{Historia de la enseñanza Superior/ Universitaria del teatro ${ }^{8}$}

En el Siglo XIII aparece la enseñanza Superior Universitaria del Teatro reglada con título Universitario en Europa, representaciones litúrgicas, tragedias populares y comedias, así como textos clásicos se escenificaban para su estudio.

Del siglo XV al siglo XIX, se expanden las universidades Europa, América y posteriormente por América Latina, y con la creación de las universidades Laicas siguiendo las pautas de las Universidades metropolitanas el Teatro desarrolla representaciones eclécticas y multiculturales combinando lo clásico con lo vulgar, los elementos cristianos con los mitológicos y la farsa con la tragicomedia.

Es en el cambio de siglo donde surge un movimiento importante: el Teatro Independiente del siglo XX. Surge por la utilización del teatro como arma propagandista de dos principales ideologías como son el Comunismo y el Fascismo, las cuales toman al teatro como un arte revolucionario para un cambio de pensamiento en la sociedad carente de valores. El teatro Burgués es aislado, para darle paso al teatro democrático y social, como el teatro de masas.

La corriente del Teatro independiente cuyo concepto exigía integrar escenarios dentro de la cultura democrática, llega al Perú a mediados del siglo XX y es en 1970 que la Universidad Mayor de San Marcos crea la Federación Nacional de Teatro Universitario Popular, de la cual nacen más de 50 grupos teatrales Independientes entre ellos Yuyachkani - Grupo Independiente, socio político y cultural, el cual persiste hasta ahora siendo un hito importante del Teatro Peruano y un laboratorio de expresiones teatrales peruanas. ${ }^{9}$

\footnotetext{
${ }^{8}$ Según, García Soriano, Justo (1945). «El teatro universitario y humanístico en España». Toledo y Saavedra Garfias, Karmen. «Teatro universitario y teatro sin universidad». Revista Ciencia y Cultura 19 (34): 127-152. ISSN 2077-3323. Consultado el 11 de junio de 2014

${ }^{9}$ Yuyachkani, 2014
} 


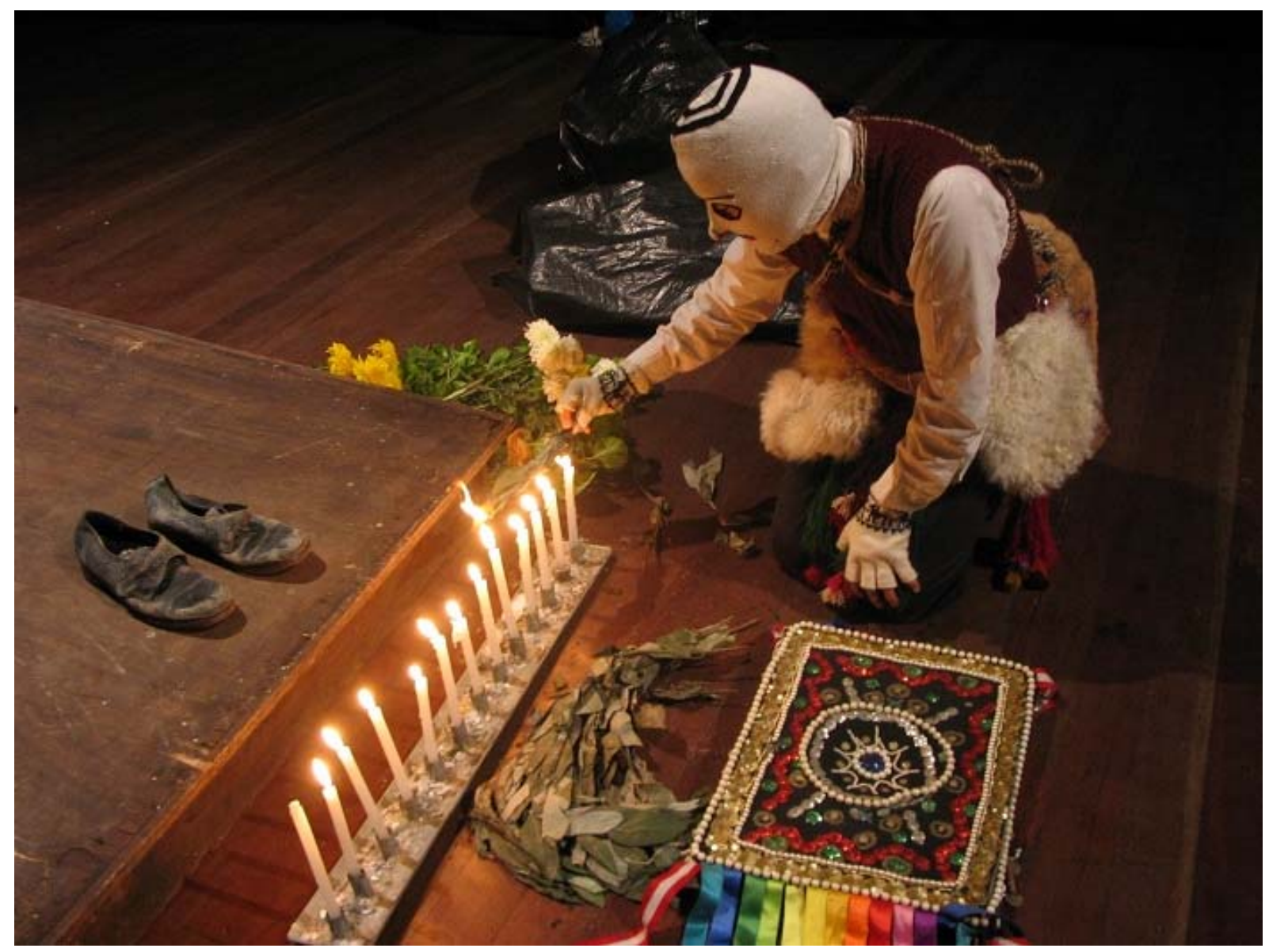

Figura 2. Puesta en Escena "Adiós Ayacucho" interpretada por el Grupo Yuyachkani, obra que hace referencia a la violencia de los años 80 vivida en Ayacucho, Perú.

Fuente: Diario Online La Mula

Actualmente en la ciudad de Lima, las escuelas que dan licencia/ Título Universitario a nombre de la nación para Arte Dramático / Teatro son cuatro:

- La Universidad Peruana de Ciencias Aplicadas

- La Pontificia Universidad Católica del Perú

- La Universidad Científica del Sur

- ENSAD (Escuela Nacional de Arte Dramático) 


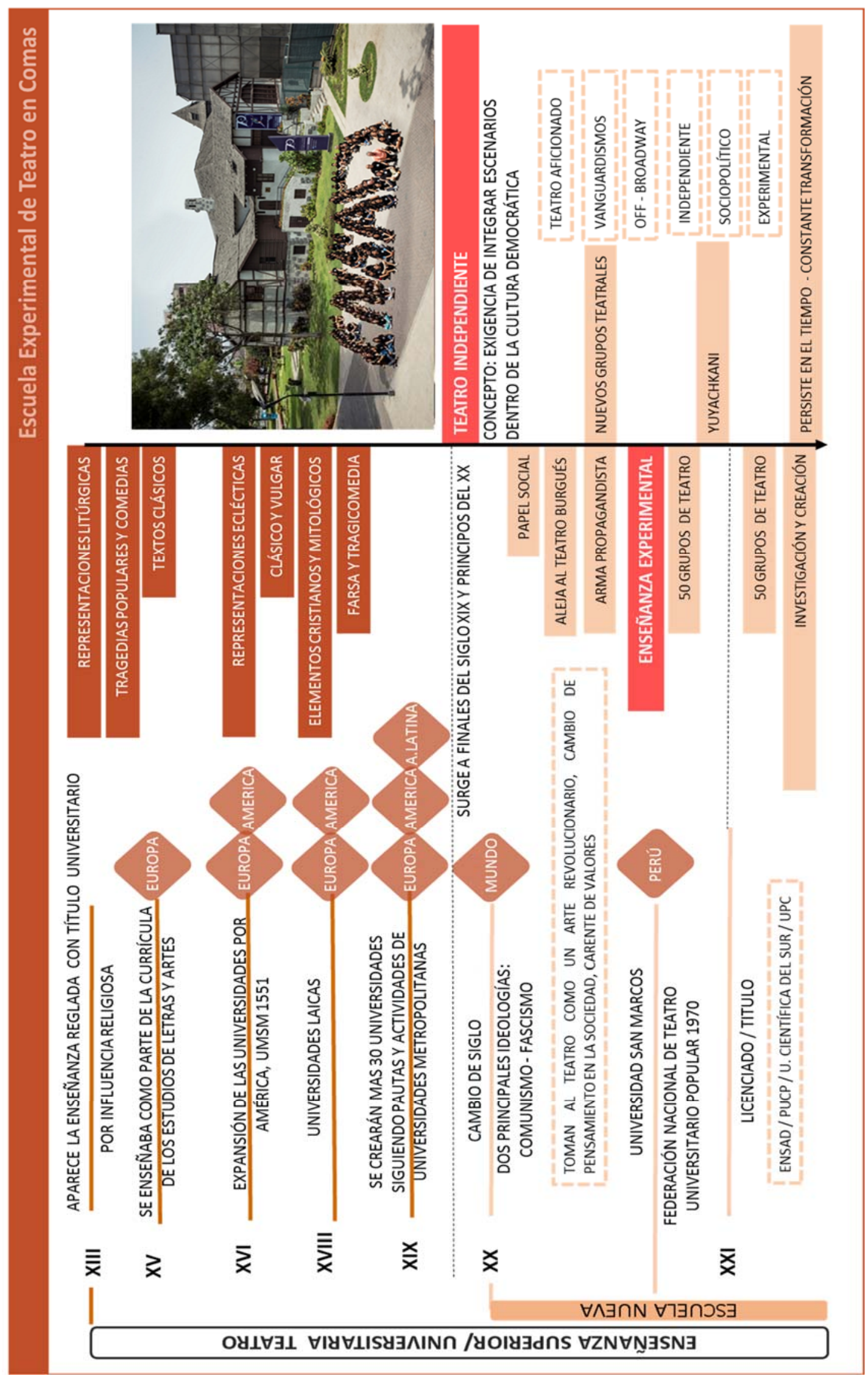

Figura 3. Línea del Tiempo de la Historia de la Enseñanza Superior del Teatro

Fuente: Elaboración propia 


\subsection{Enseñanza Básica / Superior teatral en el Perú}

En el Perú existen varias modalidades de escuelas de teatro / arte dramático que frecen estudios superiores de arte dramático como:

- Escuelas y centros educativos formales en la enseñanza que ofrecen el grado académico de Bachiller y Licenciado como son la Escuela Nacional de arte dramático (ENSAD) y la facultad de artes escénicas de la Universidad Católica del Perú (TUC) ambos ubicados en la ciudad de Lima.

- Escuelas de teatro y centros de formación teatral no oficial, con su oferta de educación no formal y abierta como La Escuela de Teatro de Lima, el Instituto Nacional de Teatro Musical (INATEM), y la Escuela de artes escénicas Vodevil ubicados en la ciudad de Lima.

- Escuelas e instituciones de teatro no formal impartida por asociaciones y grupos de artistas como la escuela de Teatro Ensamble, Teatro de la Asociación Cultural Peruano - británica y Escuela de la Asociación de Artistas Aficionados y el Instituto Charles Chaplin.

- Grupos culturales que desarrollan propuestas pedagógicas no oficiales, experimentales respaldados por su larga trayectoria y presencia en el Teatro Peruano como son la escuela de Teatro, Circo y Música de la Tarumba y La escuela de Teatro del Grupo Cultural Peruano Yuyachkani.

La Escuela de Teatro de la Universidad Católica del Perú (TUC) y ENSAD son las dos únicas Escuela Superiores formales que ofrecen, al alumno, artista un título profesional a nombre de la Nación al culminar los estudios y cuentan con una currícula que cumple con las enseñanzas teórico - práctica, exigencias pedagógicas contemporáneas en el tema.

\subsubsection{Facultad de Artes Escénicas - Teatro de la Universidad Católica del Perú}

La especialidad de Teatro tiene su origen y continúa el legado del Teatro de la Universidad Católica (TUC), institución de referencia en la historia del teatro peruano, fundada en 1961, y dedicada a la formación actoral, la investigación desde las artes escénicas, y la difusión del teatro por medio de la puesta en escena de obras clásicas y contemporáneas. (PUCP, Facultad de teatro).

Plan de Estudios: El plan de estudios de esta escuela contempla la técnica actoral, dominio del cuerpo y de la voz, preparación para desempeñarse eficientemente en teatro, en estilos que van desde el naturalismo extremo hasta el claun y la comedia musical. La especialidad de Teatro 
busca formar jóvenes interesados en su realidad social que entiendan la estética del teatro desde un punto de vista contemporáneo preparándose para investigar y crear nuevas formas de expresión dramática.

En esta escuela para la obtención del Grado de Bachiller en Artes Escénicas con mención en Teatro, los alumnos deben haber cumplido con los requisitos de 215 créditos del plan de estudios, acreditado el idioma inglés (intermedio) y realizado prácticas pre profesionales.

Para la obtención de la Licenciatura en Teatro, el alumno deberá presentar una tesis teóricopráctica que incluye la investigación y ejecución de un proyecto artístico en teatro que será aprobado por los asesores miembros del comité de evaluación de proyectos.

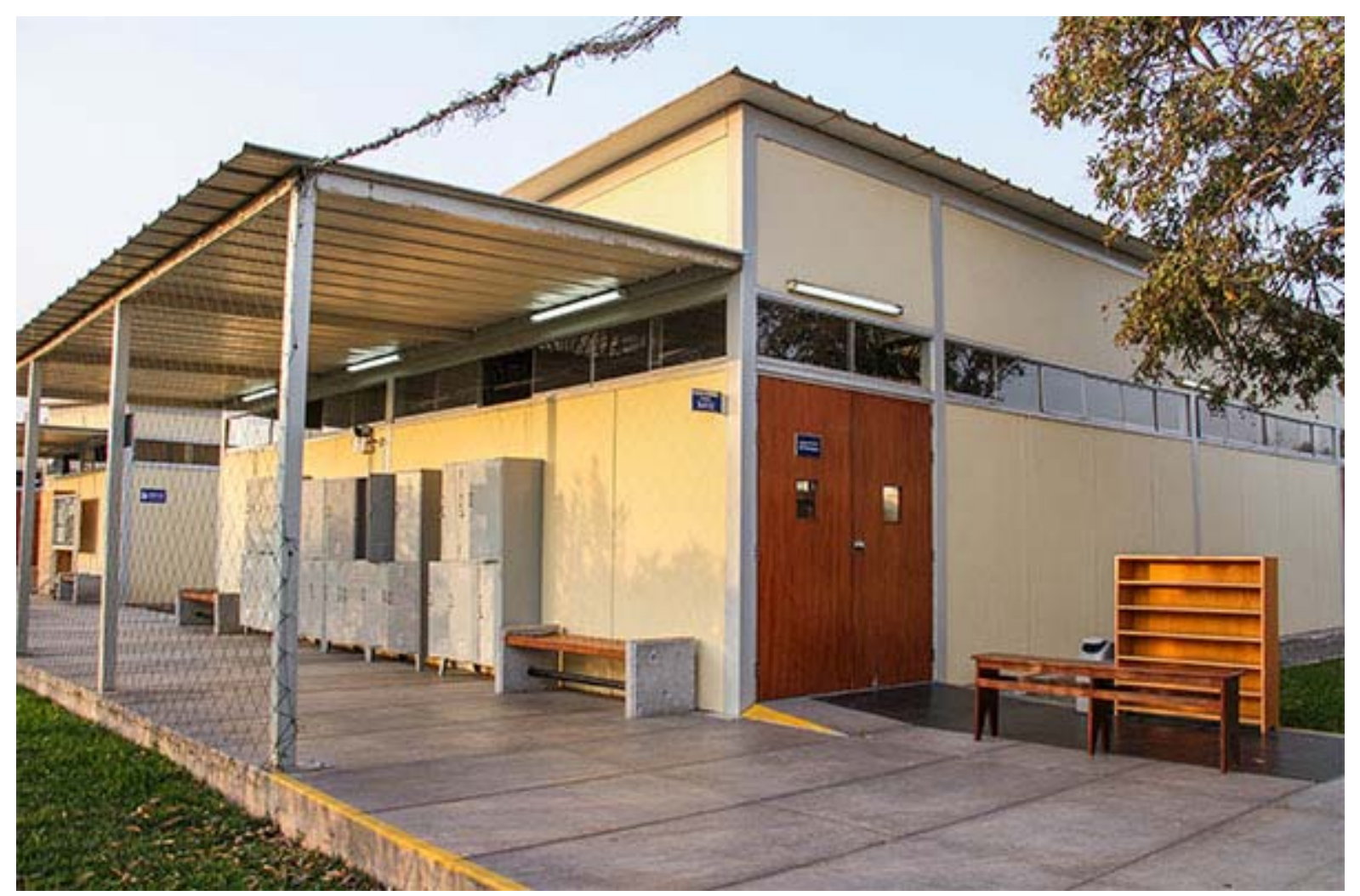

Figura 4. $\quad$ Facultad de Artes Escénicas de la Pontificia Universidad Católica del Perú Fuente: http://descubre.pucp.edu.pe/poi/fac013 


\begin{tabular}{|c|c|c|c|c|c|c|c|c|c|c|}
\hline \multirow{2}{*}{ Nivel } & \multirow{2}{*}{ Clave } & \multirow{2}{*}{ Nombre del curso } & \multirow{2}{*}{ Tipo } & \multirow{2}{*}{ Cred. } & \multirow{2}{*}{\multicolumn{3}{|c|}{ Horas }} & \multicolumn{2}{|r|}{ Requisito } & \multirow{2}{*}{$\begin{array}{c}\text { Total Créditos } \\
\text { por Nivel }\end{array}$} \\
\hline & & & & & $\mathrm{h} / \mathrm{sem}$ & & H.P. & Clave & Nombre del curso & \\
\hline \multirow{5}{*}{1} & TEA113 & Introducción a la actuación 1 & $\mathrm{OC}$ & 7.0 & 9 & 5 & 4 & & & \multirow{5}{*}{23.0} \\
\hline & TEA114 & Entrenamiento Corporal y Vocal 1 & oc & 5.0 & 8 & $\frac{3}{2}$ & $\frac{4}{6}$ & & & \\
\hline & MUS149 & Música 1 & 0 & 3.0 & 4 & 2 & 2 & & & \\
\hline & MAT155 & Matemática básica & OFG & 4.0 & 4 & 4 & & & & \\
\hline & LIN126 & Taller de escritura e Interpretación de textos & OFG & 4.0 & 4 & 4 & & & & \\
\hline \multirow{5}{*}{2} & TEA115 & Introducción a la actuación 2 & $\mathrm{oc}$ & 7.0 & 9 & 5 & 4 & $\begin{array}{l}\text { TEA113 } \\
\text { TEA114 }\end{array}$ & $\begin{array}{l}\text { Introducción a la actuación } 1 \\
\text { Entrenamiento Corporal y Vocal } 1\end{array}$ & \multirow{5}{*}{22.0} \\
\hline & TEA116 & Entrenamiento Corporal y Vocal 2 & oc & 5.0 & 8 & 2 & 6 & TEA113 & Introducción a la actuación 1 & \\
\hline & MUS150 & Música 2 & 0 & 30 & 4 & 2 & 2 & MUS149 & Música 1 & \\
\hline & HIS148 & Historia del Siglo XX & OFG & 4.0 & $\frac{4}{5}$ & $\frac{6}{3}$ & $\frac{6}{2}$ & & & \\
\hline & HUM113 & Argumentación & OFG & 3.0 & 4 & 2 & 2 & LIN126 & Taller de escritura e interpretación de textos & \\
\hline \multirow{6}{*}{3} & 1TEA11 & Actuación 1 & $\mathrm{OC}$ & 7.0 & 9 & 5 & 4 & $\begin{array}{l}\text { TEA115 } \\
\text { TEA116 }\end{array}$ & \begin{tabular}{|l|l|} 
Introducción a la actuación 2 \\
Entrenamiento Corporal $y$ Yocal 2
\end{tabular} & \\
\hline & TEA118 & & C & 50 & 8 & & & TEA115 & Introducción a la actuación 2 & \\
\hline & TEAIIO & Entrenamiento Corporal y Vocal 3 & $\mathrm{OC}$ & 5.0 & 8 & 2 & 6 & TEA116 & Entrenamiento Corporal y Vocal 2 & 22.0 \\
\hline & TEA243 & Análisis de un texto dramático & 0 & 3.0 & 4 & 2 & 2 & TEA115 & Introducción a la actuación 2 & \\
\hline & INT124 & Investigación Académica & OFG & 3.0 & 5 & 1 & 4 & HUM113 & Argumentación & \\
\hline & & Un curso del área de Historia del Perú & OFG & 4.0 & 4 & 4 & & & & \\
\hline & 1TEA12 & Actuación 2 & $\mathrm{OC}$ & 7.0 & 9 & 5 & 4 & $\begin{array}{l}\text { 1TEA11 } \\
\text { TEA118 }\end{array}$ & $\begin{array}{l}\text { Actuación } 1 \\
\text { Entrenamiento Corporal y Vocal } 3\end{array}$ & \\
\hline & TEA120 & Entrenamiento Corporal y Vocal 4 & $\mathrm{OC}$ & 5.0 & 8 & 2 & 6 & $\begin{array}{l}\text { 1TEA11 } \\
\text { TEA118 }\end{array}$ & $\begin{array}{l}\text { Actuación } 1 \\
\text { Entrenamiento Corporal y Vocal } 3\end{array}$ & \\
\hline 4 & 1TEA08 & $\begin{array}{l}\text { Lectura e interpretación de textos dramáticos } \\
1\end{array}$ & o & 3.0 & 3 & 3 & & TEA243 & Análisis de un texto dramático & 23.0 \\
\hline & LIN146 & 1 Lenguaje y Sociedad & OFG & 40 & 5 & 3 & 2 & & & \\
\hline & PSI107 & Psicologia & OFG & 4.0 & $\frac{4}{4}$ & $\frac{4}{4}$ & & & & \\
\hline & IDM104 & Idioma extranjero 1 & 0 & 0.0 & & & & & $\begin{array}{l}\text { Inglés equivalente al nivel básico concluido de } \\
\text { Idiomas Católica }\end{array}$ & \\
\hline & 1TEA13 & Actuación 3 & $\mathrm{oc}$ & 7.0 & 9 & 5 & 4 & $\begin{array}{l}\text { 1TEA12 } \\
\text { TEA120 } \\
\text { IDM104 }\end{array}$ & \begin{tabular}{|l} 
Actuación 2 \\
Entrenamiento Corporal y Vocal 4 \\
Idioma extranjero 1
\end{tabular} & \\
\hline 5 & DAN266 & Danza 1 & ० & 3.0 & 4 & 2 & 2 & $\begin{array}{l}\text { TEA120 } \\
\text { IDM104 }\end{array}$ & $\begin{array}{l}\text { Entrenamiento Corporal y Vocal } 4 \\
\text { Idioma extranjero } 1\end{array}$ & 23.0 \\
\hline & GAE104 & Teoria del Teatro & 0 & 3.0 & 3 & 3 & & IDM104 & Idioma extranjero 1 & \\
\hline & TEA205 & Historia del Espectáculo Teatral 1 & 0 & 3.0 & $\frac{3}{3}$ & $\frac{3}{3}$ & & IDM104 & dioma extranjero 1 & \\
\hline & & Un curso del área de Ciencias Sociales & OFG & 4.0 & 4 & 4 & & & & \\
\hline & CCO131 & Comunicación Social & OFG & 3.0 & 3 & 3 & & & & \\
\hline & 1TEA14 & Actuación 4 & oc & 7.0 & 9 & 5 & 4 & $\begin{array}{l}\text { 1TEA13 } \\
\text { DAN266 } \\
\text { 1TEA08 }\end{array}$ & \begin{tabular}{|l|} 
Actuación 3 \\
Danza 1 \\
Lectura e interpretación de textos dramáticos 1
\end{tabular} & \\
\hline 6 & DAN239 & Danza 2 & 0 & 3.0 & 4 & 2 & 2 & DAN266 & Danza 1 & 21.0 \\
\hline & TEA209 & \begin{tabular}{|l} 
Historia del Espectáculo Teatral 2 \\
\end{tabular} & 0 & 3.0 & $\frac{4}{3}$ & $\frac{2}{3}$ & & TEA205 & \begin{tabular}{|l|} 
Historia del Espectáculo Teatral 1 \\
\end{tabular} & \\
\hline & LIT135 & Introducción a la Literatura & OFG & 4.0 & 5 & 3 & 2 & & & \\
\hline & & Un curso del área de Filosofia & OFG & 4.0 & $\frac{5}{4}$ & $\frac{3}{4}$ & & & & \\
\hline & 1TEA15 & Actuación 5 & $\mathrm{OC}$ & 7.0 & 9 & 5 & 4 & $\begin{array}{l}1 \text { TEEA14 } \\
\text { DAN239 }\end{array}$ & $\begin{array}{l}\text { Actuación } 4 \\
\text { Danza 2 }\end{array}$ & \\
\hline & MUS259 & Canto 1 & 0 & 3.0 & 4 & 2 & 2 & TEA120 & Entrenamiento Corporal y Vocal 4 & \\
\hline & HIS145 & Historia del arte & OFG & 3.0 & 3 & 3 & & & & \\
\hline 7 & 1TEA09 & Seminario de investigación teatral 1 & 0 & 3.0 & 3 & 3 & & $\begin{array}{ll}\text { INT124 } \\
\text { GAE104 }\end{array}$ & Investigación Académica & 23.0 \\
\hline & GAE200 & Gestión y Producción & 0 & 3.0 & 3 & 3 & & & & \\
\hline & TEA241 & Práctica preprofesional en teatro & & 0.0 & & & & & Haber completado todos los cursos del nivel 6 & \\
\hline & & $\begin{array}{l}\begin{array}{l}\text { Un curso del área de Teologia y Ciencias de } \\
\text { la Religión }\end{array} \\
\end{array}$ & OFG & 4.0 & 4 & 4 & & & & \\
\hline & 1TEA16 & Actuación 6 & $\mathrm{OC}$ & 8.0 & 10 & 6 & 4 & 1TEA15 & Actuación 5 & \\
\hline & 1TEA10 & Seminario de investigación teatral 2 & 0 & 3.0 & $\frac{3}{3}$ & 3 & & 1TEA09 & Seminario de investigación teatral 1 & \\
\hline 8 & MUS 260 & Canto 2 & 0 & 3.0 & 4 & 2 & 2 & MUS259 & Canto 1 & 21.0 \\
\hline & TEA215 & Dramaturgia & 0 & 3.0 & 4 & 2 & 2 & TEA243 & Análisis de un texto dramático & \\
\hline & FIL148 & Estética & OFG & 4.0 & 4 & 4 & & & & \\
\hline & 1TEA17 & Proyecto Final 1 - Teatro & o & 4.0 & 4 & 4 & & $\begin{array}{l}\text { 1TEA16 } \\
\text { GAE200 } \\
\text { 1TEA10 }\end{array}$ & $\begin{array}{l}\text { Actuación } 6 \\
\text { Gestión y Producción } \\
\text { Seminario de investigación teatral } 2\end{array}$ & \\
\hline 9 & TEA214 & Dirección & o & 3.0 & 4 & 2 & 2 & $\begin{array}{l}\text { 1TEA16 } \\
\text { TEA215 }\end{array}$ & \begin{tabular}{|l|} 
Actuación 6 \\
Dramaturgia
\end{tabular} & 190 \\
\hline & TEA247 & Teatro y sociedad & 0 & 3.0 & 3 & 3 & & & & \\
\hline & TEA202 & Teatro peruano & 0 & 3.0 & $\frac{3}{3}$ & $\frac{3}{3}$ & & TEA209 & Historia del Espectáculo Teatral 2 & \\
\hline & & Electivo & $E$ & 3.0 & & & & & & \\
\hline & & Electivo & $E$ & 3.0 & & & & & & \\
\hline & 1TEA18 & Proyecto Final 2 -Teatro & 0 & 4.0 & 4 & 4 & & $\begin{array}{l}\text { 1TEA17 } \\
\text { GAE200 } \\
\text { TEA214 }\end{array}$ & $\begin{array}{l}\text { Proyecto Final } 1 \text { - Teatro } \\
\text { Gestión y Producción } \\
\text { Dirección } \\
190 \text { créditos aprobados }\end{array}$ & \\
\hline & TEA260 & Critica teatral & 0 & 3.0 & 3 & 3 & & & & \\
\hline 10 & ARE309 & Deontologia & OFG & 2.0 & 2 & 2 & & $\begin{array}{l}\text { HIS145 } \\
\text { FIL148 }\end{array}$ & \begin{tabular}{|l|} 
Historia del Arte \\
Estética \\
170 créditos aprobados \\
\end{tabular} & 18.0 \\
\hline & TEA250 & Taller de técnicas teatrales contemporáneas & 0 & 3.0 & 4 & 2 & 2 & & & \\
\hline & & Electivo & $E$ & 3.0 & & & & & & \\
\hline & & Electivo & $E$ & 3.0 & & & & & & \\
\hline & IDM204 & Idioma extranjero 2 & 0 & 0.0 & & & & & $\begin{array}{l}\text { Inglés equivalente al nivel intermedio concluido de } \\
\text { Idiomas Católica }\end{array}$ & \\
\hline & & TOTAL & & 215.0 & & & & & & 215.0 \\
\hline
\end{tabular}

Se permite la matricula en cursos obligatorios de 3 niveles consecutivos como máximo.

Figura 5. Plan de estudios de la especialidad de teatro desde el 2016 - 1

Fuente: Pagina web de la Pontificia Universidad Católica del Perú

http://facultad.pucp.edu.pe/artes-escenicas/wp-content/uploads/2012/10/Teatro-plan-2016$\underline{\text { desde-2018-1.pdf }}$ 


\subsubsection{Escuela Nacional Superior de Arte Dramático ENSAD}

ENSAD es una escuela de proyección internacional, que forma profesionales en Arte Dramático, Pedagogía Teatral y Diseño Escenográfico. Su plan de estudios contempla la misión de formar profesionales comprometidos con el arte y la cultura del Perú, así como la investigación artística para aportar elementos pedagógicos necesarios para el mejoramiento de la calidad artística y educativa, en el campo del Arte Dramático.

Plan de estudios: La currícula del plan de estudios de ENSAD no se limita a la actuación y abarca una amplia gama de temas relacionados al teatro como el Programa de Complementación Pedagógica con la finalidad de atender a los actores y actrices comprendidos dentro del marco de la Ley del Artista, para que de esta forma puedan obtener un título pedagógico a nombre de la Nación.

ENSAD es parte del instituto internacional de teatro de la UNESCO y cuenta con 2 carreras a optar dentro de la escuela: Carrera de formación artística con especialidad en teatro y/o con especialidad en diseño escenográfico y Carrera de educación artística con especialidad en arte dramático, que al culminar los 10 ciclos de estudios (total de 220 créditos) se obtienen el Bachillerato y Título de Licenciado a Nombre de la Nación.

\section{Estado de la Institución en Fotografías:}

El Edificio en donde se desarrolla la Escuela Nacional de Arte Dramático es 


\section{Carrera de Formación Artística, Especialidad Teatro, Mención Actuación.}

\section{CICLO}

- Habilidades Comunicativas

- Métodos para el Trabajo Intelectual

- Historia de la Cultura Peruana

- Preparación Corporal I

- Técnica Vocal

- Técnica Actoral I

30 Horas | 21 Créditos

\section{CICLO}

- Historia del Teatro II

- Antropología Cultural I

- Estética del Teatro I

- Comunicación y Teatro II

- Expresión Corporal I

- Expresión Oral I

- Técnica Actoral III

30 Horas | 22 Créditos

\section{CICLO}

- Seminario de Teatro Peruano

- Comunicación y Teatro IV

- Movimiento I

- Taller de Expresión Oral I

- Interpretación Teatral I

- Maquillaje

30 Horas | 22 Créditos

\section{CICLO}

- Historia del Teatro I

- Introducción a la Filosofía

- Comunicación y Teatro I

- Preparación Corporal II

- Técnica Vocal II

- Técnica Actoral II

30 Horas | 21 Créditos

\section{CICLO}

- Historia del Teatro III

- Antropología Cultural II

- Estética del Teatro II

- Comunicación y Teatro III

- Expresión Corporal II

- Expresión Oral II

- Técnica Actoral IV

30 Horas | 22 Créditos

\section{CICLO}

- Historia del Arte I

- Movimiento II

- Taller de Expresión Oral II

- Taller de Teatro Clásico

- Práctica Preprofesional de Actuación I

- Taller de Música y Canto

30 Horas | 23 Créditos

\section{CICLO}

- Seminario de Deontología Teatral

- Fundamentos del Folklore

- Composición II

- Taller de Teatro Contemporáneo

- Prácticas Preprofesional de Actuación II

- Laboratorio de Investigación Actoral II

30 Horas | 23 Créditos

\section{CICLO}

- Psicología II

- Seminario de Técnicas Actorales II

- Prácticas Preprofesional de Actuación IV

- Proyecto de Investigación Teatral II

- Práctica de Dirección Escénica

30 Horas | 22 Créditos

Figura 6. Plan de estudios de la carrera de formación artística desde el 2010 ENSAD

Fuente web: https://drive.google.com/file/d/0B0X3JiZNK1NpazVfQUdwUEVJMWM/view 


\subsection{La Educación Tradicional y Nueva en el Mundo}

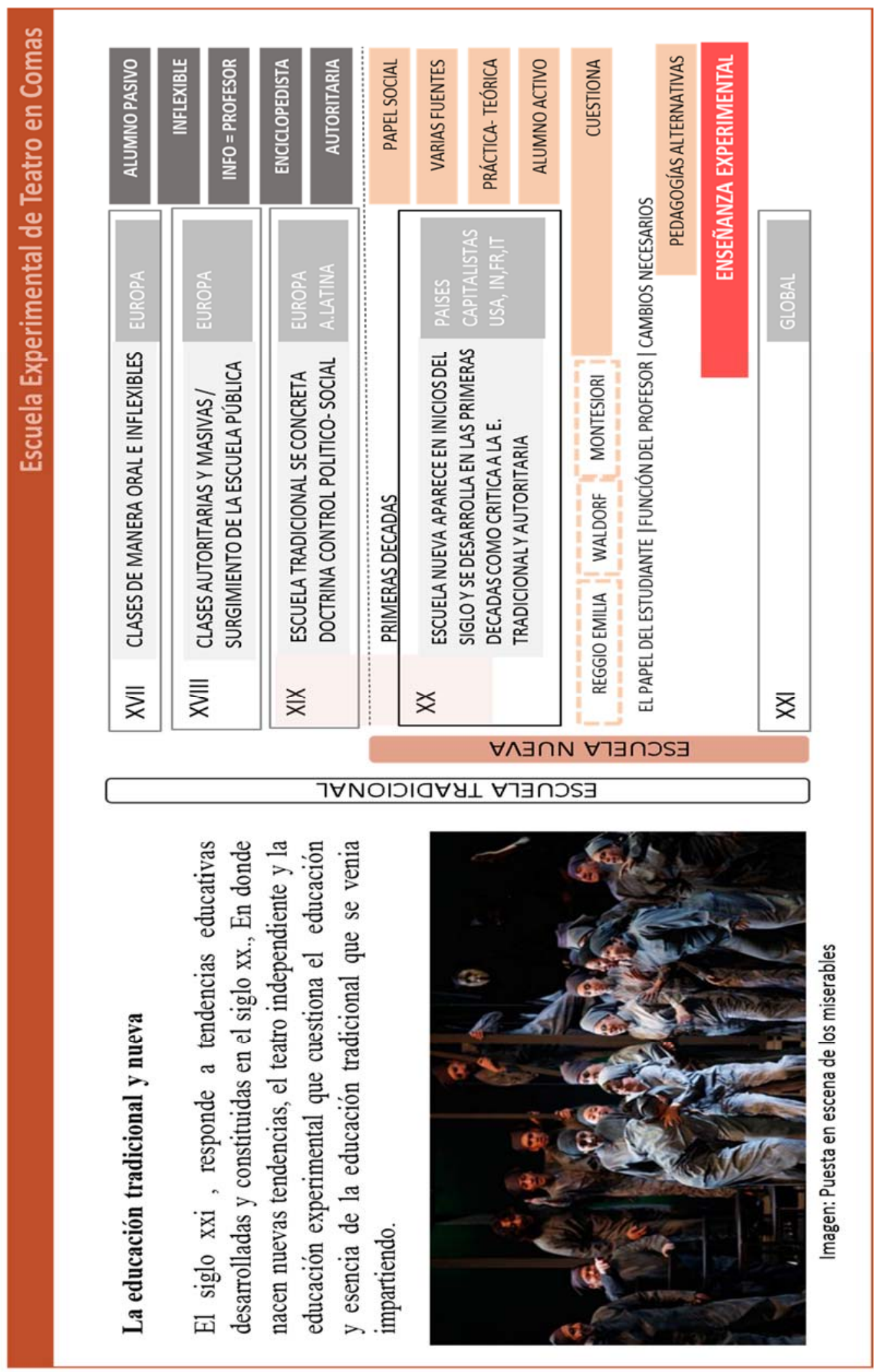

Figura 7. La educación Tradicional y Nueva

Fuente: Elaboración Propia 


\subsection{Educación y Espacios Experimentales en el Teatro}

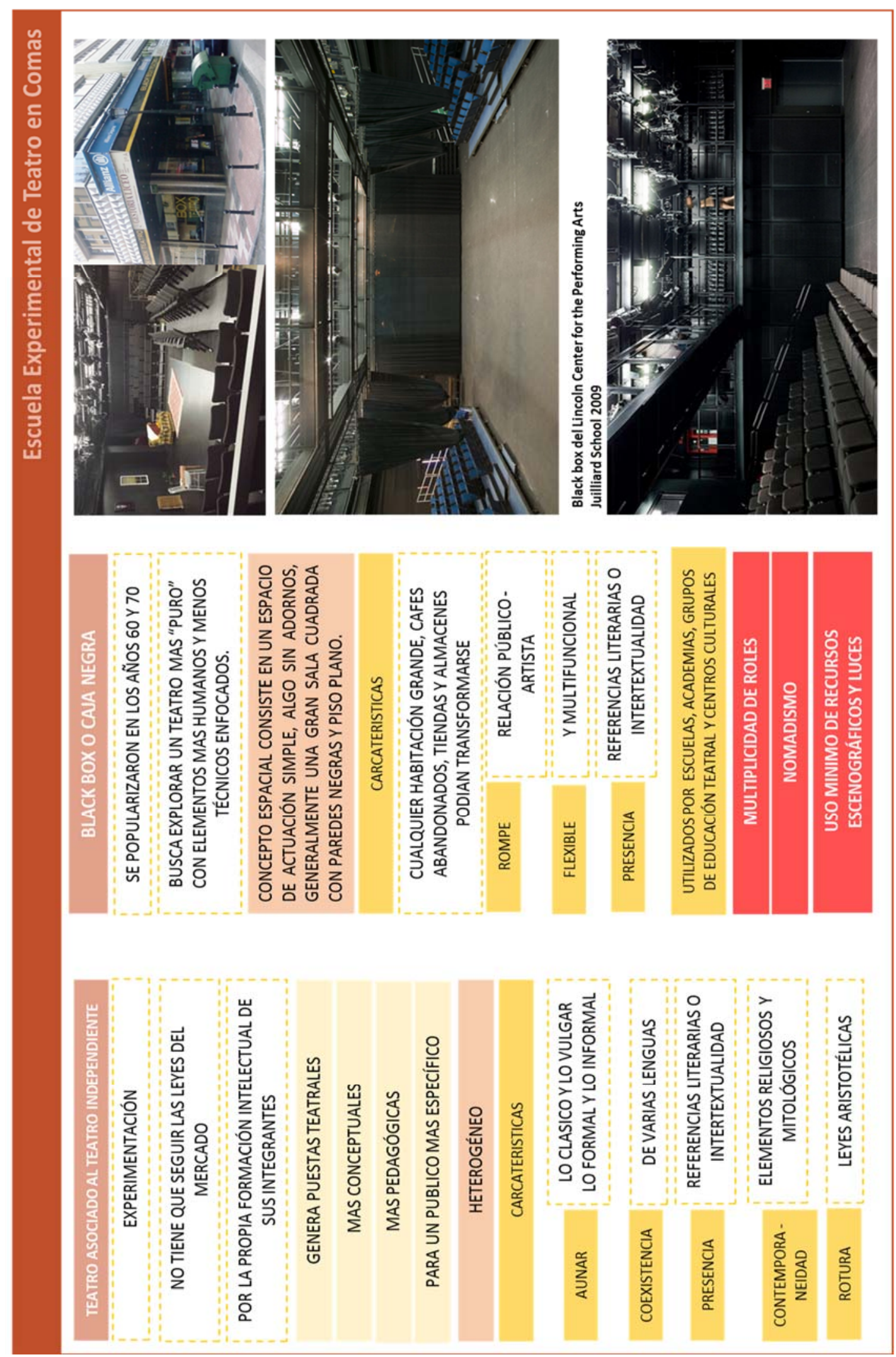

Figura 8. Educación y Espacios Experimentales en el Teatro

Fuente: Elaboración Propia 


\subsection{Proyectos Referenciales de la Tipología}

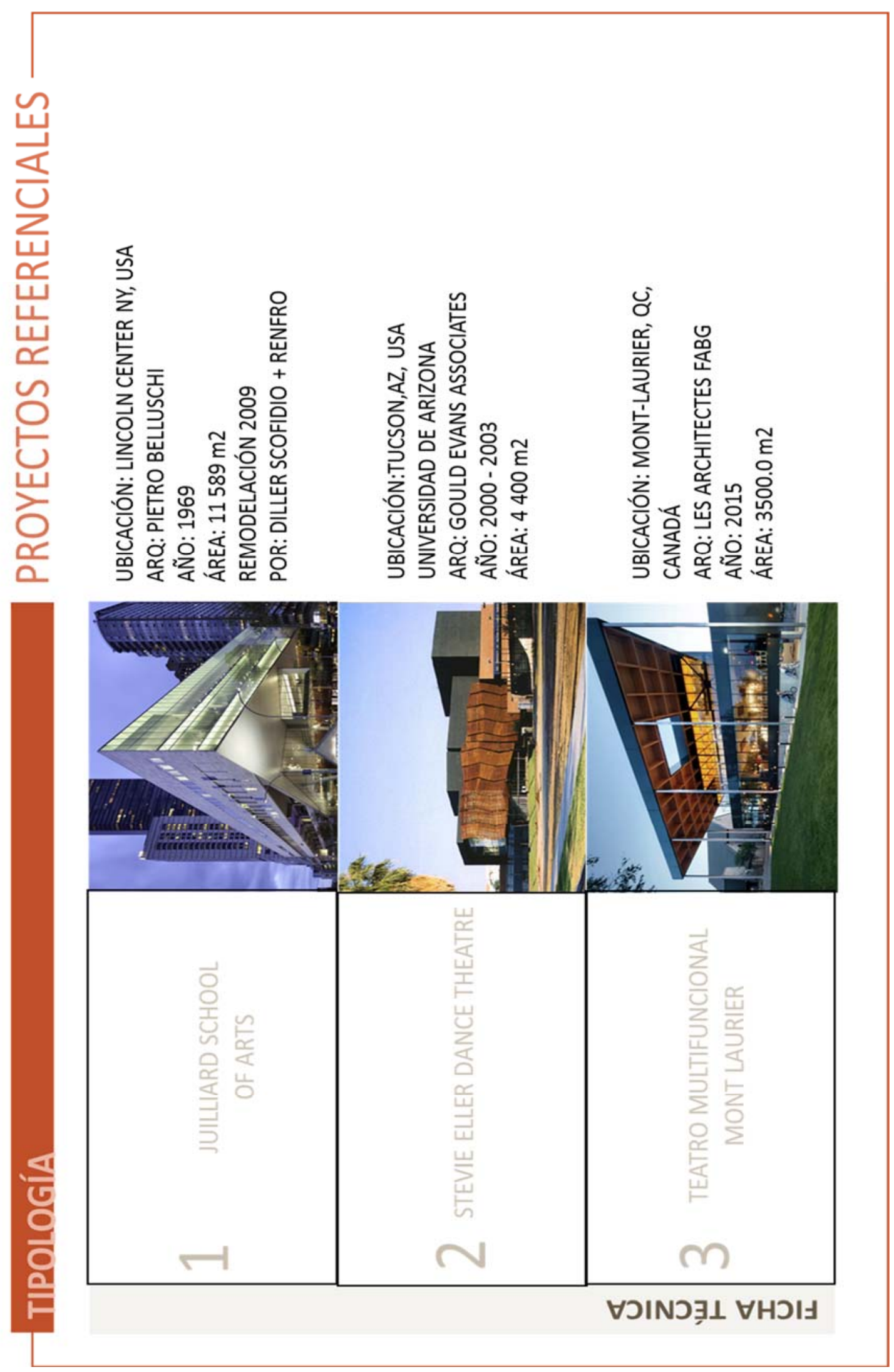

Figura 9. Lista de Proyectos Referenciales 


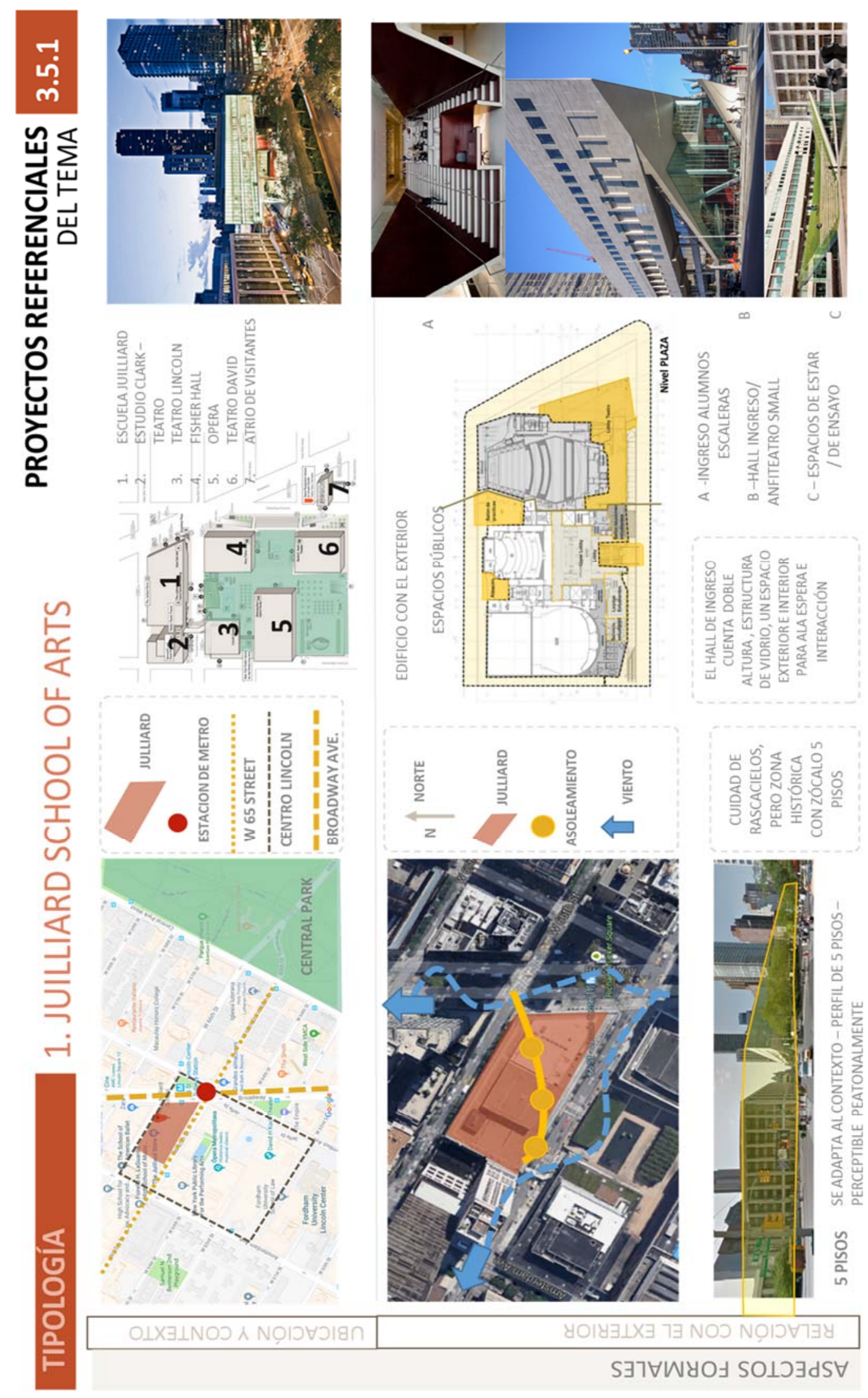

Figura 10. Proyecto referencial. Elaboración Propia 


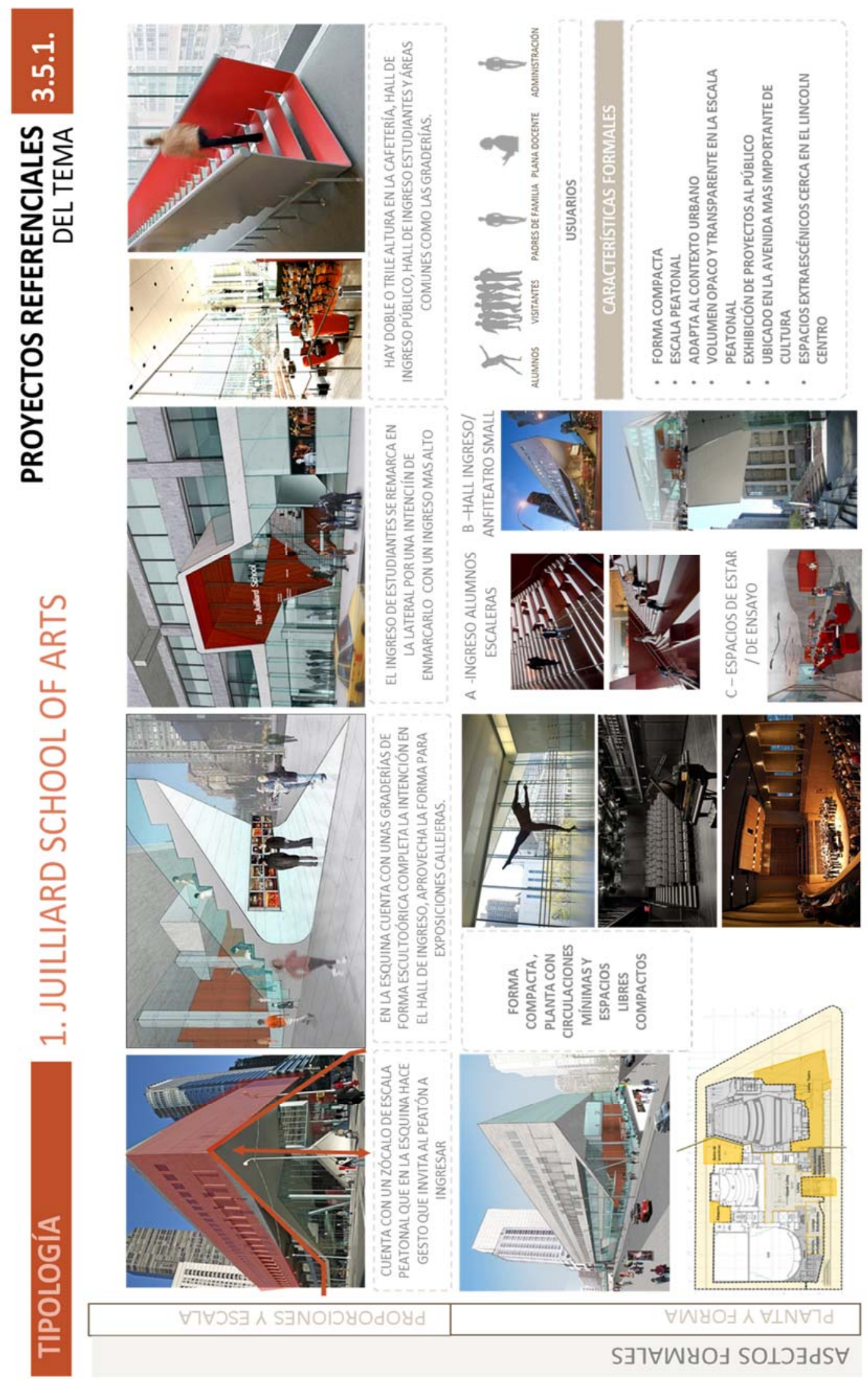

Figura 11. Proyecto referencial. Elaboración Propia 


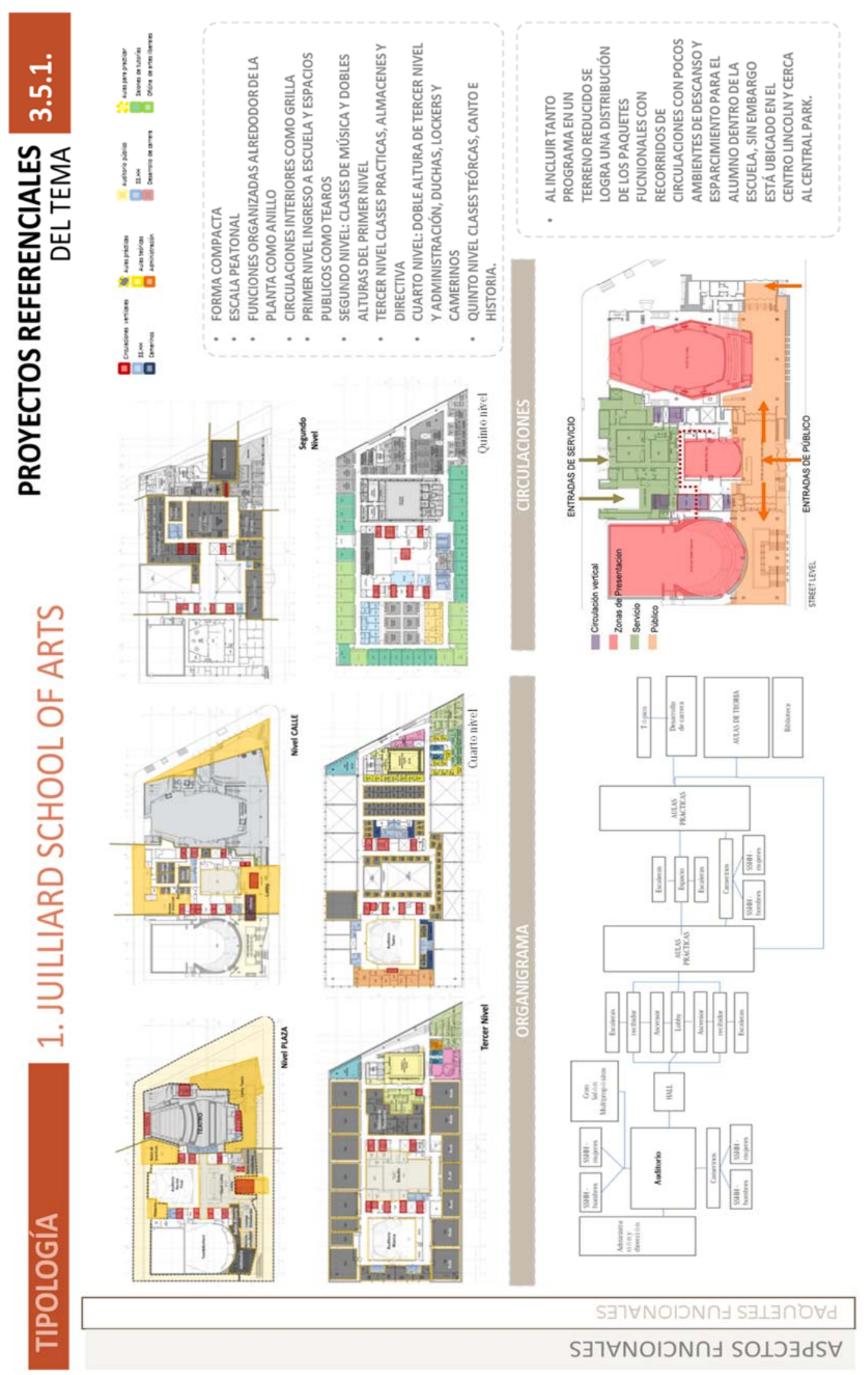

Figura 12. Proyecto referencial. Elaboración Propia 


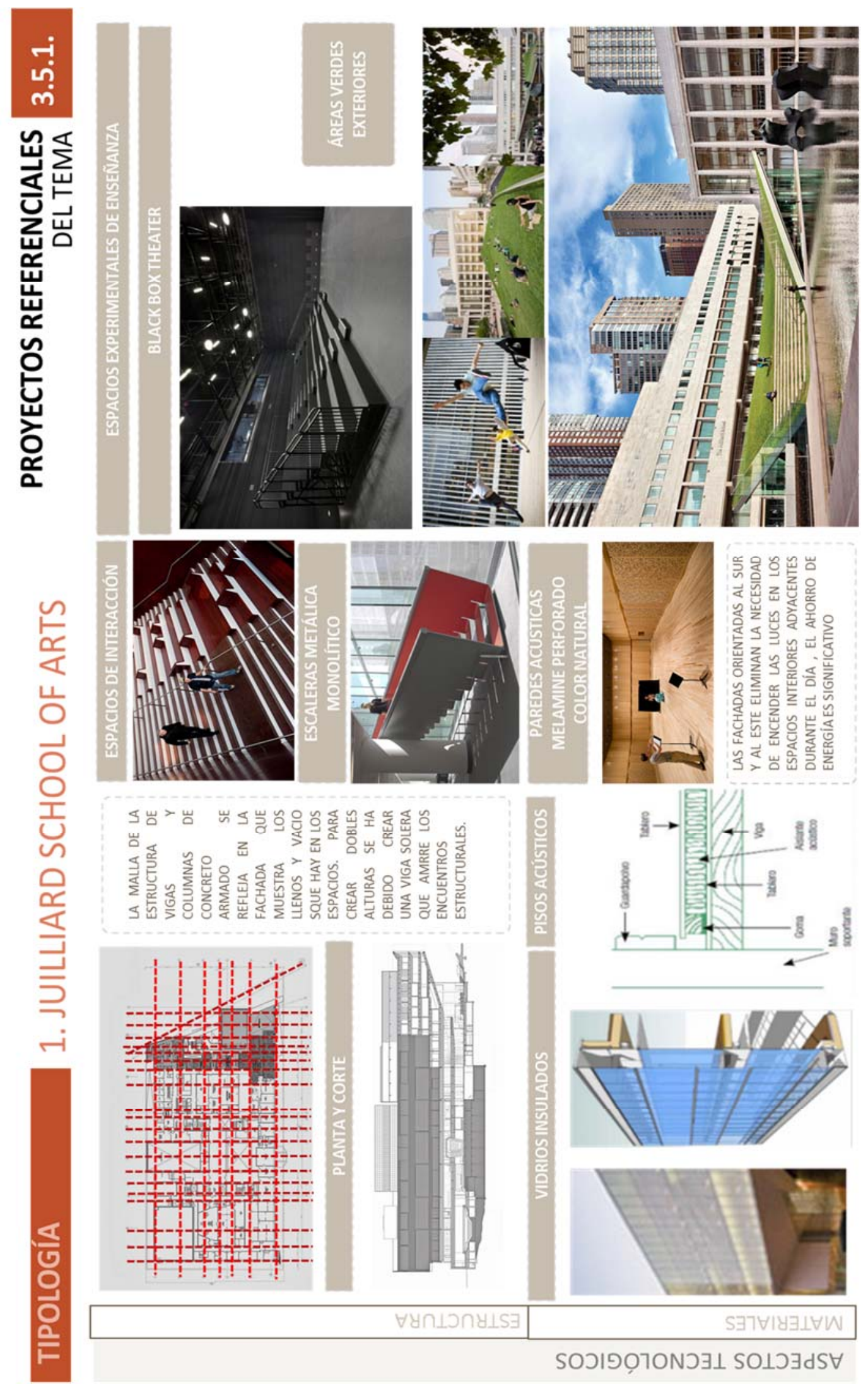

Figura 13. Proyecto referencial. Elaboración Propia 


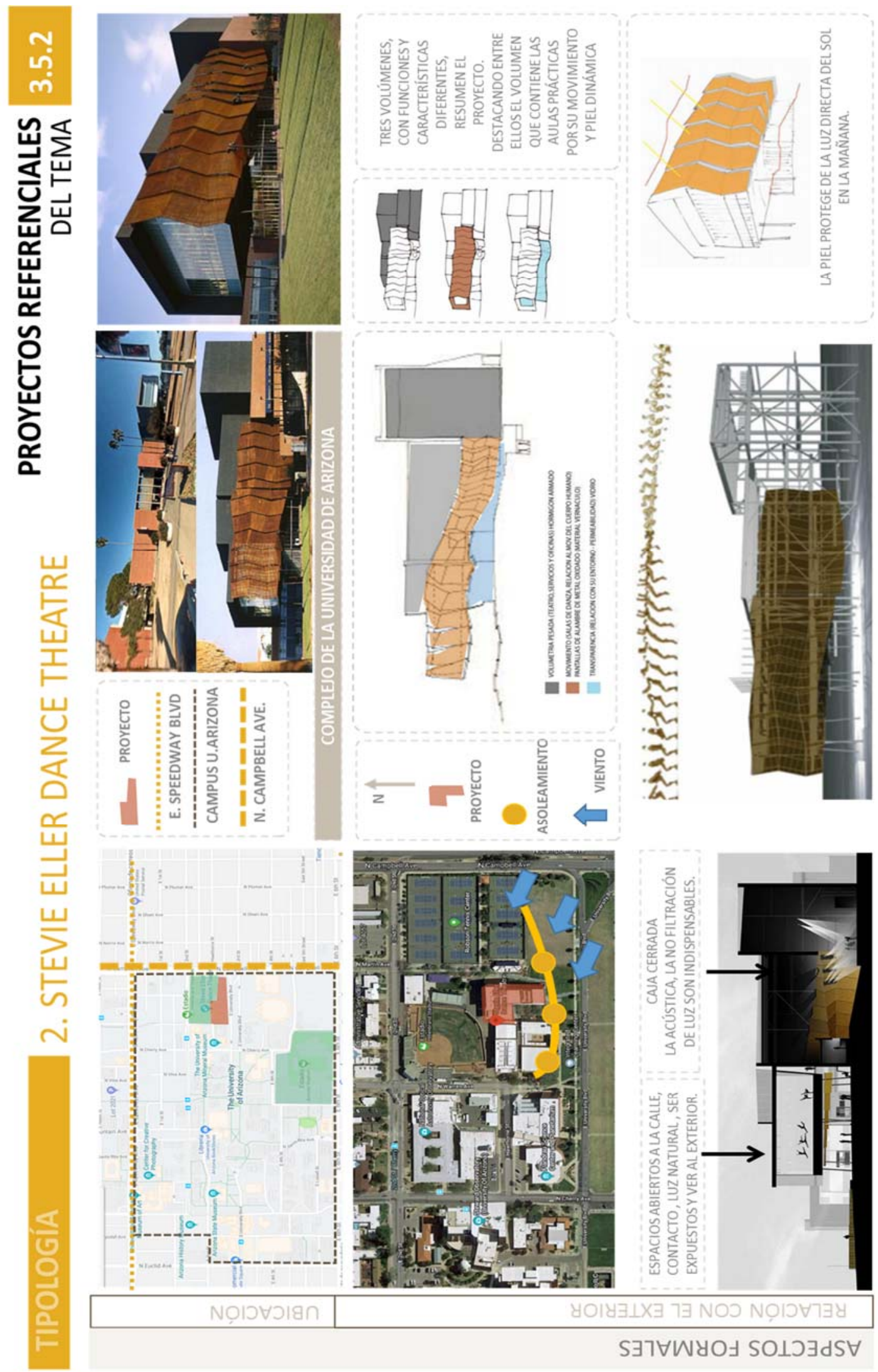

Figura 14. Proyecto referencial. Elaboración Propia 


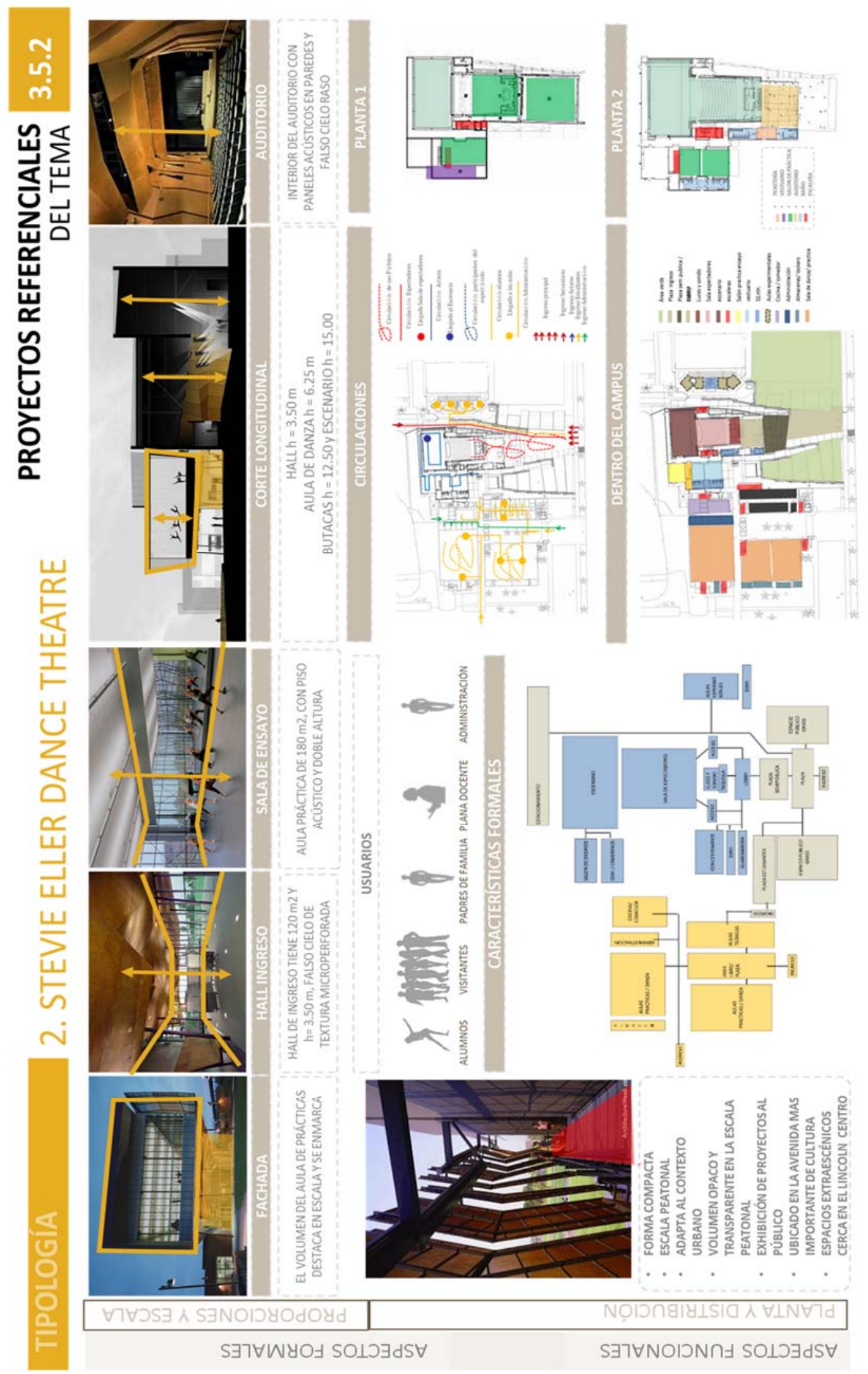

Figura 15. Proyecto referencial. Elaboración Propia 


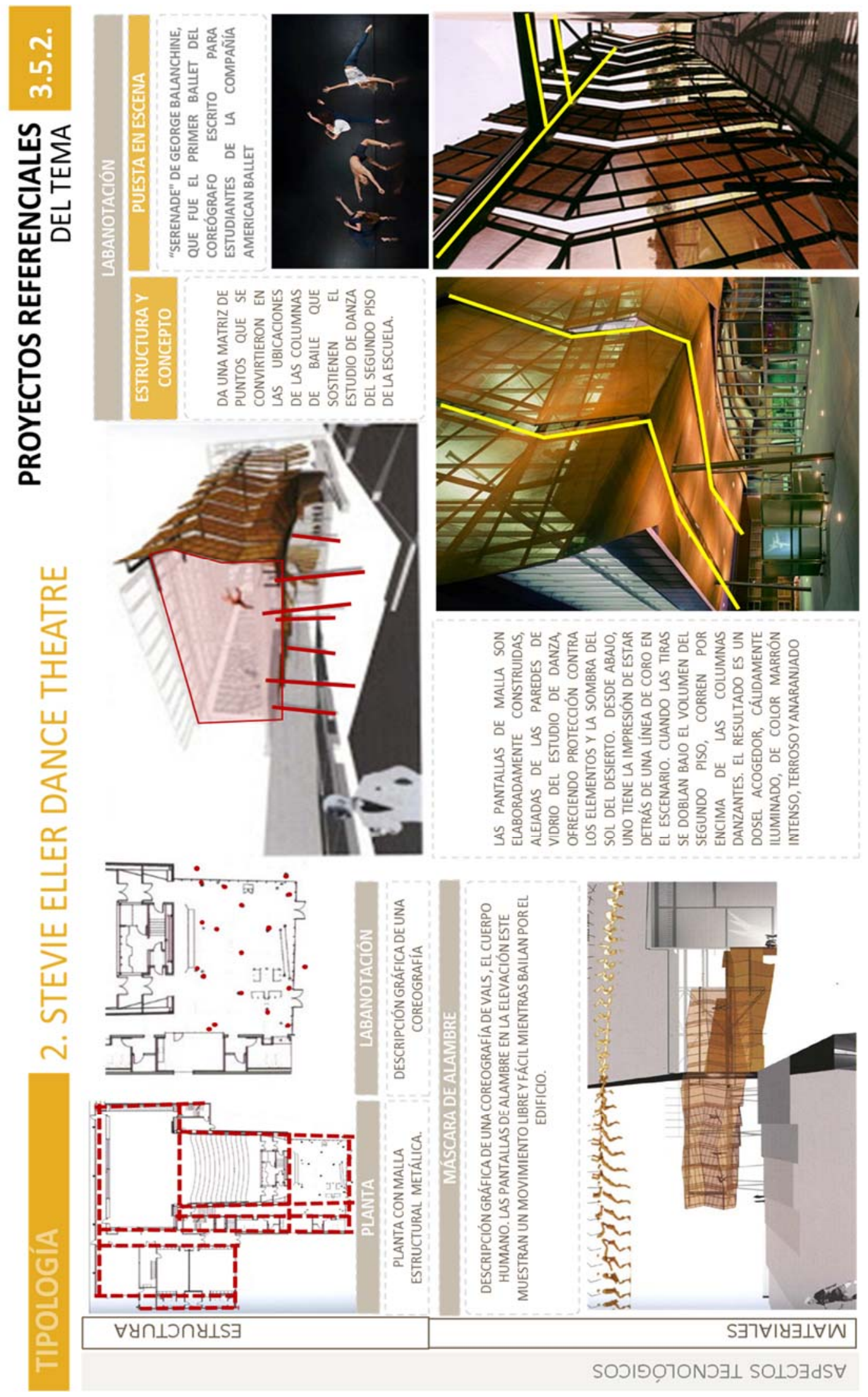

Figura 16. Proyecto referencial. Elaboración Propia 


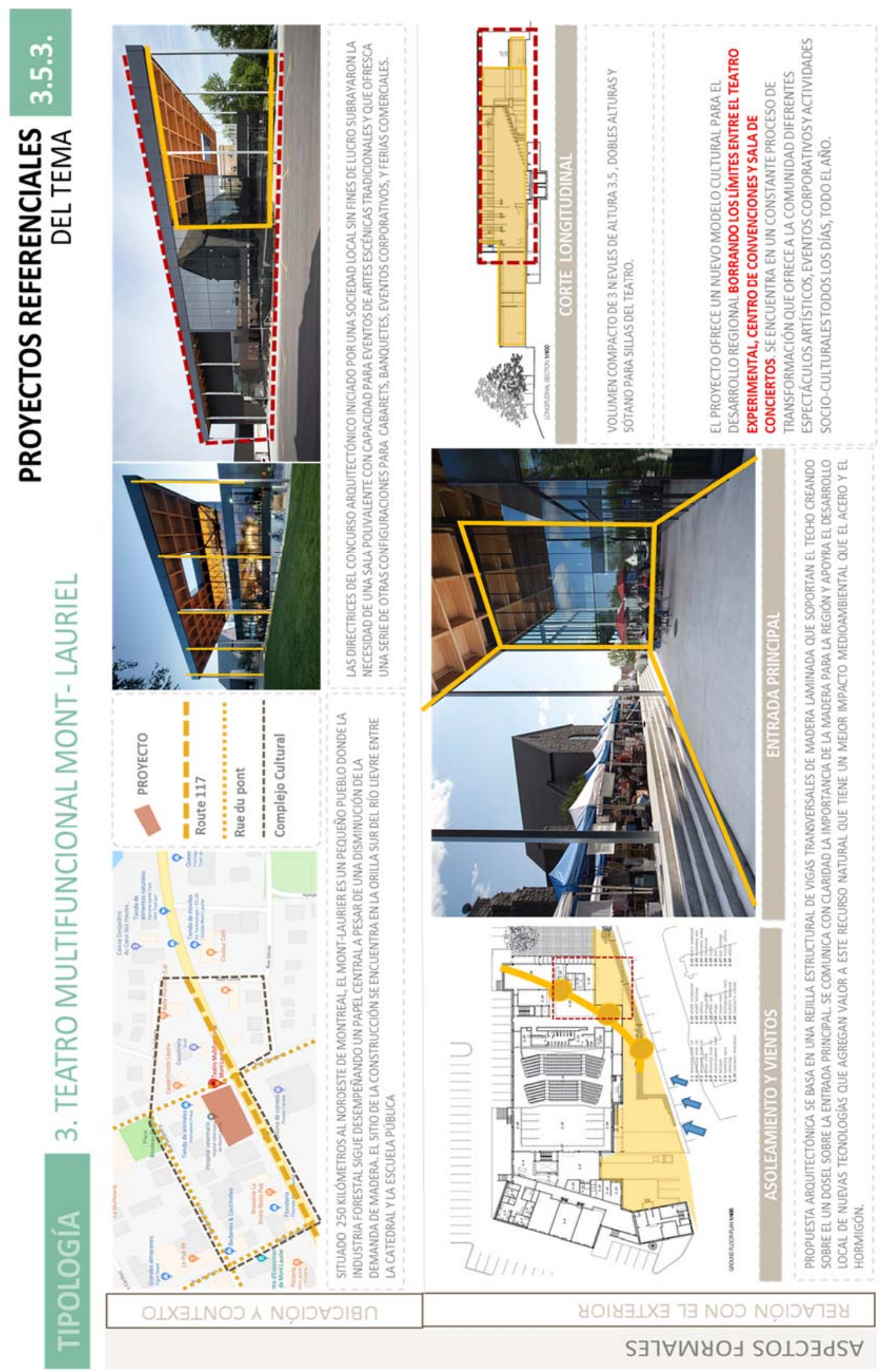

Figura 17. Proyecto referencial. Elaboración Propia 


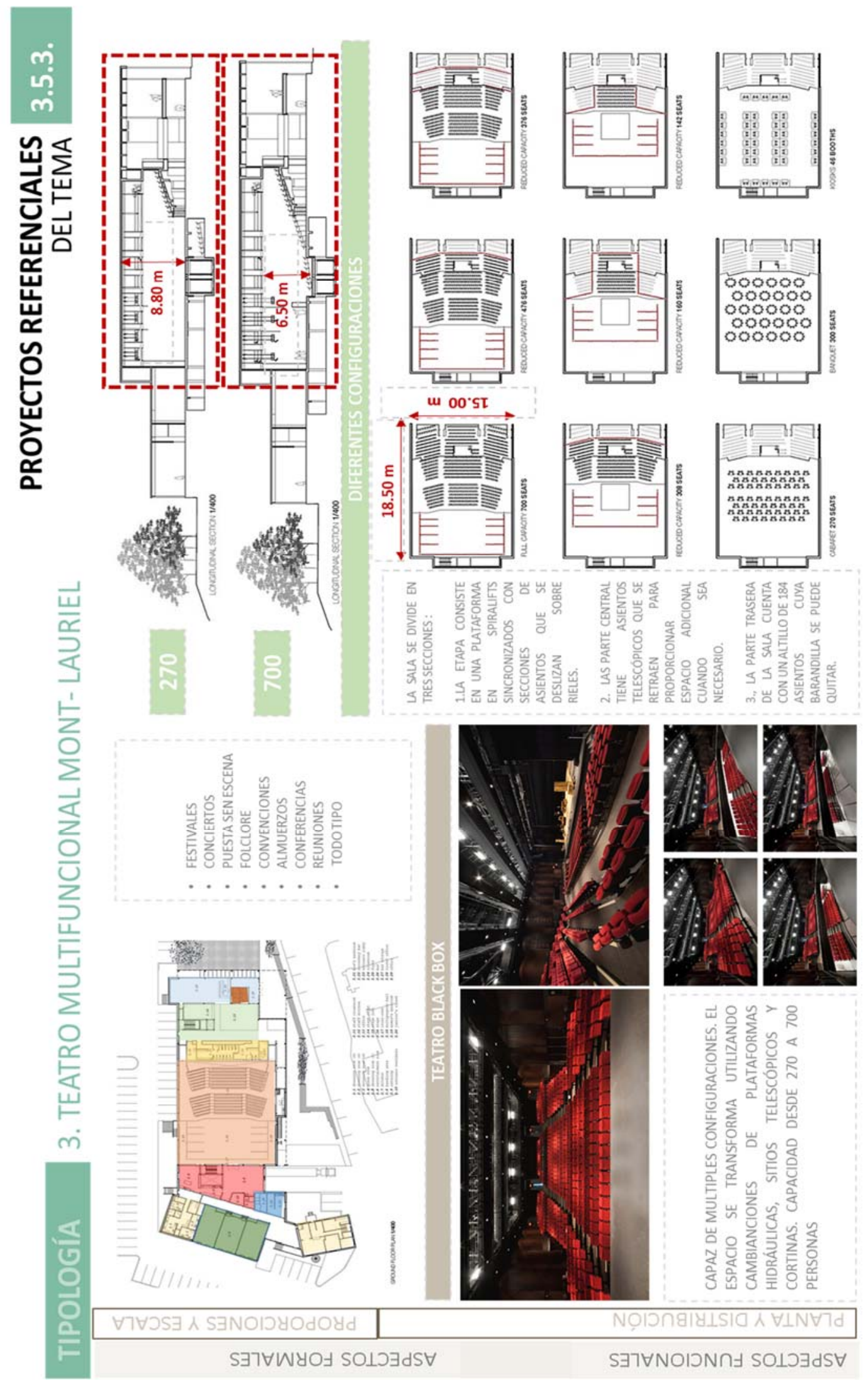

Figura 18. Proyecto referencial. Elaboración Propia 


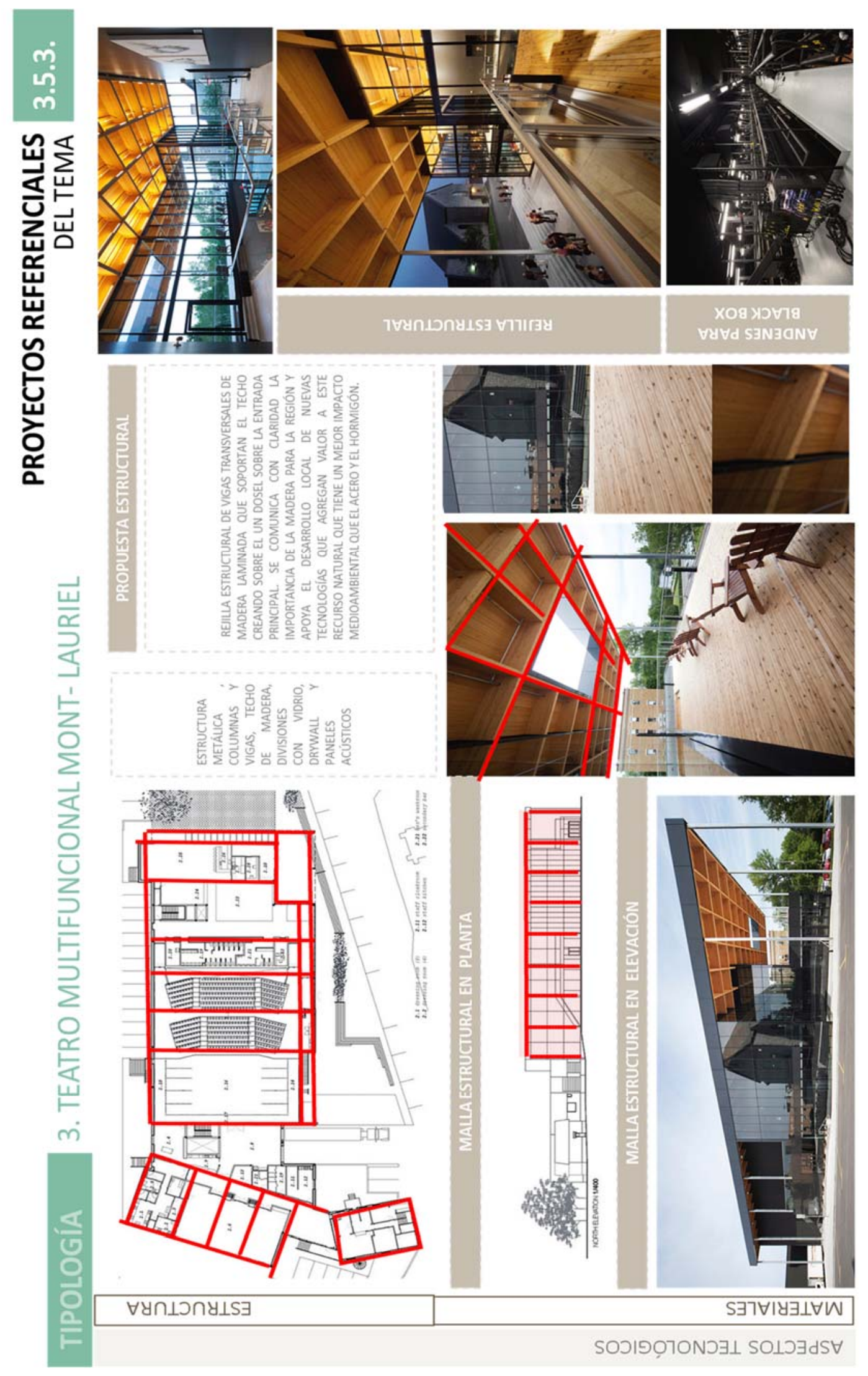

Figura 19. Proyecto referencial. Elaboración Propia 


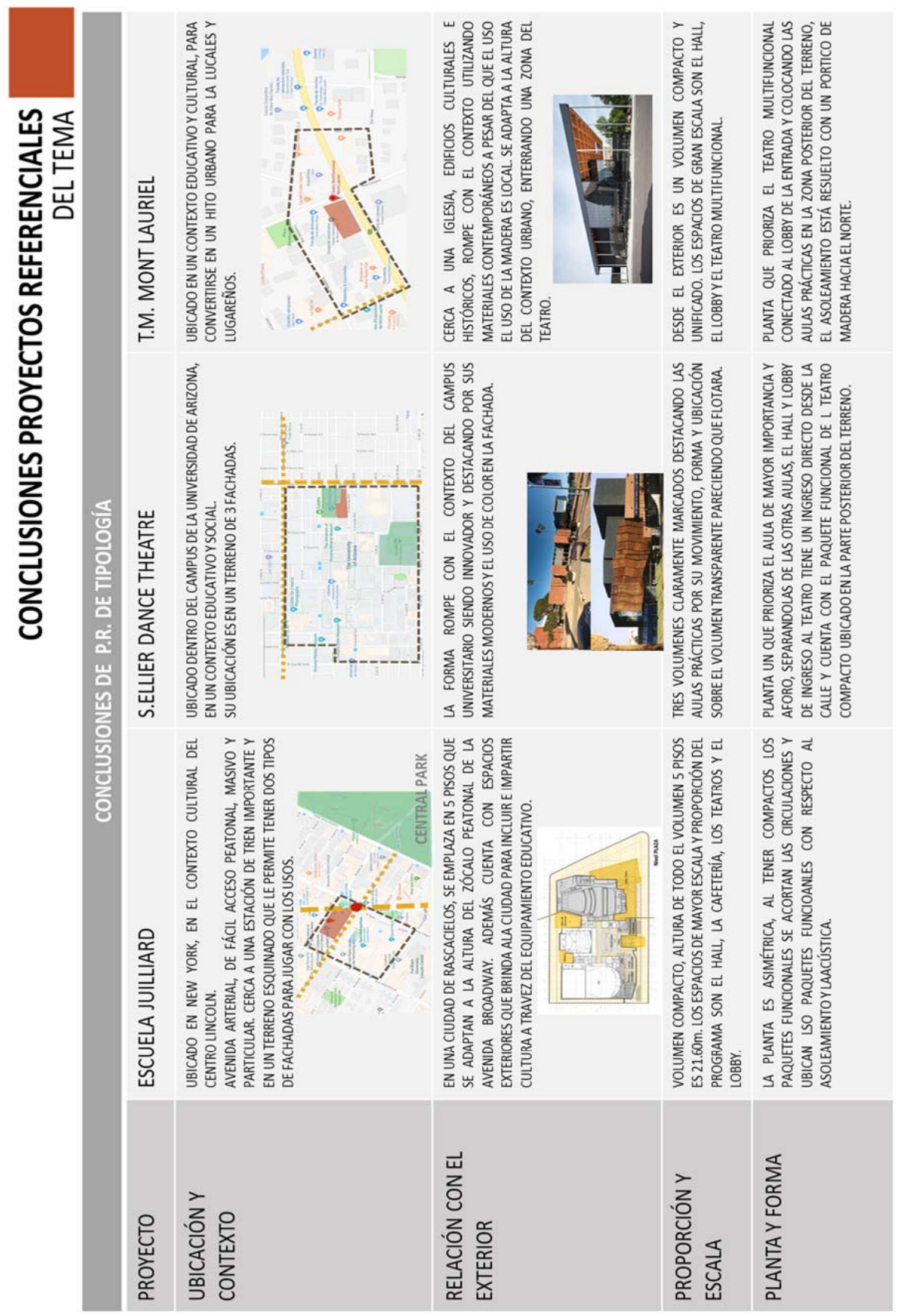

Figura 20. Proyecto referencial. Elaboración Propia 


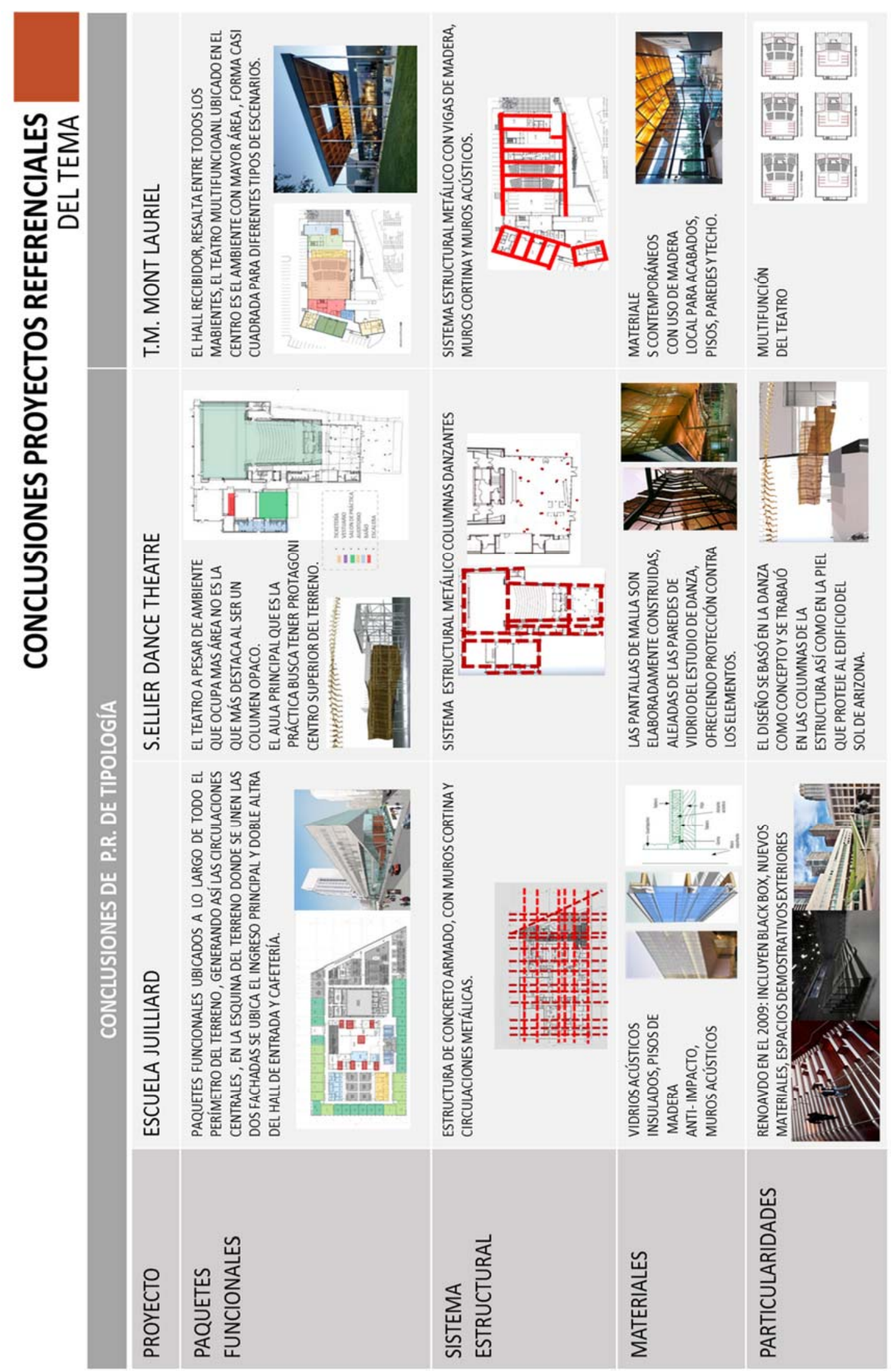

Figura 21. Proyecto referencial. Elaboración Propia 


\section{CAPITULO IV: EL ÉNFASIS}

\subsection{Selección y Sustentación de fuentes}

\section{TEXTO 1}

Libro: Life Between Buildings: Using Public Space

Autor: Jan Gehl

Editorial: Editorial Reverté

Año y Lugar de Publicación: España 2006

Capítulo y páginas: Capítulo I, pág. 17 a la pág. 57

Contenido: El Contenido General de la Obra entabla una reflexión y estudio del lugar público por excelencia: La Vida entre los Edificios y su uso humano. Analiza el contexto del ser humano y profundiza en las necesidades que tiene para su relación con el otro, y para la conformación de espacios en las ciudades cuyo objetivo es que la ciudad tenga habitantes felices.

Aspectos Importantes extraídos: Del libro se extraen las numerosas metodologías que el autor utiliza para analizar las ciudades, y aplicar ese análisis en el contexto en el que se desarrolla un proyecto Arquitectónico. Así en la presente Tesis se analiza como a través de la arquitectura se puede lograr hacer la calle en la que se emplaza más atractiva, que tipo de actividades se realizan en una escuela y cuáles son las necesidades para el encuentro del alumno con la comunidad de Comas.

Este libro es un aporte que enriquece el estudio del espacio público exterior, uno de los dos puntos de espacios experimentales de enseñanza que se concluyen en este Capítulo. Investigación por la cual se evalúan los distintos espacios extraescénicos en el Teatro y se aplican como espacios públicos en la tesis, enriqueciendo el entorno de la Escuela y Fomentando el uso de los espacios públicos en los ciudadanos de Comas. 


\section{TEXTO 2}

Publicación: Jornadas Internacionales: La Humanización del espacio público del 13 al 14 mayo 2009

Tema: Transcripción de conclusiones y ponencias de las jornadas

Autor: Ministerio de Desarrollo Urbano de Buenos Aires

Año y Lugar de Publicación: 2009, Buenos Aires - Argentina

Contenido: El Contenido General de la Publicación es un debate e intercambio de ideas entre ponientes y participantes sobre La Humanización del Espacio Público, brindando una nueva oportunidad de aporte y reflexión para la labor del Ministerio Público de desarrollo Urbano.

Aspectos Importantes extraídos: Esta Publicación llega a acercar el tema de la Humanización del espacio Urbano en Latinoamérica y ubica y analiza problemáticas actuales en el contexto socio político y cultural en el que se desarrollan las principales ciudades.

Se extraen conceptos y ejemplo de proyectos referenciales de buen manejo del espacio público y cuyo uso con los años han afirmado su buen funcionamiento para el encuentro social.

Temas como la accesibilidad, la discapacidad, la inseguridad y seguridad de los bordes, entre otros; son tratados con ejemplos reales y actuales ejecutados por los ministerios competentes. Por ejemplo el Plan Urbano de La Ciudad de Rosario en Argentina contempla un sistema de 13 parques metropolitanos alrededor de 10 años (2007 - 2017), los cuales han sido diseñados y concebidos bajo conceptos urbanos de humanización. Así se creó una red de parques, en donde los existentes se rediseñan para su consolidación y reavivamiento social, como también se crean nuevos parques con características cualitativas y cuantitativas con respecto al crecimiento demográfico y al impacto metropolitano que se buscaba. 


\section{TEXTO 3}

Libro: Espacios Urbanos en el Teatro Español S. XX y S. XXI

Autor: Georg Olms Verlag

Editorial: Cerstin Bauer - Funke editorial

Año y Lugar de Publicación: 2016, Hildesgeim - Alemania

Contenido: El Contenido General de la Obra abarca desde una vasta aproximación a la creación dramática en torno a los espacios urbanos y a sus formas diversas, entendiendo lo urbano como una red de espacios y seres que lo habitan. El teatro, presente en la sociedad democrática desde el siglo XX a la actualidad.

Aspectos Importantes extraídos: Esta Publicación llega a acercar el tema del entendimiento de los espacios urbanos teatrales y sus formas de expresión más diversas. Se logra entender que la expresión teatral ubicada en el espacio urbano y en los problemas sociales.

Se extrae del libro conceptos de espacios Urbanos adaptables para representaciones Teatrales como plataformas, anfiteatros, metros, calles, escaleras, entre otros son descritos y sus componentes. El libro analiza la manera en que el espacio dramático, definido por los diferentes objetos en un espacio concreto, está relacionado con los rasgos psicológicos y sociales de los personajes.

El libro expone las cualidades heterogéneas que tiene el teatro en cada espacio, y como las escenas primarias y secundarias (espacios accesorios en medio de un patio de butacas, podios de demostración, pasarelas) se adaptan, mimetizan y reescriben de acuerdo a las cualidades del espacio urbano en donde se escenifican. 


\subsection{Espacios Experimentales de Enseñanza}

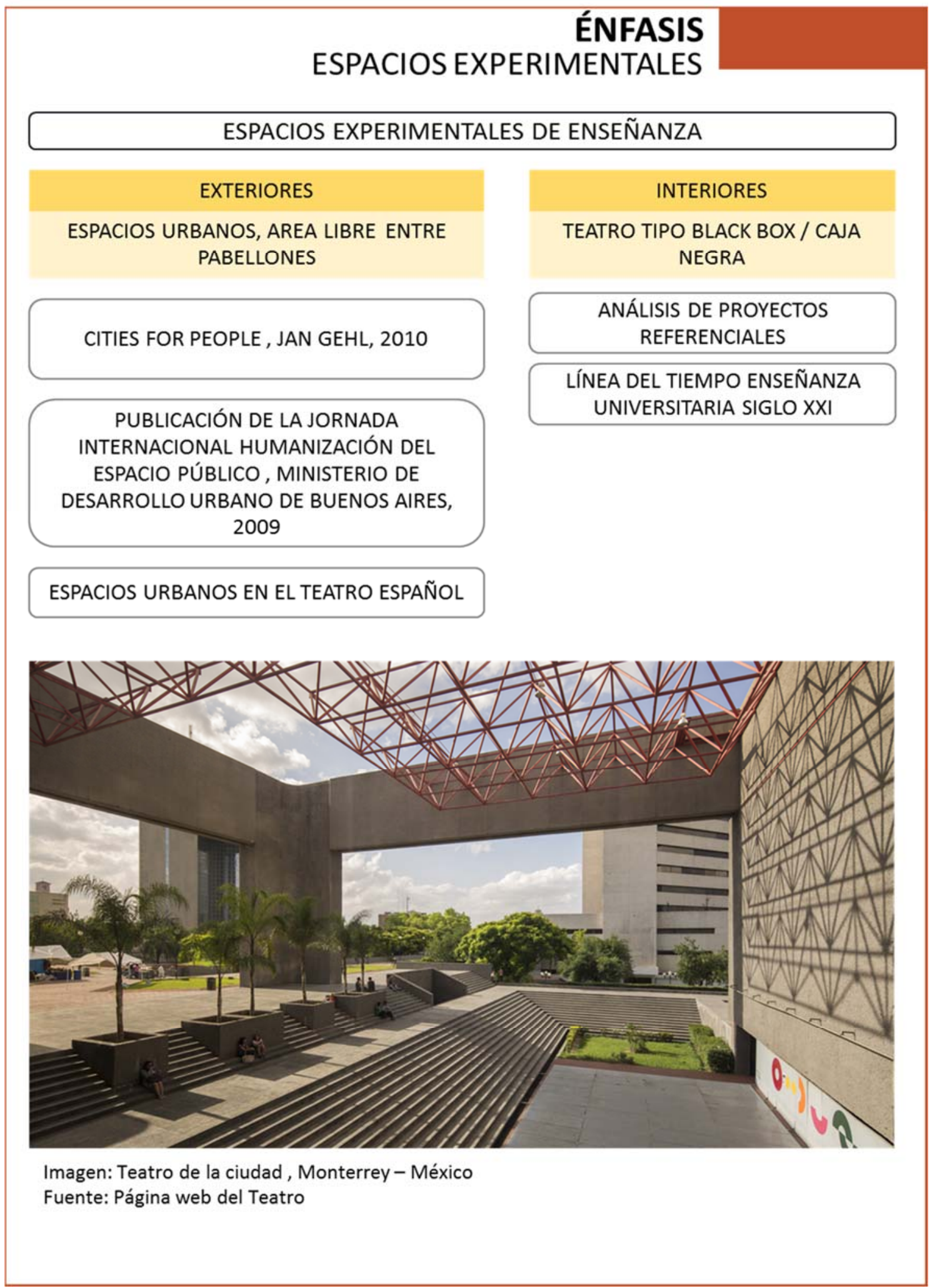

Figura 22. Espacios Experimentales de enseñanza

Fuente: Elaboración Propia 
Los espacios en los que se desarrolla la vida de un estudiante de Teatro se dan tanto dentro como fuera de las escuelas. Siendo las aulas espacios de aprendizaje y el auditorio escolar el espacio de demostración de los alumnos al finalizar cada ciclo. Como espacios experimentales de enseñanza se elige el Teatro Black box como espacio interior y el ámbito urbano como espacio exterior por excelencia en donde la composición del diseño de los espacios exteriores complementa la interacción y aprendizaje de los alumnos quienes encuentran muchas más posibilidades para el aprendizaje, la demostración, la improvisación y la práctica.

\subsubsection{Espacios Experimentales Exteriores}

Los espacios exteriores vuelven atractivo un proyecto, y son esenciales y relevantes en la arquitectura teatral. En un proyecto, como una Escuela Experimental de Teatro, es fundamental poder ofrecerles al alumno y al ciudadano espacios para encontrarse y reunirse con otras personas de manera informal. El contacto o lazo que establezca la escuela con los vecinos se dará en los espacios públicos, los cuales cuentan con 3 requisitos básicos para un buen funcionamiento según los conceptos de la vida entre los edificios según el Arq. Jan Gehl.

La interacción entre las actividades sociales desarrolladas en los espacios públicos y los procesos sociales deben considerarse en varios aspectos:

El diseño organizado en torno a los espacios comunes

- Estableciendo espacios comunitarios, interiores y exteriores, en los diferentes niveles de la estructura jerárquica. (La función principal de los espacios comunitarios es proporcionar el escenario para la vida entre los edificios, para actividades cotidianas imprevistas y actividades sociales)

- La importancia que las personas lleguen a pie a la estancia. Hasta donde se puede llegar a pie desde un punto determinado y cuanto se puede ver y experimentar en su recorrido.

- A cada actividad se le da la oportunidad de colaborar con otra. A través de transiciones suaves entre zonas públicas y privadas, actuando como elementos de conexión, y no como zonas totalmente privadas, ni totalmente públicas. Por ejemplo, las escuelas pueden estar situadas en medio de un conjunto residencial y sin embargo estar eficazmente separadas de los alrededores con vallas, muros y praderas. Pero las escuelas también pueden proyectarse como parte esencial del conjunto. 
Por ejemplo, el Teatro Black box los fines de semana puede ser usado por la comunidad y diseñar su acceso de tal manera que al ingresar a este recinto no ingresen a la escuela; las aulas se pueden colocar en torno a las calles públicas de la ciudad que sirven de pasillos y patios de juego; el café de la plaza se usa también como cafetería de la escuela, y así la ciudad llega a formar parte del proceso educativo.

Algunos ejemplos de espacios públicos que se consideraron pertinentes al paradigma de la humanización y que fueron nombrados en la Jornada internacional: Humanización del espacio público realizada por el Ministerio de desarrollo urbano de buenos aires, 2009, son:

- $\quad$ El Fórum de Barcelona

- $\quad$ Orquideorama, Medellín

- $\quad$ Museo del Prado, Madrid

Estos proyectos cumplen con el respeto e integración del espacio natural, la coherencia con la cultura local y el uso de los recursos materiales para aproximarse a la construcción de espacios destinados al uso de todos los ciudadanos.

El interés común es más que la suma de los intereses individuales. Lo que debería ser el espacio público:

Un lugar lúdico, de intercambio, de juegos de fiesta, de prácticas libres, sin restricciones, y no segmento, fragmentado con separaciones de usos y funciones. Esto supone que humanizar el espacio público no es solamente un desafío para arquitectos, urbanistas y diseñadores, sino que es verdaderamente un desafío para la sociedad. La humanización del espacio público implica pedagogía, aprender a vivir juntos, a compartir usos (Ministerio de desarrollo urbano de Buenos Aires, 2009)

Se deberá desarrollar, por lo tanto, un espacio público conforme a su identidad y a su historia. La ciudad debe ser responsable de la concepción y de la realización de su espacio público y debe constituir sus útiles, sus instrumentos para poder dotarse del espacio público que refleje su espíritu y su cultura urbana. 


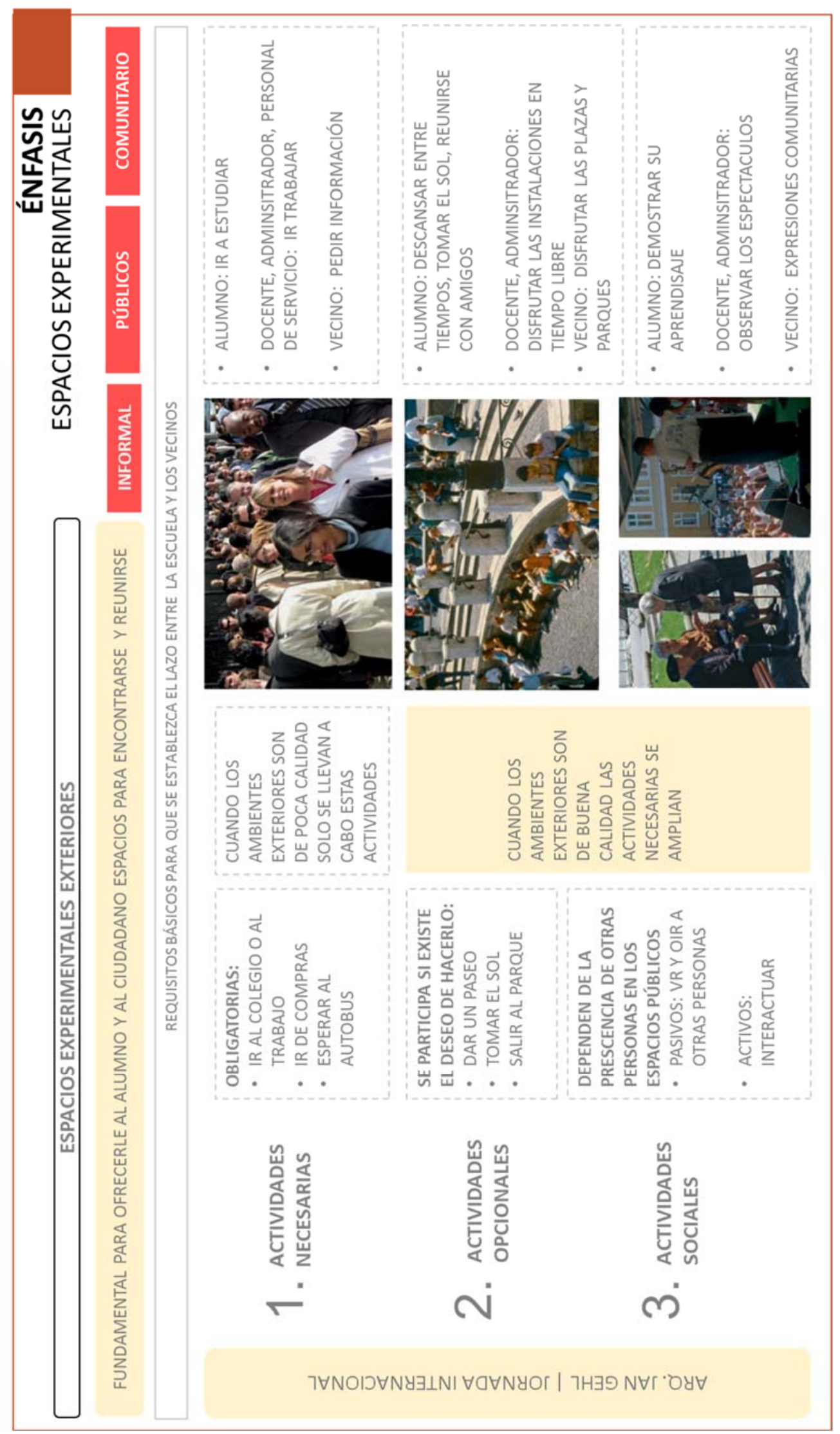

Figura 23. Espacios Experimentales Exteriores

Fuente: Elaboración Propia 


\subsubsection{Espacios Experimentales en el Teatro}

Desde mediados de los años 70, el teatro contemporáneo ha ido invadiendo todo tipo de espacios fuera del recinto teatral. Ocurre debido a la necesidad del estudiante de teatro de expresarse en un nuevo entorno, en donde demuestre las lecciones aprendidas al público, generando confianza, autoestima y solidez en el aprendiz. Estos espacios permiten la espontaneidad, la exploración, adaptación y la improvisación.

Los tipos de espacios extra escénicos para el desarrollo del teatro y la danza:

\section{PLATAFORMAS}

Es un espacio público en donde se representan obras previamente diseñada y ensayadas para su representación en un contexto exterior. La pieza coreográfica es fijada de antemano y adaptada a las dimensiones de la plataforma en uso. Como se observa en los espacios al aire libre del Teatro de la ciudad Monterrey - México, estos espacios están conformados por una plataforma de piso plano que se repite lo más fielmente posible a la disposición de un espacio escénico.

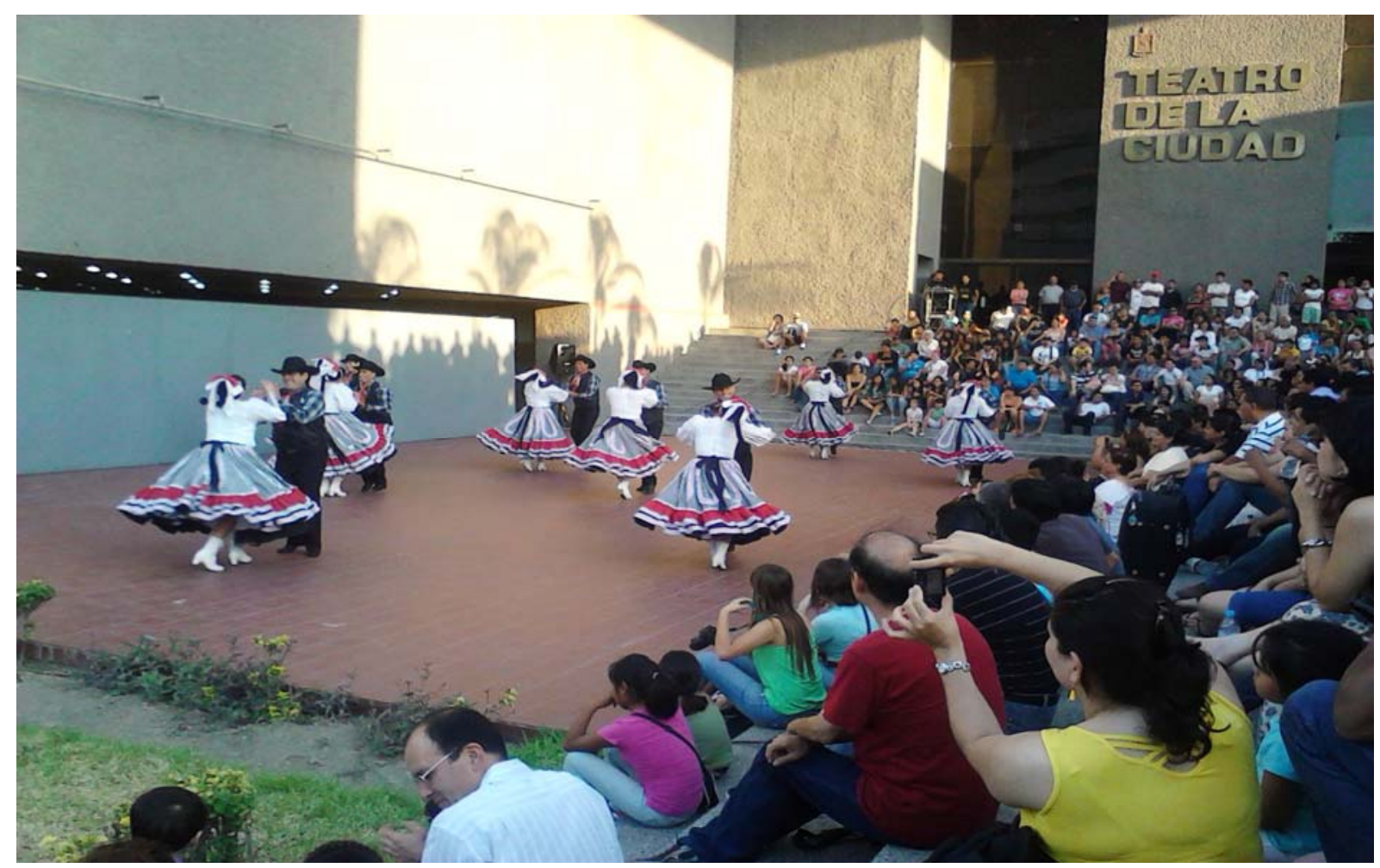

Figura 24. Plataforma a aire libre del teatro de Monterrey, México

Fuente: Galería de fotos de la Página web del teatro, México es cultura.com 2014 


\section{ANFITEATROS}

Los anfiteatros, conchas acústicas, áreas libres delimitadas, plazas y escenarios urbanos son diseñados especialmente para representaciones artísticas exteriores. Tal situación pasa en el parque Kennedy del distrito de Miraflores cuyos espacios permiten este tipo de expresión.
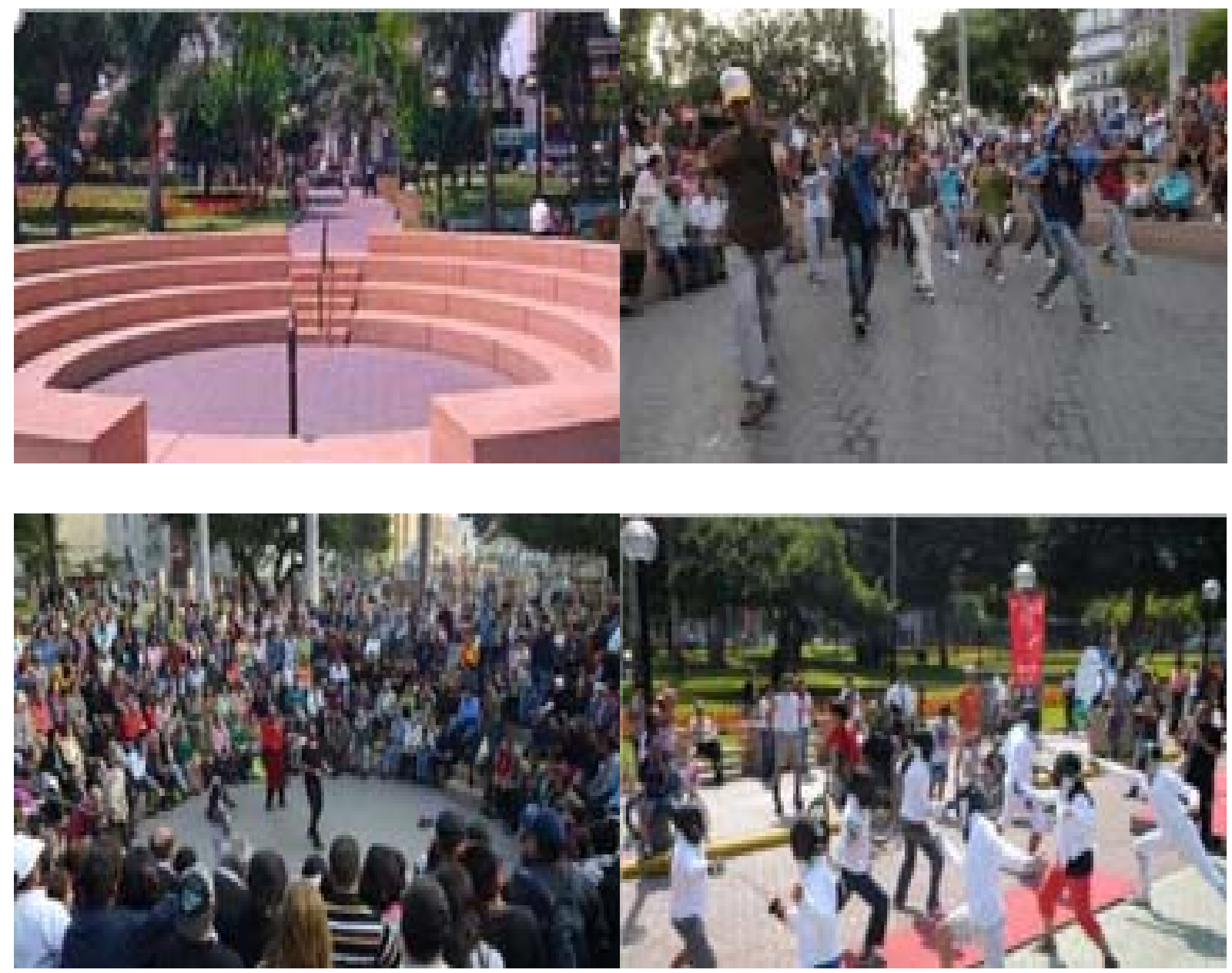

Figura 25. Actividades realizadas en Site Specific en el Distrito de Miraflores

Fuente: página web de la agenda cultural de la municipalidad de Miraflores

\section{ESPACIOS SITE SPECIFIC}

El Site Specific es un tipo de expresión que muestra preferencia por el espacio urbano como lugar de creación y movimiento de exploración como los anfiteatros a menor escala, escaleras urbanas, calles cerradas y diferentes espacios que generen dificultad y diferentes respuestas de los estudiantes. Se da en todo contexto alternativo y diferente al tradicional. 
Las condiciones espaciales son distintas a las usuales, el suelo plano y despejado se sustituye por uno se pliega formando escaleras, rampas y desniveles; la amplitud de la sala en la que los grandes saltos y los desplazamientos se remplazan por espacios estrechos, esquinas y rincones donde el movimiento se encuentra limitado. Apartándose de los suelos de linóleo y las paredes de yeso habituales se investigan las reacciones del cuerpo frente a determinadas texturas como las que ofrecen los adoquines, el asfalto, el césped, la tierra o el agua. (Nick Kaye, 2000)

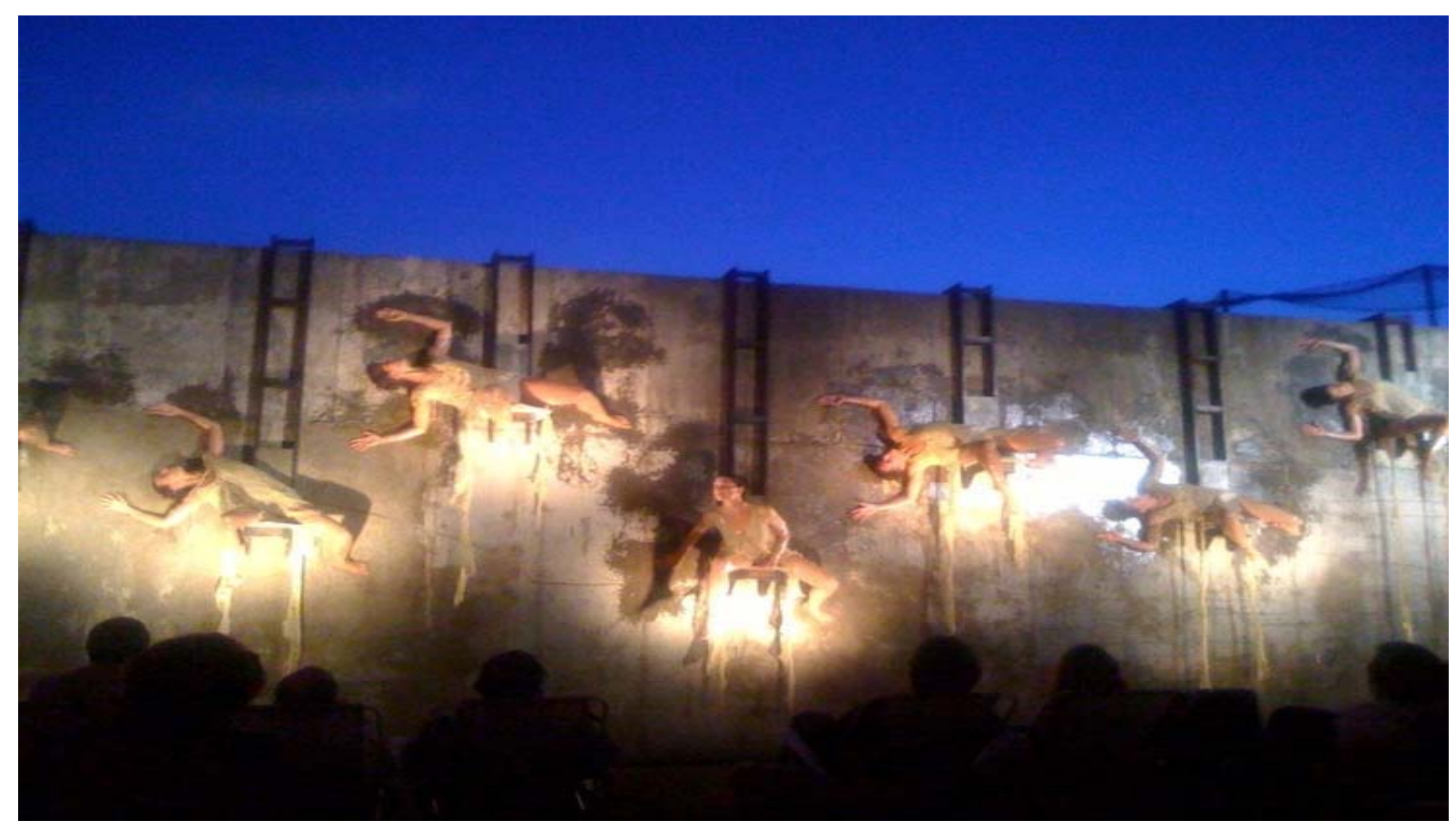

Figura 26. Instalación Site-specific en Noemie Lafrance por Marcy Schlissel

Fuentes: Site-Specific Art: Performance, Place and Documentation, Nick Kaye, 2000

"Ocho bailarinas colgadas en una pared y envueltas en esculturales ceras de abejas y trajes de lanolina se están desvaneciendo lentamente, progresando en euforia y agotamiento como si se acercaran al sol, derritiéndose hasta que sus almas escapen de sus cuerpos efímeros y se desintegren en la luz.” (Marcy Schilissel)

\section{ESPACIO URBANO: CALLE}

La Calle es el espacio urbano por excelencia y los espacios vacíos en el plano urbano siempre serán ricos en exploración teatral: pasacalles, túneles de metros, viejas estaciones, terrenos baldíos, entre otros. 


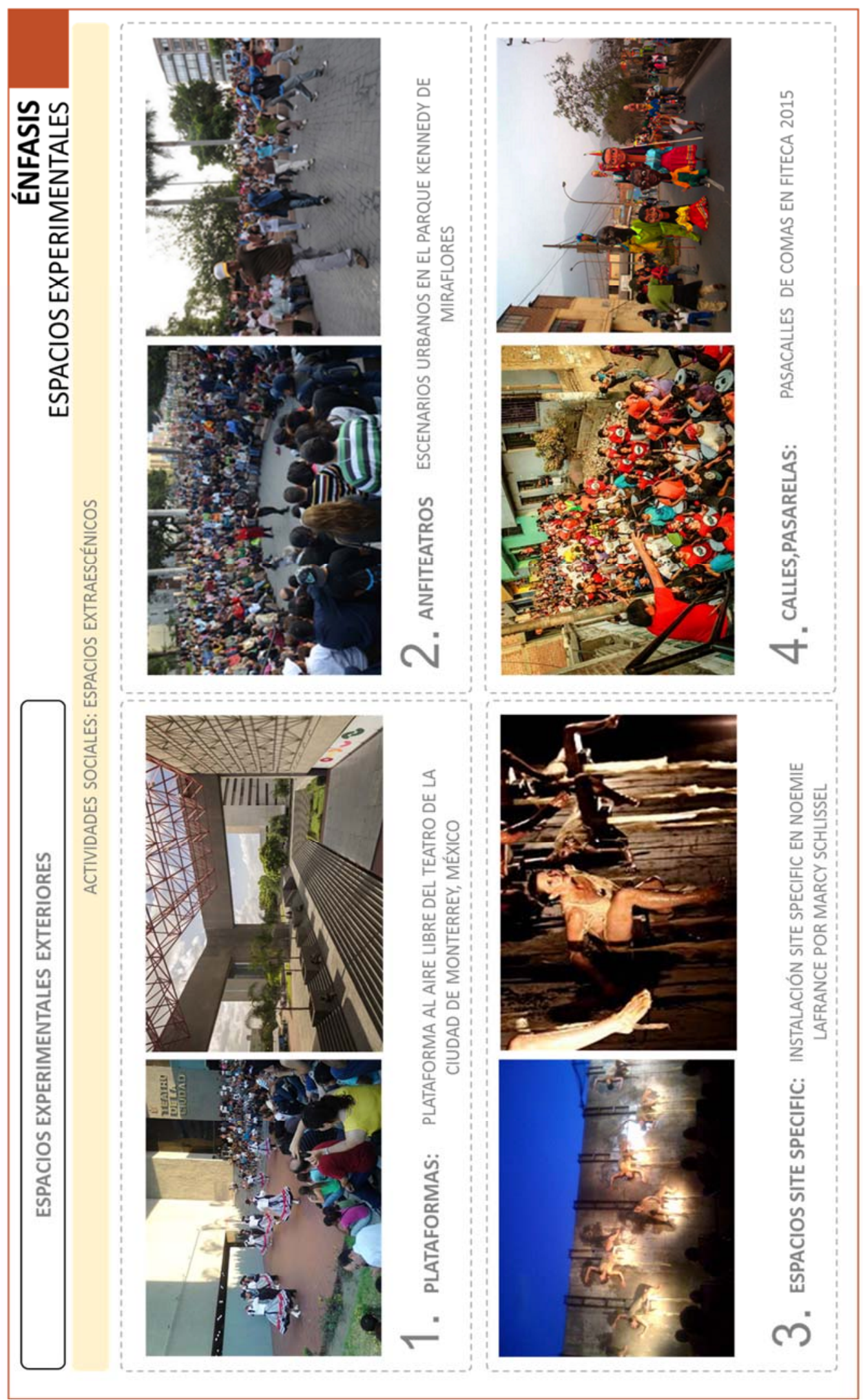

Figura 27. Espacios Experimentales Interiores. Elaboración Propia 


\subsubsection{Espacios Experimentales Interiores}

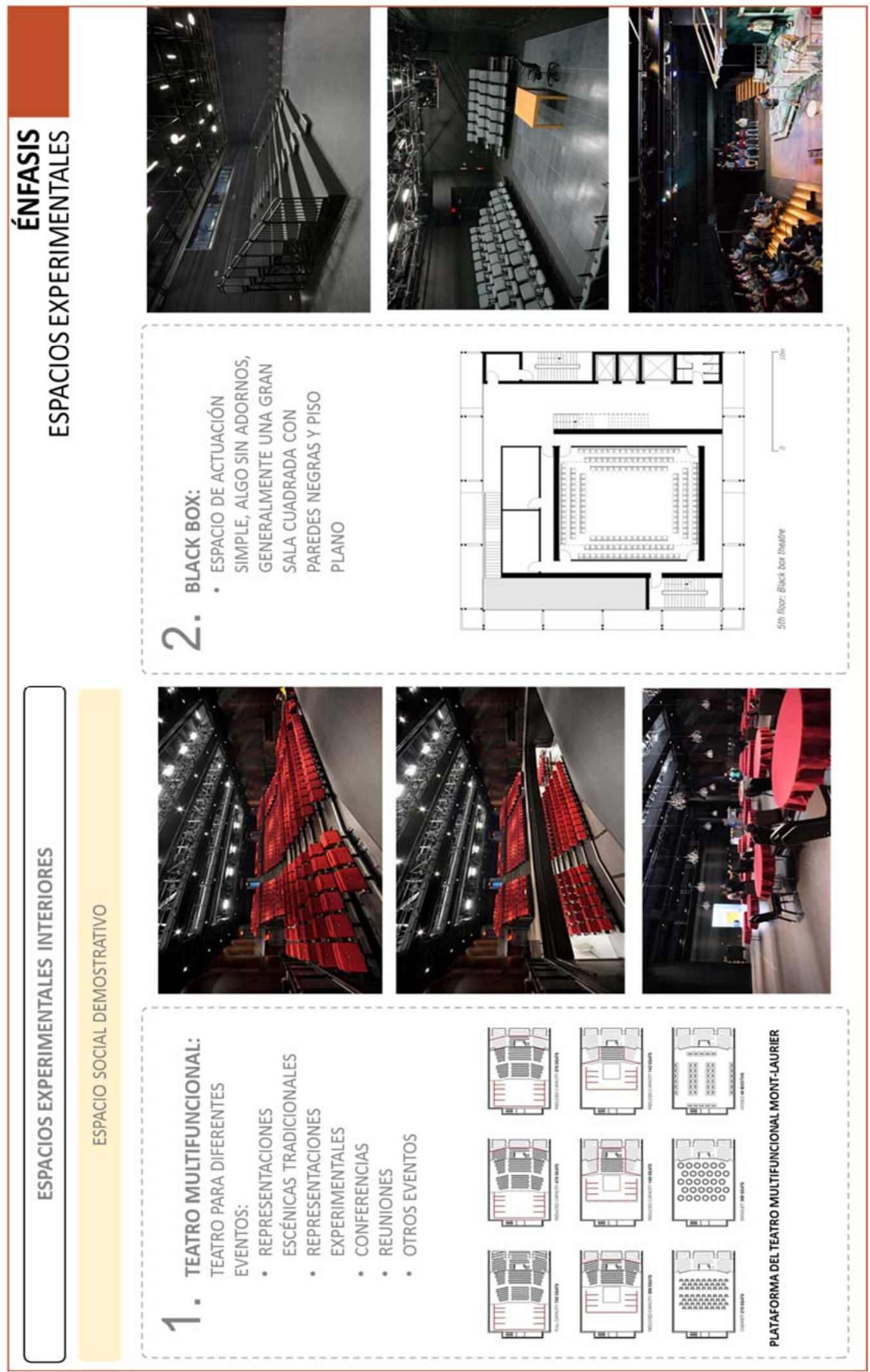

Figura 28. Espacios Experimentales Interiores. Elaboración Propia 


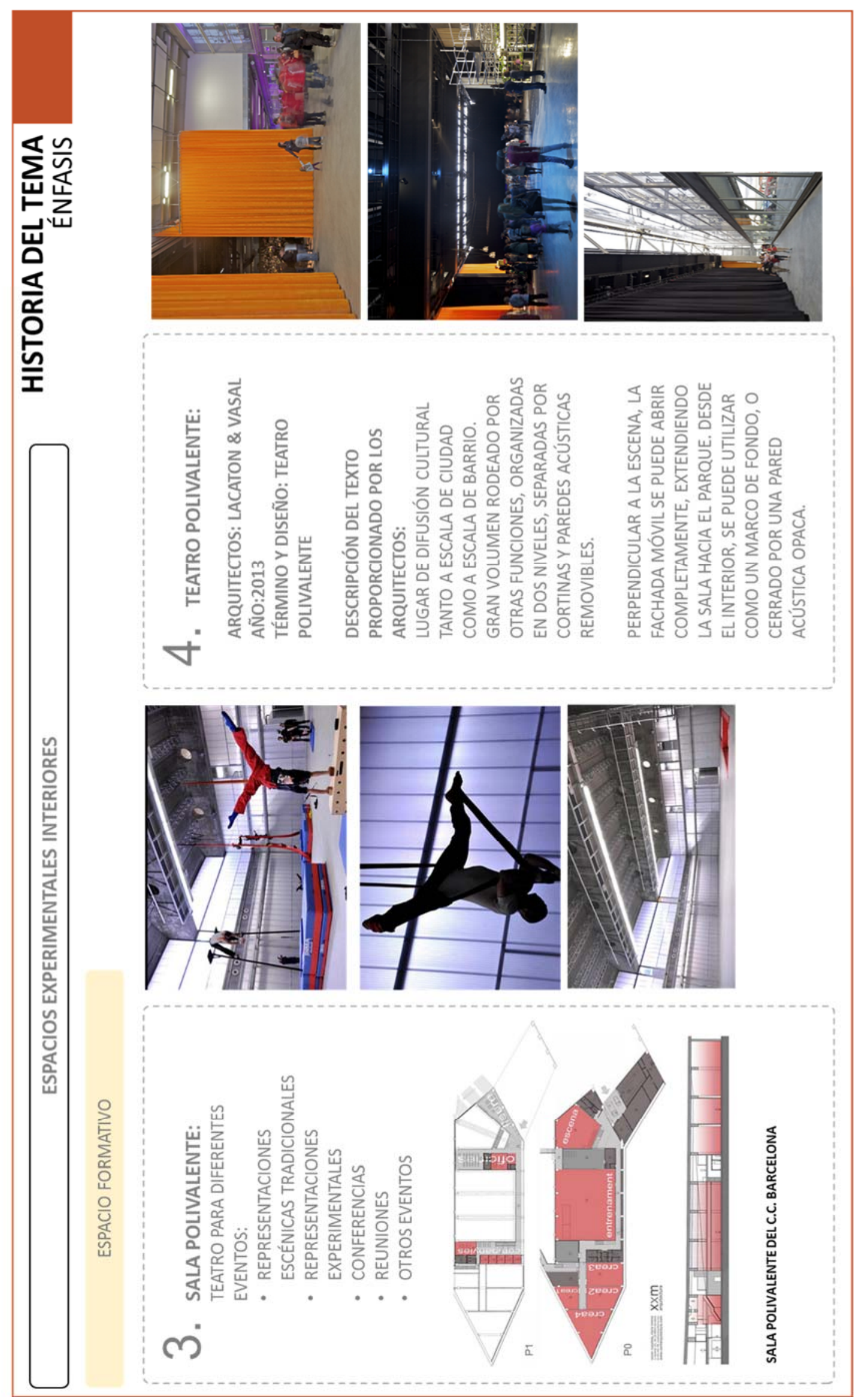

Figura 29. Espacios Experimentales Interiores. Elaboración Propia. 


\section{CAPITULO V: PROGRAMA ARQUITECTÓNICO}

\subsection{Determinación de Usuarios}

\subsection{1. ¿Quiénes son?}

Proceso de determinación de Usuarios según:

\subsubsection{Según visita a ENSAD:}

Figura 30. Esquema de Organización de Usuarios de ENSAD 2014

Fuente: Elaboración propia en base a visita realizada a la Escuela Nacional Superior de Arte Dramático ENSAD y entrevista realizada al director de la ENSAD Jorge Sarmiento, 2014.

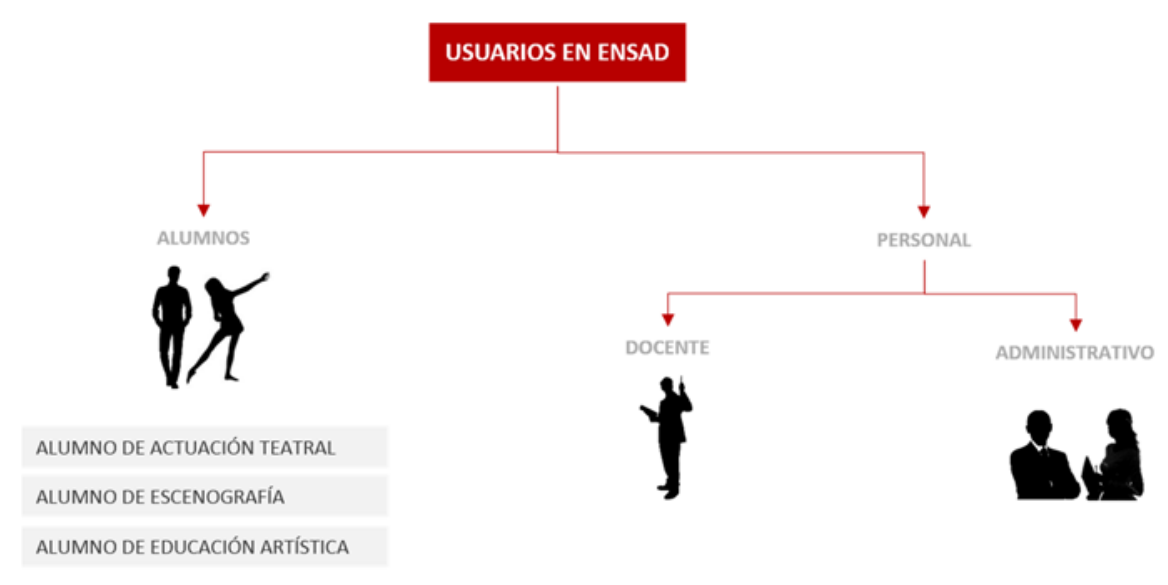

Los Usuarios en la Escuela Nacional Superior de Arte Dramático son los alumnos de las 3 carreras que ofrecen en la Escuela, el Personal docente temporal y a tiempo completo y el grupo de Directivos y Administradores de la Escuela, detallados específicamente en la Figura 21. Como parte de los Usuarios de la Escuela no se incluye a los visitantes, ya que el área de informes se atiende hacia el exterior de la escuela y no se permiten visitas sin programación, ni el ingreso de Usuarios externos a los 3 usuarios mencionados en la Figura 20. 


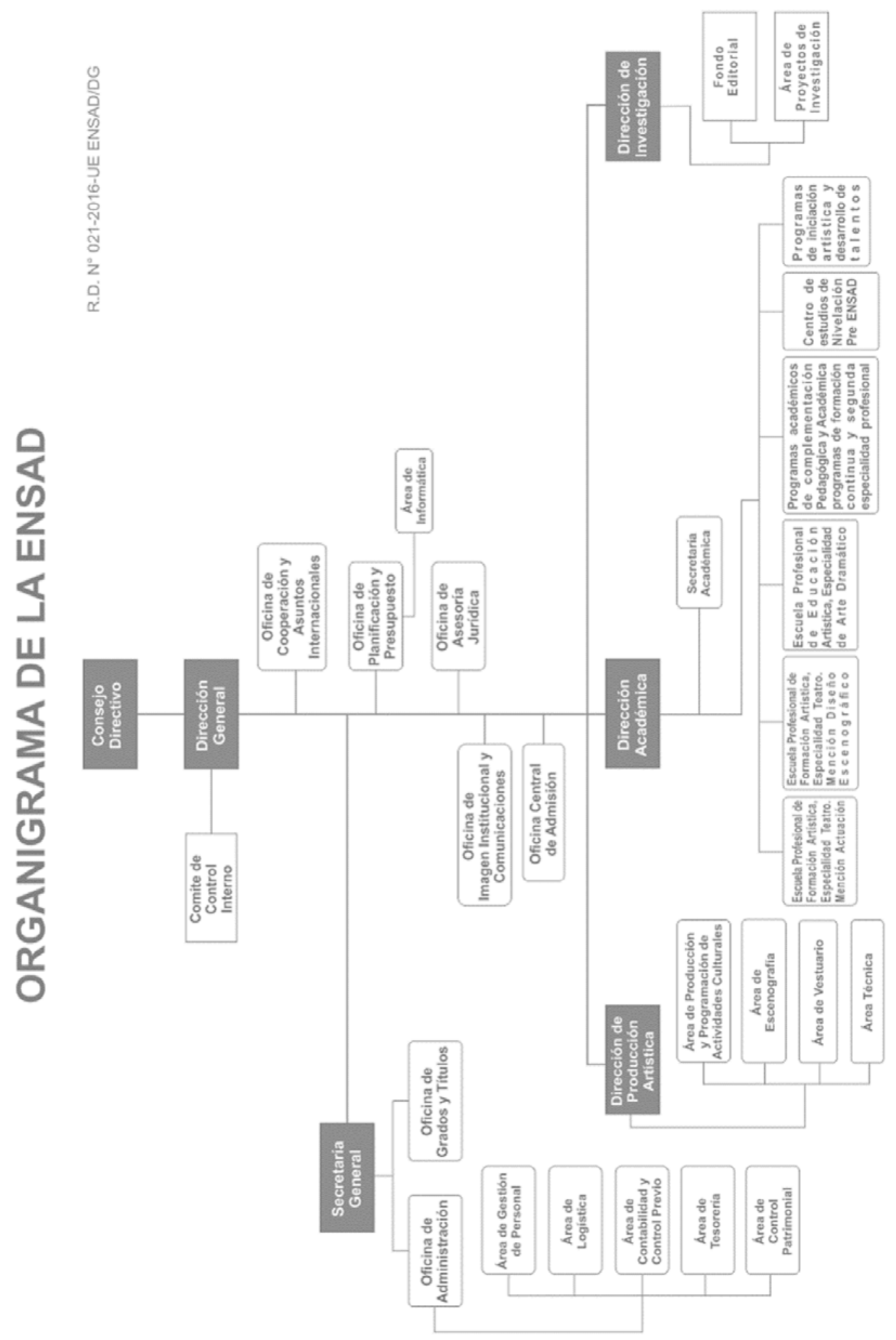

Figura 31. Esquema Conceptual de Organización Administrativa de ENSAD

Fuente: Página web de ENSAD. https://www.ensad.edu.pe/transparencia/organigrama/ 


\subsubsection{Según Texto:}

Según la Ley de Institutos y Escuelas de educación Superior y la Carrera Pública de sus docentes el Organigrama de Usuarios es el siguiente:

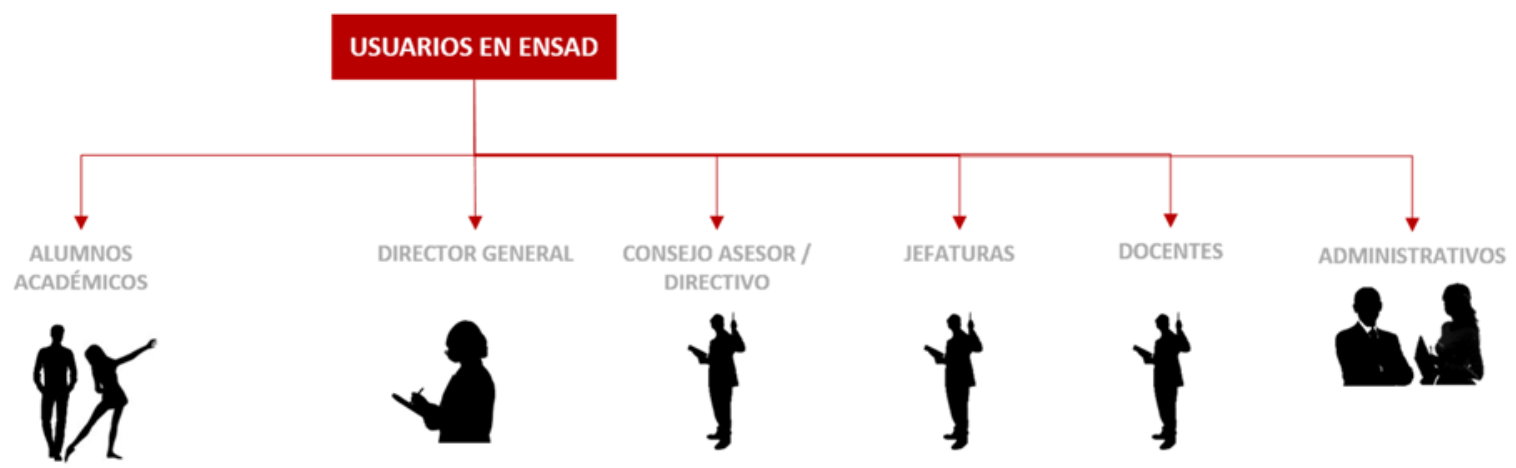

Figura 32. Esquema Conceptual de Organización de Usuarios en una Escuela Superior Fuente: Elaboración propia en base a el Proyecto de Ley, MINEDU, Ley de Institutos y Escuelas de educación Superior y la Carrera Pública.

http://www.minedu.gob.pe/minedu/archivos/proyecto_de_ley_institutos_escuelas.pdf

\subsubsection{Según el Lugar:}

Se incluirá a la comunidad de Comas dentro de los Usuarios de la escuela, ya que se incluirá en el programa un teatro Black Box el cual servirá también para la comunidad de grupos y asociaciones culturales de Comas, según la Investigación del Tema realizada en el capítulo 1.

\subsubsection{Conclusión de Organigrama Tipo de Usuarios:}

Los usuarios se pueden resumir en dos grupos:

- Usuarios Internos: corresponde a Alumnos, Profesores, Personal de servicio, Dirección y Administración de la Escuela

- Usuarios Externos: corresponde a los visitantes y parte de la comunidad de Comas que ocupe el Black Box con sus presentaciones. 


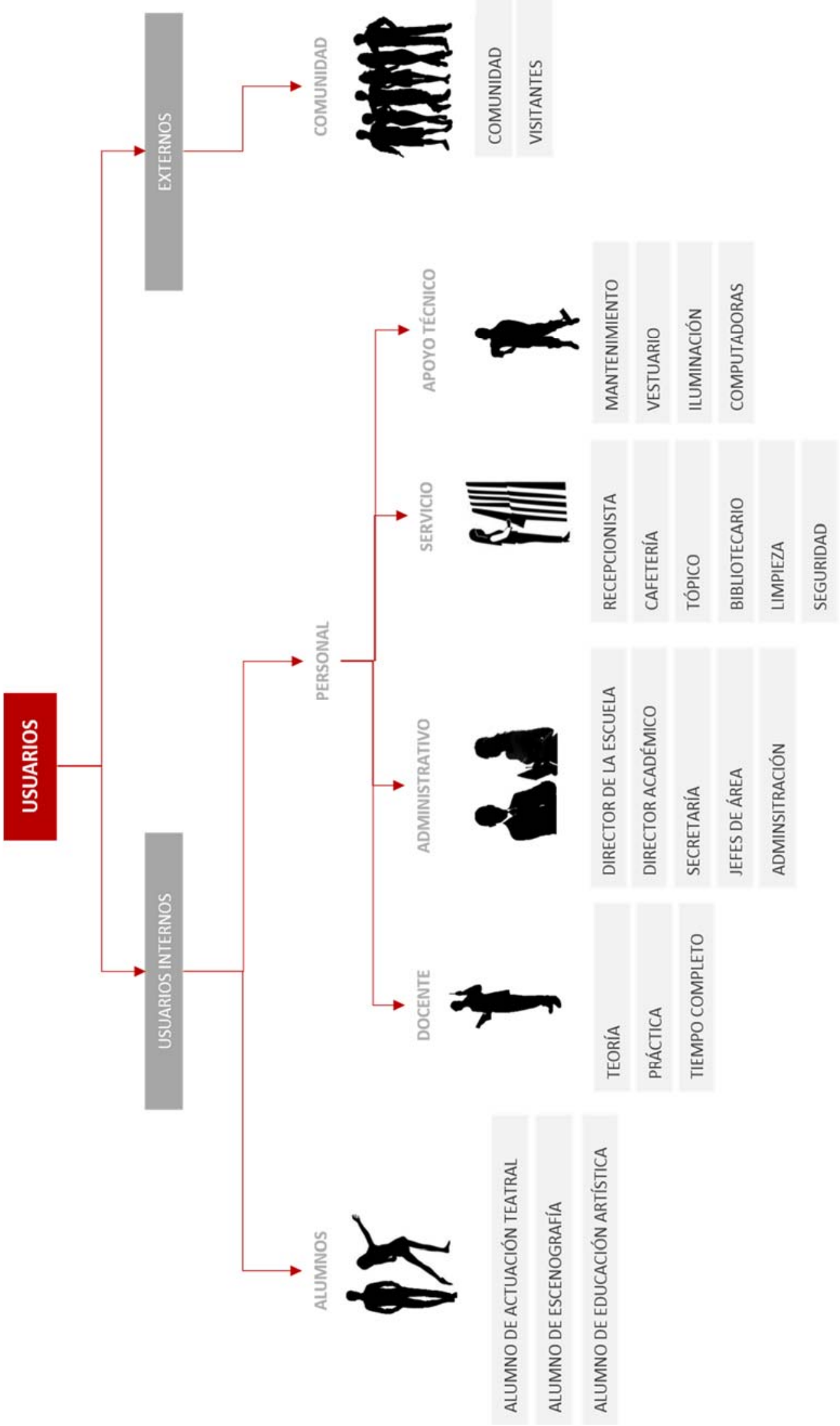

Figura 33. Esquema Final de Organización de Usuarios

Fuente: Elaboración propia en base las tres fuentes de los puntos 6.1.1.1, 6.1.1.2 y 6.1.1.3. 


\subsection{2. ¿Cómo son?}

\subsubsection{Usuarios Internos}

\begin{tabular}{|c|c|c|}
\hline \multicolumn{3}{|c|}{ USUARIOS } \\
\hline \multicolumn{3}{|c|}{ USUARIOS INTERNOS } \\
\hline \multirow[t]{3}{*}{ ALUMNOS } & ALUMNO DE ACTUACIÓN & \multirow{3}{*}{$\begin{array}{l}\text { DESCRIPCIÓN: EL ESTUDIANTE DE TEATRO LLEGA A LA } \\
\text { ESCUELA SIENDO INTUITIVO, CREATIVO E INNOVADOR CON } \\
\text { GRAN INTERÉS EN DESARROLLAR SUS ACTITUDES ESCÉNICAS. } \\
\text { NSE: A - D } \\
\text { LUGAR DE RESIDENCIA: LIMA NORTE } \\
\text { EDAD: } 18 \text { A } 35 \text { AÑOS }\end{array}$} \\
\hline & ALUMNO DE ESCENOGRAFÍA & \\
\hline & ALUMNO DE EDUCACIÓN ARTÍSTICA & \\
\hline \multirow{4}{*}{$\begin{array}{l}\text { PERSONAL } \\
\text { DOCENTE }\end{array}$} & PROFESOR DE TEORÍA & \multirow{4}{*}{$\begin{array}{l}\text { DESCRIPCIÓN: PROFESIONALES EN EL ÁREA, CONOCEDORES } \\
\text { DEL CONJUNTO DE PRINCIPIOS, NORMAS, PROCESOS Y } \\
\text { CONDICIONES TÉCNICAS NECESARIAS PARA IMPARTIR LAS } \\
\text { CLASES. ES IDÓNEO, MULTIDICIPLINARIO,COMPETENTE EN } \\
\text { DOCENCIA Y GESTIÓN ACADÉMICA. } \\
\text { LUGAR DE RESIDENCIA: LIMA METROPOLITANA } \\
\text { EDAD: } 28 \text { A } 60 \text { AÑOS }\end{array}$} \\
\hline & PROFESOR DE PRÁCTICA CORPORAL & \\
\hline & $\begin{array}{l}\text { PROFESOR DE PRÁCTICA VOCAL Y } \\
\text { MUSICAL }\end{array}$ & \\
\hline & PROFESOR DE ESCENOGRAFÍA & \\
\hline \multirow{5}{*}{$\begin{array}{l}\text { PERSONAL } \\
\text { ADMINIS } \\
\text { TRATIVO }\end{array}$} & DIRECTOR DE LA ESCUELA & \multirow{3}{*}{$\begin{array}{l}\text { DESCRIPCIÓN: CONDUCIR, PLANIFICAR, GESTIONAR Y } \\
\text { MONITOREAR LA MARCHA INSTITUCIONAL. PROPONER LOS } \\
\text { PROGRAMAS DE ESTUDIO A OFRECER CONSIDERANDO LOS } \\
\text { REQUERIMIENTOS DEL MERCADO LABORAL ACTUAL. } \\
\text { LUGAR DE RESIDENCIA: LIMA METROPOLITANA } \\
\text { EDAD: } 28 \text { A } 65 \text { AÑOS }\end{array}$} \\
\hline & DIRECTOR ACADÉMICO & \\
\hline & JEFE DE ÁREA & \\
\hline & SECRETARÍA & \multirow{2}{*}{$\begin{array}{l}\text { DESCRIPCIÓN: ENCARGADOS DE LA ADMINISTRACIÓN Y } \\
\text { LOGÍSTICA DE LA ESCUELA PARA QUE FUNCIONE } \\
\text { CORRECTAMENTE. } \\
\text { LUGAR DE RESIDENCIA: LIMA METROPOLITANA } \\
\text { EDAD: } 28 \text { A } 65 \text { AÑOS }\end{array}$} \\
\hline & ADMINISTRACIÓN & \\
\hline \multirow[t]{5}{*}{$\begin{array}{l}\text { PERSONAL } \\
\text { DE SERVICIO }\end{array}$} & RECEPCIONISTA & $\begin{array}{l}\text { DESCRIPCIÓN: TRABAJA EN LA RECEPCIÓN E INFORMES, } \\
\text { RESUELVE Y ATIENDE A VISITANTES. }\end{array}$ \\
\hline & CAFETERÍA Y COCINA & $\begin{array}{l}\text { DESCRIPCIÓN: CHEFS, COCINEROS Y MESEROS ENCARGADOS } \\
\text { DE PREPARAR, SERVIR Y ATENDER EN LA COCINA Y COMEDOR. }\end{array}$ \\
\hline & TÓPICO & $\begin{array}{l}\text { DESCRIPCIÓN: ENFERMEROS ENCARGADOS DE LA ATENCIÓN } \\
\text { MÉDICA PRIMARIA EN LA ESCUELA. }\end{array}$ \\
\hline & BIBLIOTECARIO & $\begin{array}{l}\text { DESCRIPCIÓN: EN LA BIBLIOTECA RESUELVE CONSULTAS Y } \\
\text { PROPORCIONA LOS LIBROS. }\end{array}$ \\
\hline & LIMPIEZA Y SEGURIDAD & $\begin{array}{l}\text { DESCRIPCIÓN: CONTRSTISTA CON PERSONAL. ESPECIALMENTE } \\
\text { CALIFICADO PARA DESARROLLAR SUS LABORES. }\end{array}$ \\
\hline \multirow[t]{4}{*}{$\begin{array}{l}\text { APOYO } \\
\text { TÉCNICO }\end{array}$} & MANTENIMIENTO & $\begin{array}{l}\text { DESCRIPCIÓN: PERSONAL CUYAS ACTIVIDADES A REALIZAR } \\
\text { DEPENDERÁN DE UN HORARIO DISTINTO AL DE CLASES. }\end{array}$ \\
\hline & VESTUARIO & $\begin{array}{l}\text { DESCRIPCIÓN: PERSONAL ENCARGADO DEL MANTENIMIENTO, } \\
\text { CONFECCIÓN Y DISPONIBILIDAD DEL VESTUARIO. }\end{array}$ \\
\hline & TÉCNICO ILUMINACIÓN Y SONIDO & $\begin{array}{l}\text { DESCRIPCIÓN: PERSONAL CUYAS ACTIVIDADES A REALIZAR } \\
\text { DEPENDERÁN DE UN HORARIO DISTINTO AL DE CLASES. }\end{array}$ \\
\hline & TÉCNICO EN COMPUTADORAS & $\begin{array}{l}\text { DESCRIPCIÓN: PERSONAL CUYAS ACTIVIDADES A REALIZAR } \\
\text { DEPENDERÁN DE UN HORARIO DISTINTO AL DE CLASES. }\end{array}$ \\
\hline
\end{tabular}

Figura 34. Cuadro de Usuarios Internos y descripción

Fuente: Elaboración propia en base a ENSAD, 2014. 


\section{Descripción del Usuario Principal}

Según la propuesta pedagógica del Teatro de la Escuela de Arte Dramático del Perú, el alumno de actuación deberá pasar un proceso de admisión cuyos criterios son: Improvisación, Representación, Voz y Movimiento. La edad mínima para iniciar la carrera será edad adulta en el Perú es decir desde los 18 años en adelante.

\section{- Alumno de Actuación}

Alumno que opta por la carrera de formación artística con especialidad en teatro - mención actuación. En este rubro la escuela formará profesionales idóneos altamente competentes en el arte dramático, capaces de responder ética y creativamente a los desafíos de la cultura inmaterial y a las exigencias de la producción artística del ámbito teatral.

\section{- Alumno de escenografía}

Alumno que opta por la carrera de formación artística con especialidad en teatro - mención diseño escenográfico. En este rubro los alumnos realizarán bocetos escenográficos a partir de un texto, compondrán espacialmente y afinarán la calidad de representación, imaginación y precisión de escenografías.

\section{- Alumno de Educación Artística}

Alumno que opta por la carrera de educación artística - especialidad arte dramático. La realización de proyectos de investigación en arte educación, interpretación de textos, aptitud artística, voz y movimiento se desarrollarán en el alumno en este rubro. 


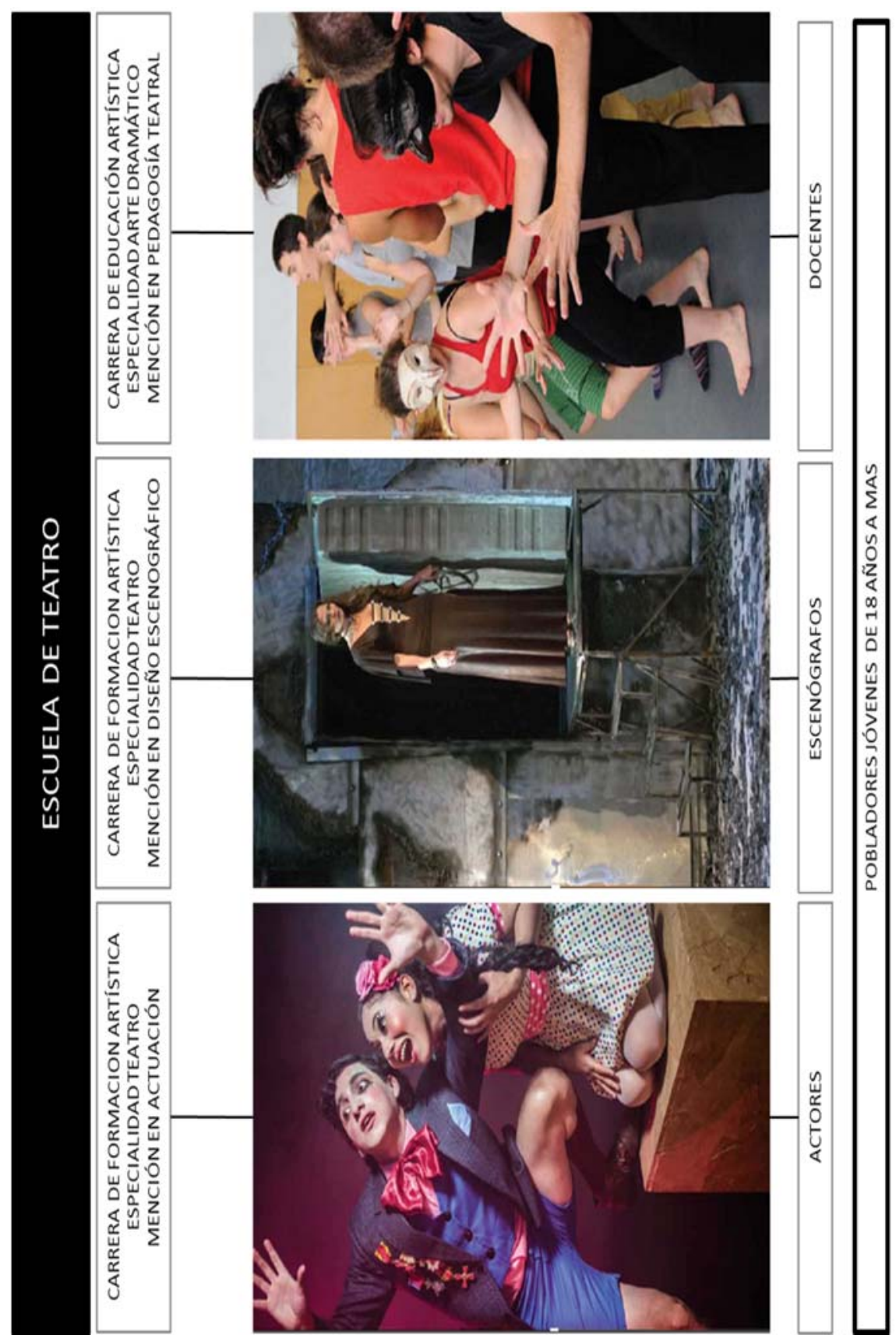

Figura 35. Cuadro Resumen del alumno estudiante de teatro Fuente: ENSAD 


\subsubsection{Usuario Externo}

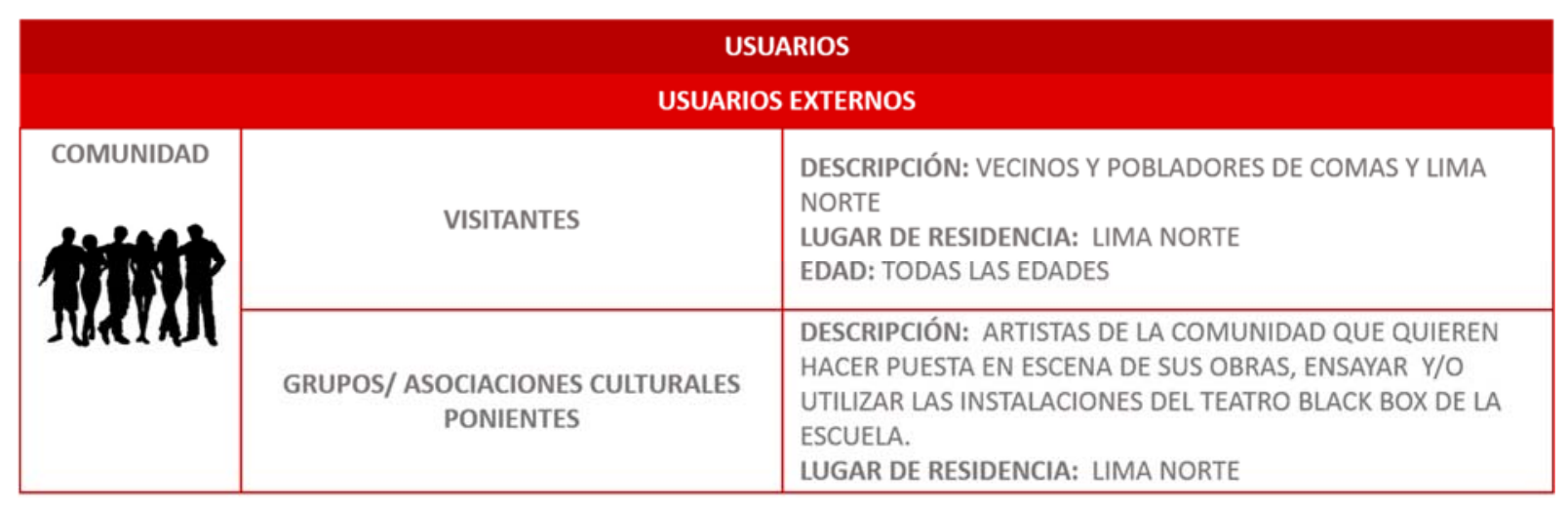

Figura 36. Cuadro de Usuario Externo

Fuente: elaboración propia

- La Comunidad

Actualmente Comas es una población joven, interesada por las artes: el teatro y la danza. Se caracteriza por realizar diversas actividades artísticas y culturales urbanas. En la escuela la comunidad participará de dos maneras externamente:

- Como Artista, grupo cultural y/o asociación que ensaya y propone un acto escénico cultural en el Teatro Black Box de la Escuela.

- Como Público que visita el Teatro Black Box para su entretenimiento y educación cultural. 


\subsection{3. ¿Cuántos son?}

El análisis del número de usuarios se dio en base al siguiente cálculo:

\subsubsection{Cálculo de Alumnos en la escuela}

La escuela al estar ubicada en Comas tendrá entonces los siguientes tipos de usuario:

a) Estudiantes de Lima metropolitana:

- Estudiantes Universitarios: que pueden corresponder tanto a alumnos de La PUCP como de ENSAD que vivan en Lima Norte.

- Estudiantes de nivel técnico: se refiere a los alumnos de institutos y centros de formación técnica no Superior que vivan en Lima Norte.

b) Estudiantes de Teatro en Comas

- Estudiantes de escuelas independientes, vernaculares y tradicionales creadas por el impulso de la cultura en Comas, que quieran estudiar profesionalmente.

Por ello, para el cálculo de Vacantes y estudiantes en la escuela de Teatro de Comas se investigó las cifras de alumnado de escuelas de Artes dramáticas en Lima Metropolitana al año.

Cuadro 3. Escuela de Artes Dramáticas en Lima Metropolitana

Fuente: Elaboración propia

\begin{tabular}{|c|c|c|c|c|}
\hline \multicolumn{2}{|c|}{ Nombre } & Ubicación & Lugar & \#alumnos \\
\hline $\begin{array}{c}\text { Escuela Nacional Superior de Arte } \\
\text { Dramático }\end{array}$ & ENSAD & Centro de Lima & $\begin{array}{c}\text { Parque de la } \\
\text { exposición }\end{array}$ & 350 \\
\hline $\begin{array}{c}\text { Escuela de Artes escénicas } \\
\text { Teatro/ PUCP }\end{array}$ & TUC & San Miguel & Sede de la PUCP & 380 \\
\hline $\begin{array}{c}\text { Facultad de artes escénicas de } \\
\text { Científica del Sur }\end{array}$ & Teatro & Villa el Salvador & Villa el Salvador & 280 \\
\hline $\begin{array}{c}\text { Facultad de Artes Escénicas de la } \\
\text { UPC }\end{array}$ & Teatro & varios & Varias sedes & 220 \\
\hline \multicolumn{2}{|r|}{} & & Promedio & 327.50 \\
\hline
\end{tabular}


Con este dato obtenemos el siguiente número de estudiantes tomando en cuenta los 328 estudiantes promedio del cuadro anterior y la fórmula de Población a futuro con el método lineal aritmético:

\section{FÓRMULA DE POBLACIÓN A FUTURO ( 5 AÑOS )}

\begin{tabular}{|c|c|c|c|}
\hline \multicolumn{4}{|c|}{$P f=P i(1+r \cdot T)$} \\
\hline $\begin{array}{c}\text { R: } 4.9 \% \\
\text { TASA DE CRECIMIENTO }\end{array}$ & $\begin{array}{l}\text { T: } 5 \text { años } \\
\text { TIEMPO }\end{array}$ & $\begin{array}{l}\text { Pi: } 328 \text { estudiantes } \\
\text { POBLACIÓN INICIAL }\end{array}$ & $\begin{array}{c}\text { PF: } 5 \text { años } \\
\text { POBLACIÓN A FUTURO }\end{array}$ \\
\hline \multicolumn{4}{|c|}{408 ESTUDIANTES } \\
\hline
\end{tabular}

Figura 37. Cuadro de Uso de la Fórmula de Población a Futuro

Fuente: elaboración propia

Obteniendo así el número de estudiantes en la escuela: 408 estudiantes. 


\subsubsection{Cálculo de personal Administrativo en la escuela}

Se realizó un Organigrama del Personal administrativo Estimando una cifra de 22 personas en el área de Dirección y Administración.

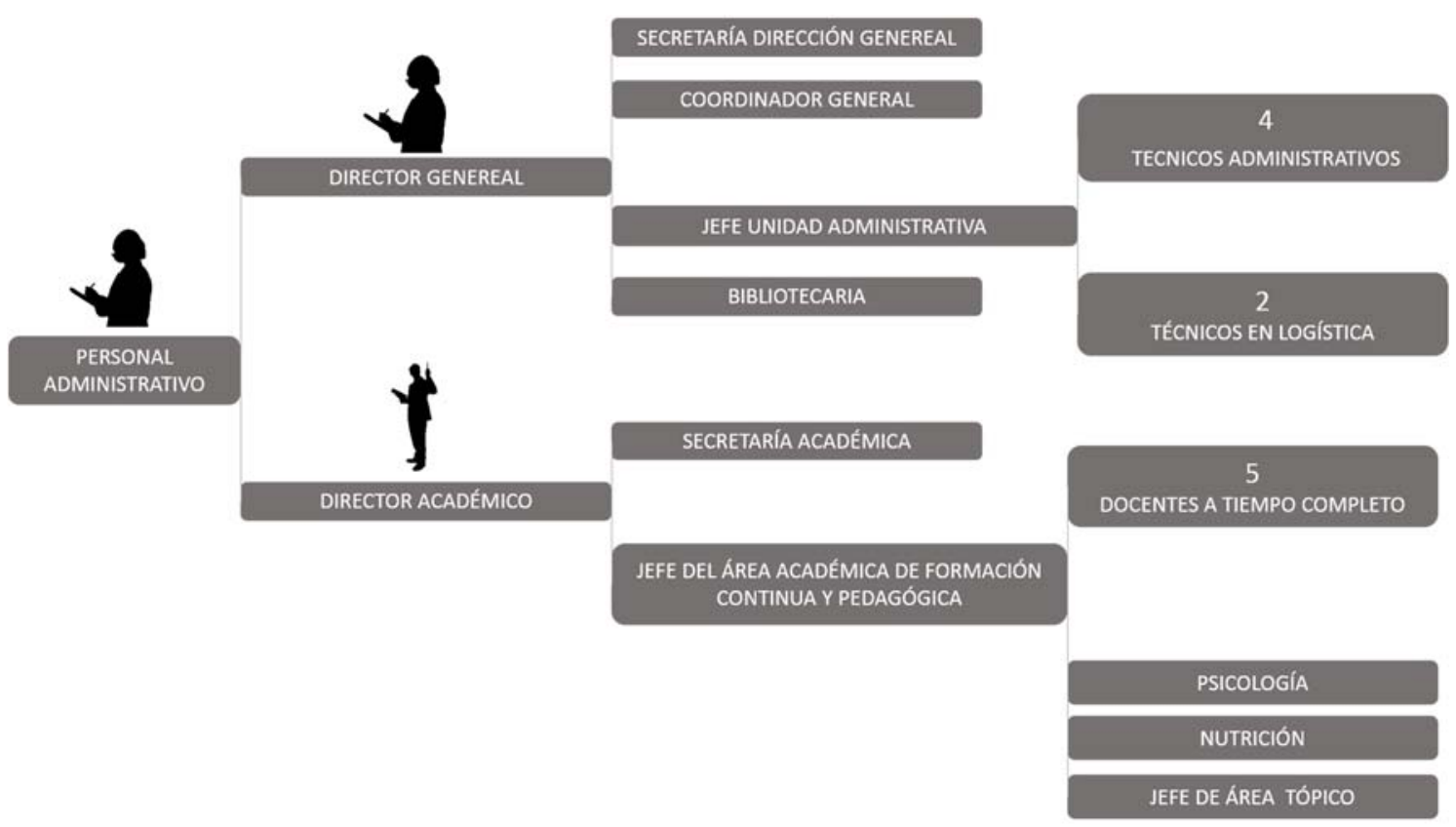

Figura 38. Personal Administrativo. Elaboración Propia

\subsubsection{Cálculo de la Plana Docente}

El Plan Docente: Los profesores se dividirán en tres ramas: Los teóricos, los prácticos y los permanentes que se quedarán en la Escuela para resolver y atender las dudas de los alumnos con respecto a los cursos.

El Cálculo de la cantidad de Docentes: Para el cálculo de la Cantidad de Docentes se consideró un supuesto horario basado en 3 turnos: Mañana (de 8 am a $12 \mathrm{~m}$ ), Tarde (de $12 \mathrm{~m}$ a $5 \mathrm{pm}$ ) y Noche (de $5 \mathrm{pm}$ a $9 \mathrm{pm}$ ). En total se necesitan 15 profesores por turno. Al haber 3 turnos se necesitarían en total 45 profesores.

Total de profesores 45 . 


\begin{tabular}{|c|c|c|c|c|c|c|}
\hline \multicolumn{7}{|c|}{ HORARIO PRIMER CICLO } \\
\hline & Lunes & Martes & Miércoles & Jueves & Viernes & Sabado \\
\hline $8: 00-9: 00$ & \multirow{2}{*}{$\begin{array}{c}\text { Preparación } \\
\text { Corporal }\end{array}$} & \multirow{2}{*}{$\begin{array}{l}\text { Ha bilida des } \\
\text { comunicativas }\end{array}$} & \multirow{2}{*}{$\begin{array}{c}\text { Preparación } \\
\text { Corporal }\end{array}$} & \multirow{2}{*}{$\begin{array}{l}\text { Habilida des } \\
\text { comunica tivas }\end{array}$} & \multirow{4}{*}{ Técnica Actoral } & \\
\hline $9: 00-10: 00$ & & & & & & \\
\hline $10: 00-11: 00$ & & Métodos & & Métodos & & \\
\hline $11: 00-12: 00$ & \multirow{2}{*}{ Técnica vocal } & $\begin{array}{c}\text { p/trabajo } \\
\text { intelectual }\end{array}$ & \multirow{2}{*}{ Técnica vocal } & $\begin{array}{c}\text { p/trabajo } \\
\text { intelectual }\end{array}$ & & \\
\hline $12: 00-1: 00$ & & & & & & \\
\hline $2: 00-3: 00$ & \multirow{3}{*}{ Técnica Actoral } & \multirow{2}{*}{$\begin{array}{c}\text { Historia cultura } \\
\text { Peruana }\end{array}$} & & \multirow{3}{*}{$\begin{array}{c}\text { Comunicación y } \\
\text { teatro }\end{array}$} & \multirow{2}{*}{$\begin{array}{l}\text { Sistema de } \\
\text { representación }\end{array}$} & \\
\hline $3: 00-4: 00$ & & & & & & \\
\hline $4: 00-5: 00$ & & \multirow{2}{*}{$\begin{array}{l}\text { Sistema de } \\
\text { representación }\end{array}$} & & & & \\
\hline $5: 00-6: 00$ & & & & & & \\
\hline $6: 00-7: 00$ & & & & & & \\
\hline 7:00 - 8:00 & & & & & & \\
\hline
\end{tabular}

Total de Cursos: 7 cursos

- Profesor vocal : 1

Profesor actoral :1

- Profesor de Preparación corporal:1

- Profesor de Técnica Actoral y Sist. De representación: 1

- Profesor de Habilidades, métodos y comunicación: 1

- Profesor Historia: 1

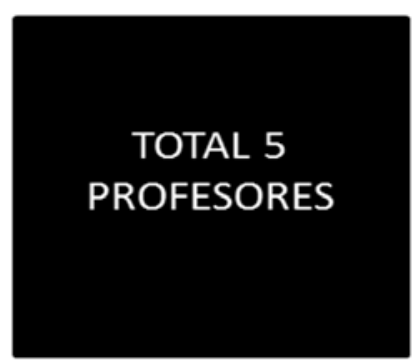

Figura 39. Horario Primer ciclo. Elaboración Propia

\begin{tabular}{|c|c|c|c|c|c|c|}
\hline \multicolumn{7}{|c|}{ HORARIO SEGUNDO CICLO } \\
\hline & Lunes & Martes & Miércoles & Jueves & Viernes & Sabado \\
\hline $8: 00-9: 00$ & & Preparación & Historia del & Preparación & Historia del & \multirow{5}{*}{ Técnica Actoral 2} \\
\hline $9: 00-10: 00$ & & Corporal 2 & tea tro 1 & Corporal 2 & teatro 1 & \\
\hline $10: 00-11: 00$ & & & \multirow{3}{*}{$\begin{array}{l}\text { Introd. a la } \\
\text { filosofía }\end{array}$} & & \multirow{3}{*}{$\begin{array}{c}\text { Comunicacióny } \\
\text { teatro } 2\end{array}$} & \\
\hline $11: 00-12: 00$ & & \multirow{2}{*}{ Técnica vocal 2} & & \multirow{2}{*}{ Técnica vocal 2} & & \\
\hline $12: 00-1: 00$ & & & & & & \\
\hline $2: 00-3: 00$ & & \multirow{6}{*}{ Técnica Actoral 2} & Siste ma de & & \multirow{6}{*}{$\begin{array}{l}\text { Sistema de } \\
\text { representación } 2\end{array}$} & \\
\hline $3: 00-4: 00$ & & & $\begin{array}{c}\text { representacion } \\
2 \\
\end{array}$ & & & \\
\hline $4: 00-5: 00$ & & & & & & \\
\hline $5: 00-6: 00$ & & & & & & \\
\hline $6: 00-7: 00$ & & & & & & \\
\hline 7:00 - 8:00 & & & & & & \\
\hline
\end{tabular}

Total de Cursos: 7cursos

Profesores prácticos: 4

Profesores teóricos 2

TOTAL 6 PROFESORES

Figura 40. Horario Segundo Ciclo. Elaboración Propia 


\section{CICLO 3}

Profesores prácticos: 3

Profesores teóricos 2

\section{TOTAL 5}

PROFESORES

\section{CICLO 4}

Profesores prácticos: 3

Profesores teóricos 2

\section{CICLO 5}

Profesores prácticos: 3

Profesores teóricos 2

\section{CICLO 6}

Profesores prácticos: 2

Profesores teóricos 2

\section{CICLO 7}

Profesores prácticos: 3

Profesores teóricos 2

\section{CICLO 8}

Profesores prácticos: 2

Profesores teóricos 2

\section{CICLO 9}

Profesores prácticos: 1

Profesores teóricos 2

\section{CICLO 10}

Profesores prácticos: 1

Profesores teóricos 2

\section{TOTAL 5}

PROFESORES

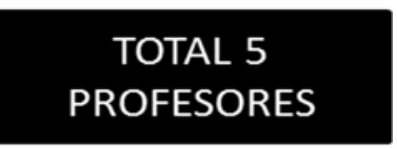

TOTAL 4

PROFESORES

TOTAL 5 PROFESORES

TOTAL 4 PROFESORES

\section{TOTAL 3} PROFESORES

\section{TOTAL 3} PROFESORES

Figura 41. Total de Docentes. Elaboración Propia 
5.1.6. Cálculo de Visitantes - Comunidad

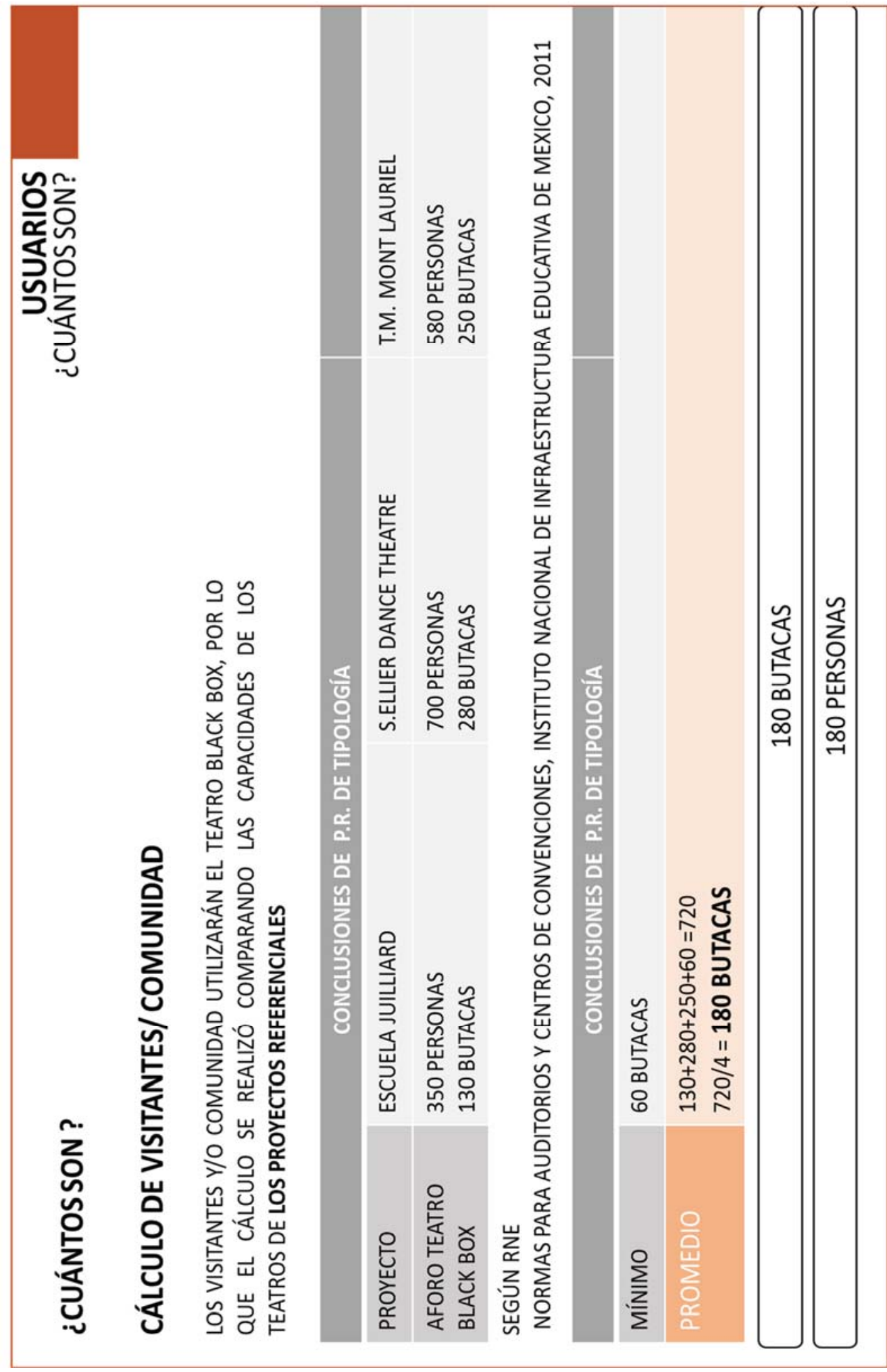

Figura 42. Cálculo Número de Usuarios. Elaboración Propia 
5.1.7. Conclusión número de Usuarios Total en la Escuela

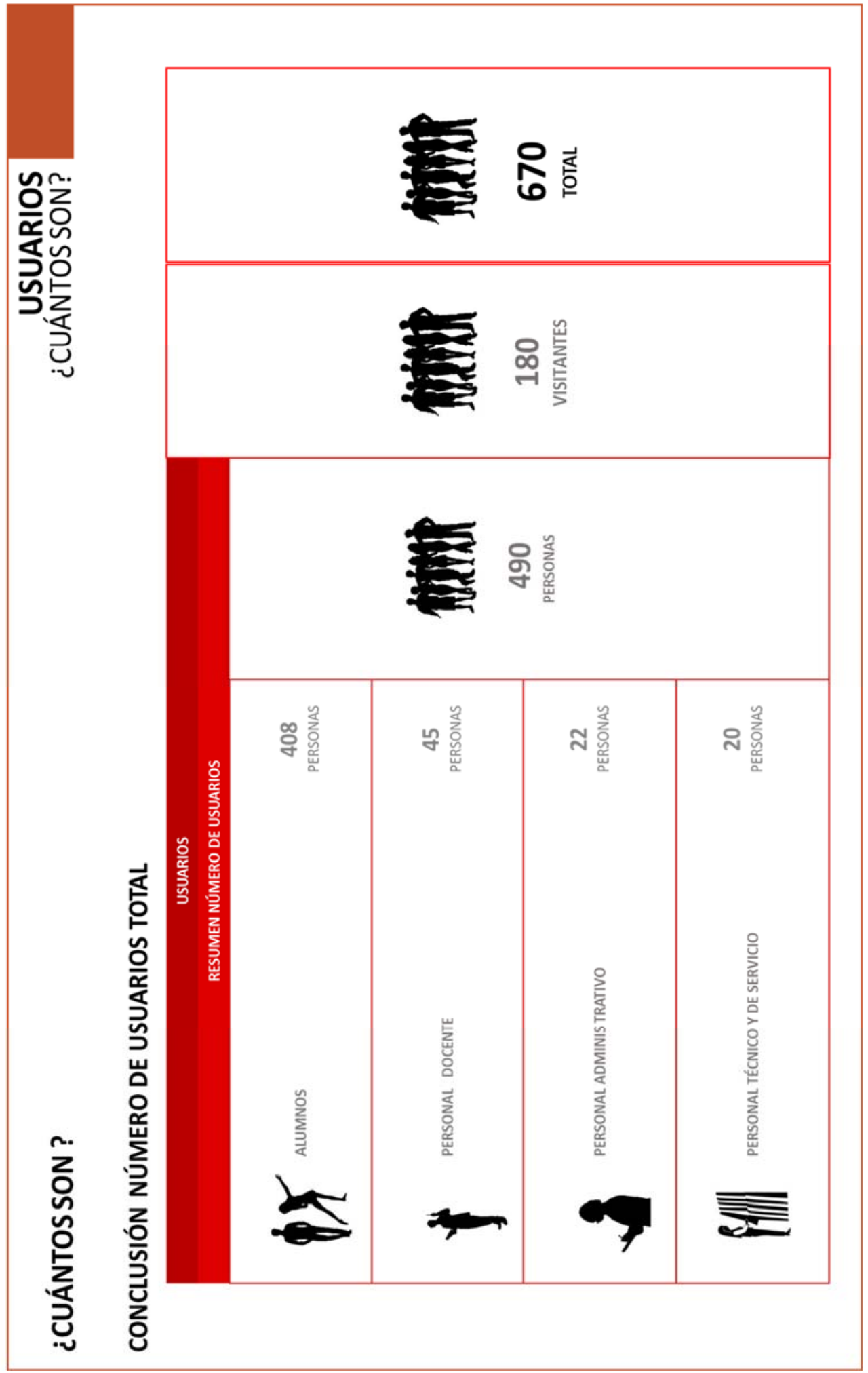

Figura 43. Total Número de Usuarios. Elaboración Propia 


\subsection{Determinación de Ambientes}

\subsubsection{Actividades y necesidades de los Usuarios}

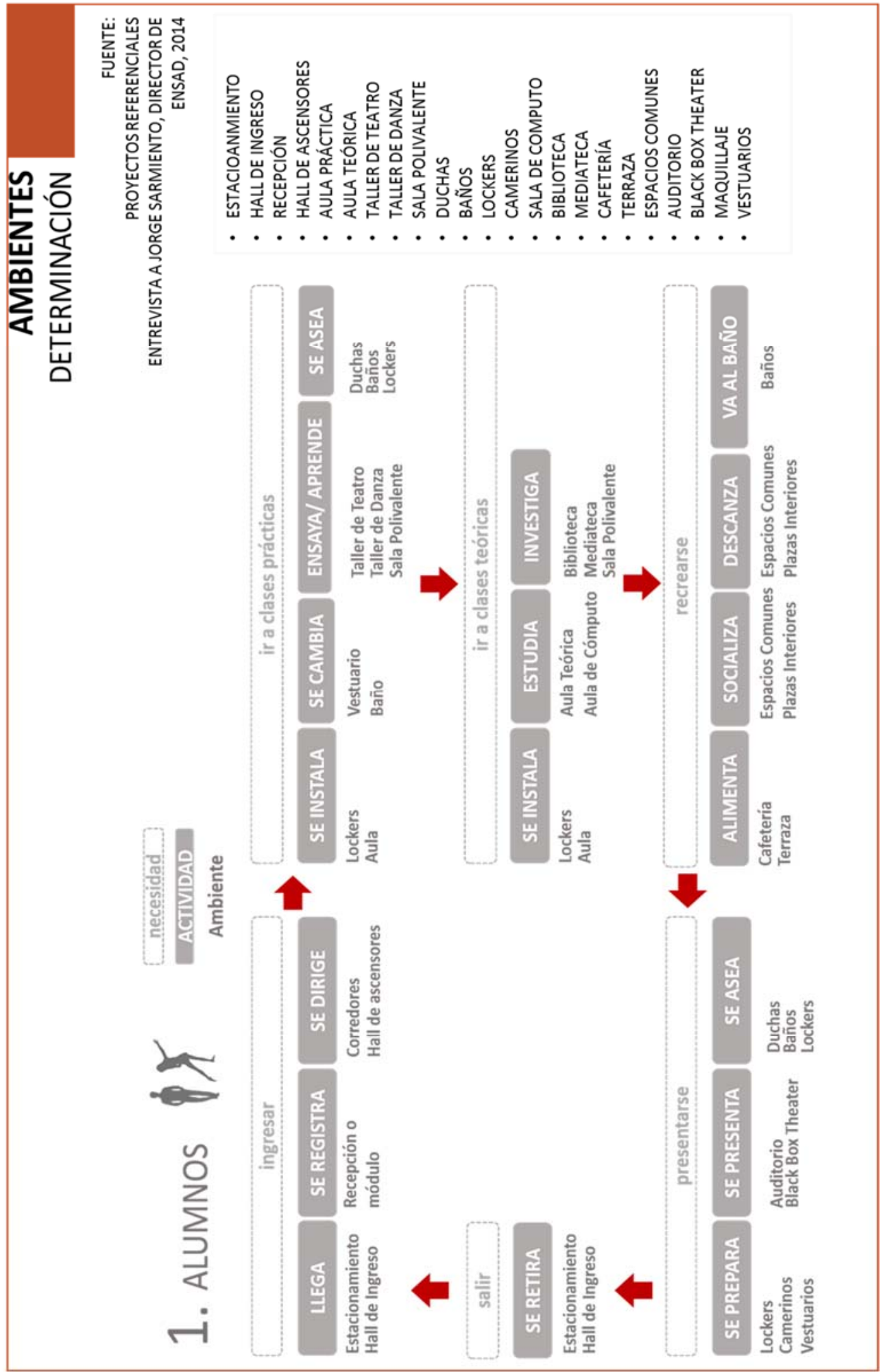

Figura 44. Actividades y Necesidades del Alumno

Fuente: Elaboración Propia 


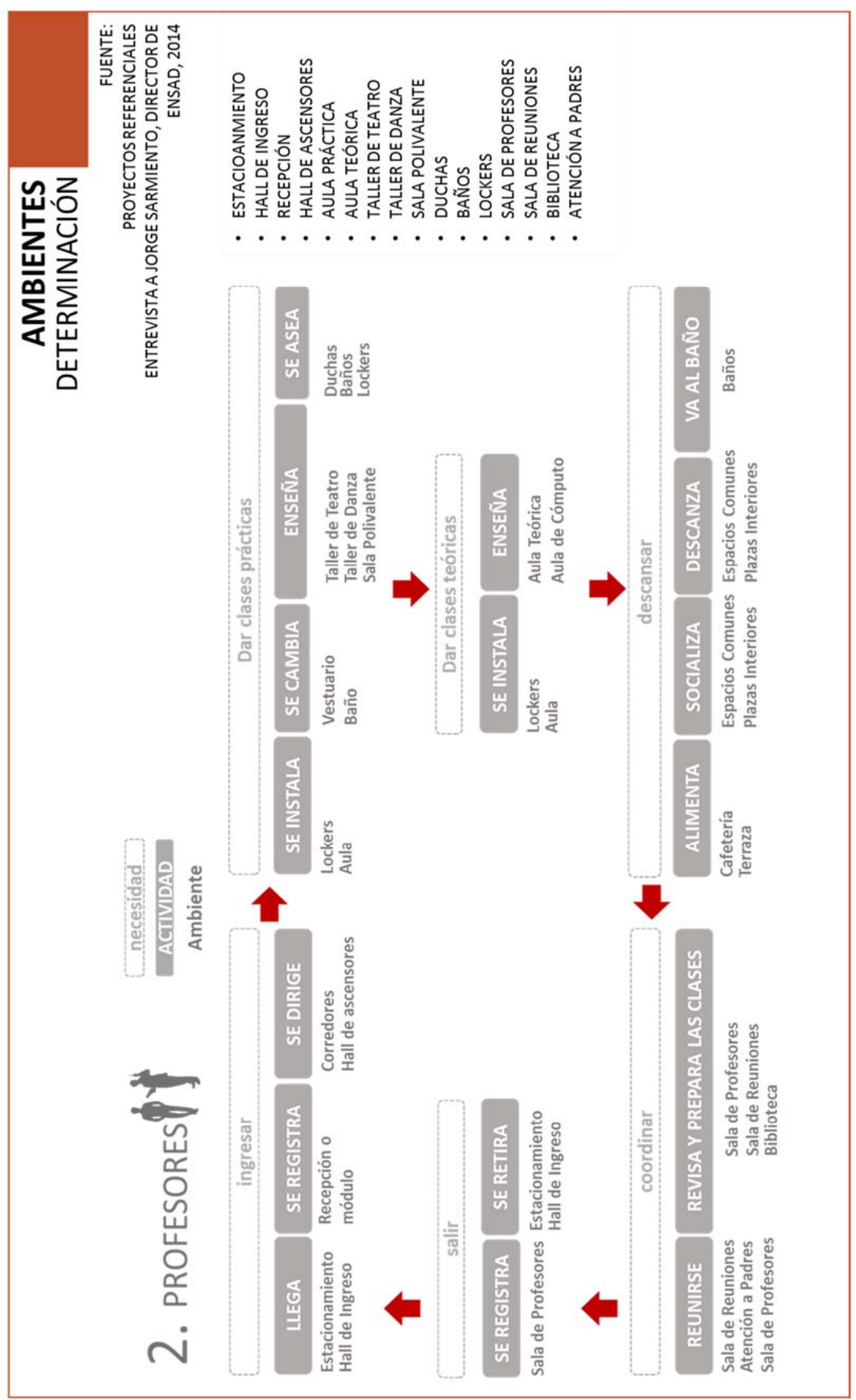

Figura 45. Actividades y Necesidades del Profesor

Fuente: Elaboración Propia 


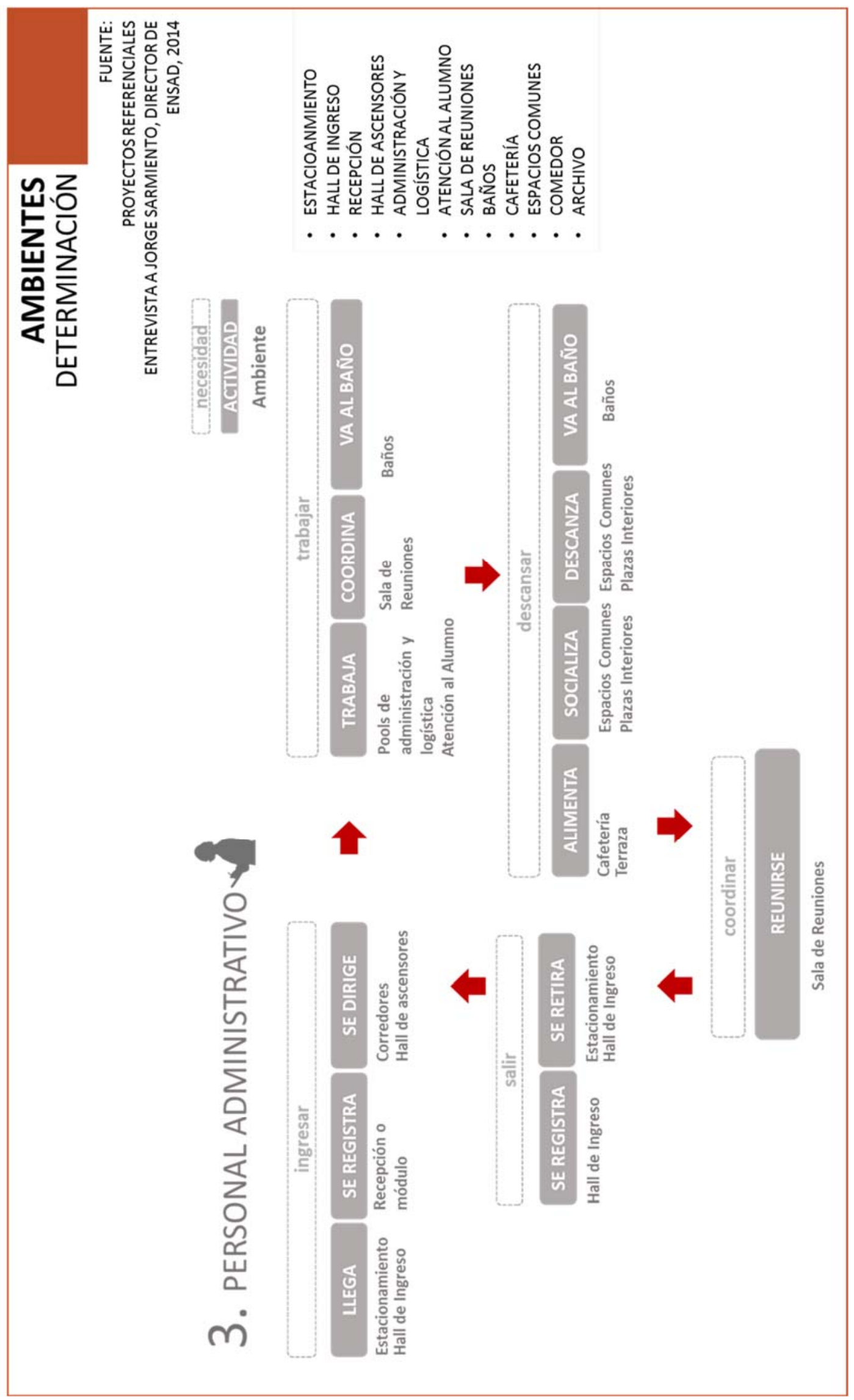

Figura 46. Actividades y Necesidades del Personal Admirativo Fuente: Elaboración Propia 


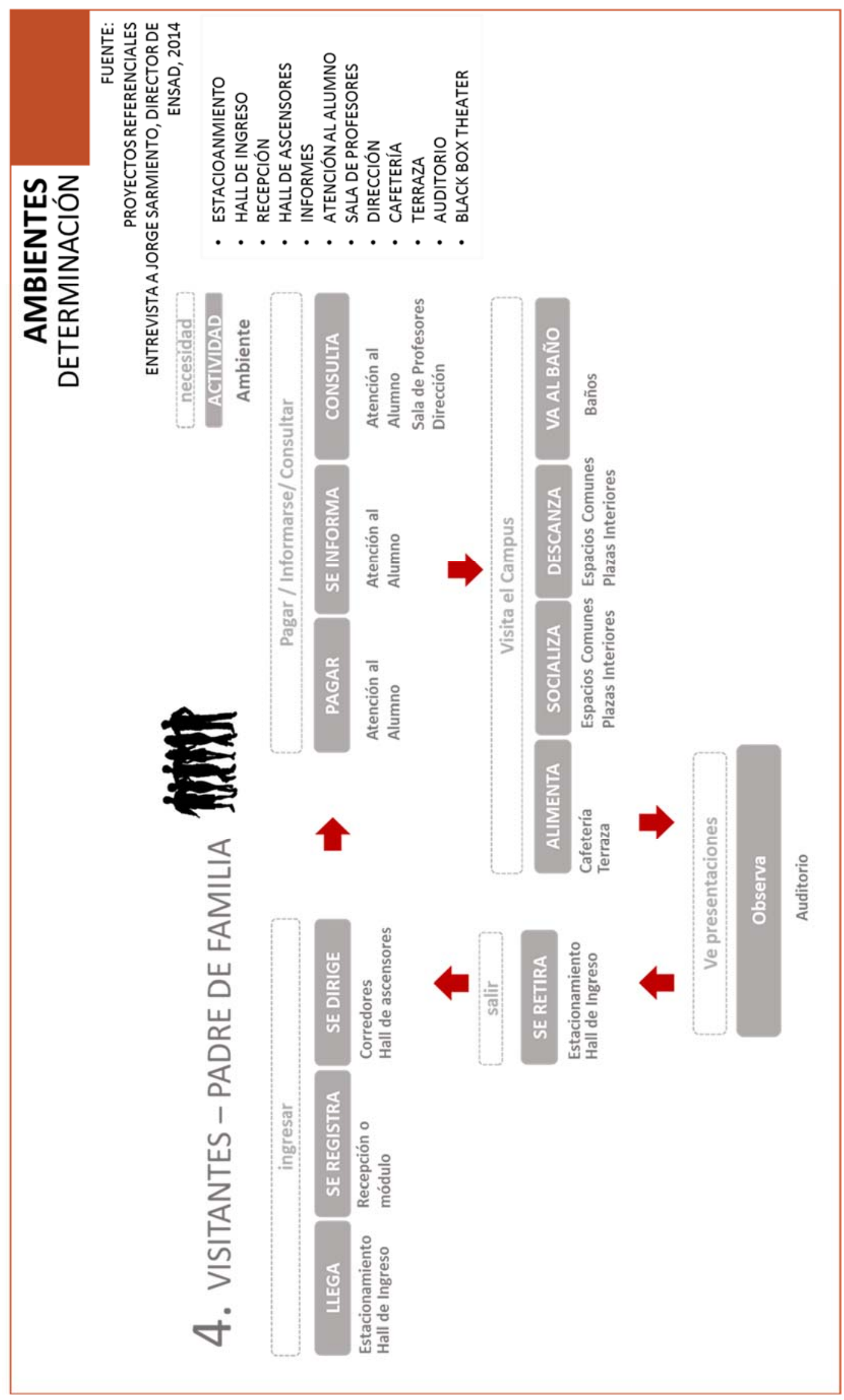

Figura 47. Actividades y Necesidades del Visitante -Padre de Familia Fuente: Elaboración Propia 


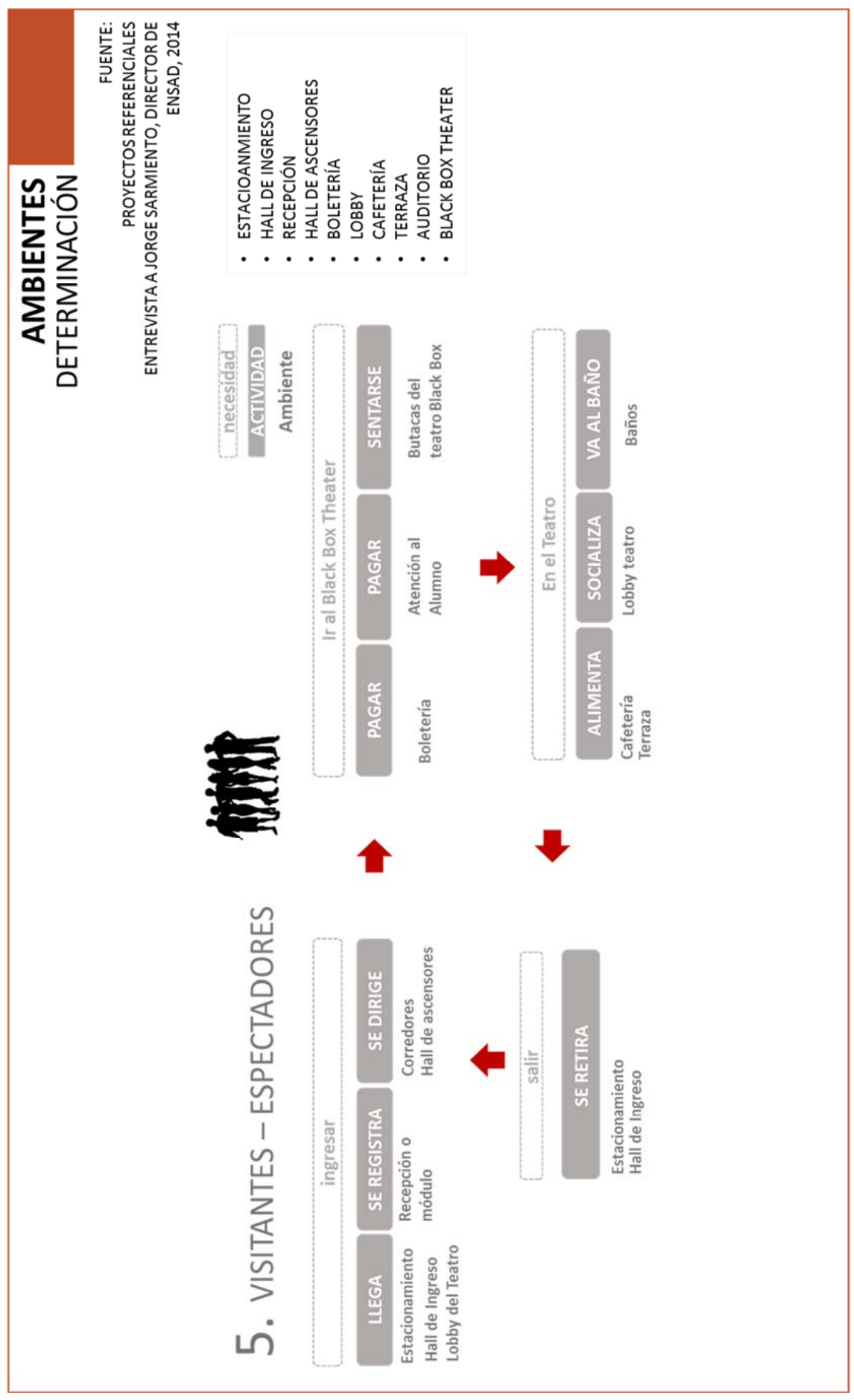

Figura 48. Actividades y Necesidades del Visitante - Espectador

Fuente: Elaboración Propia 


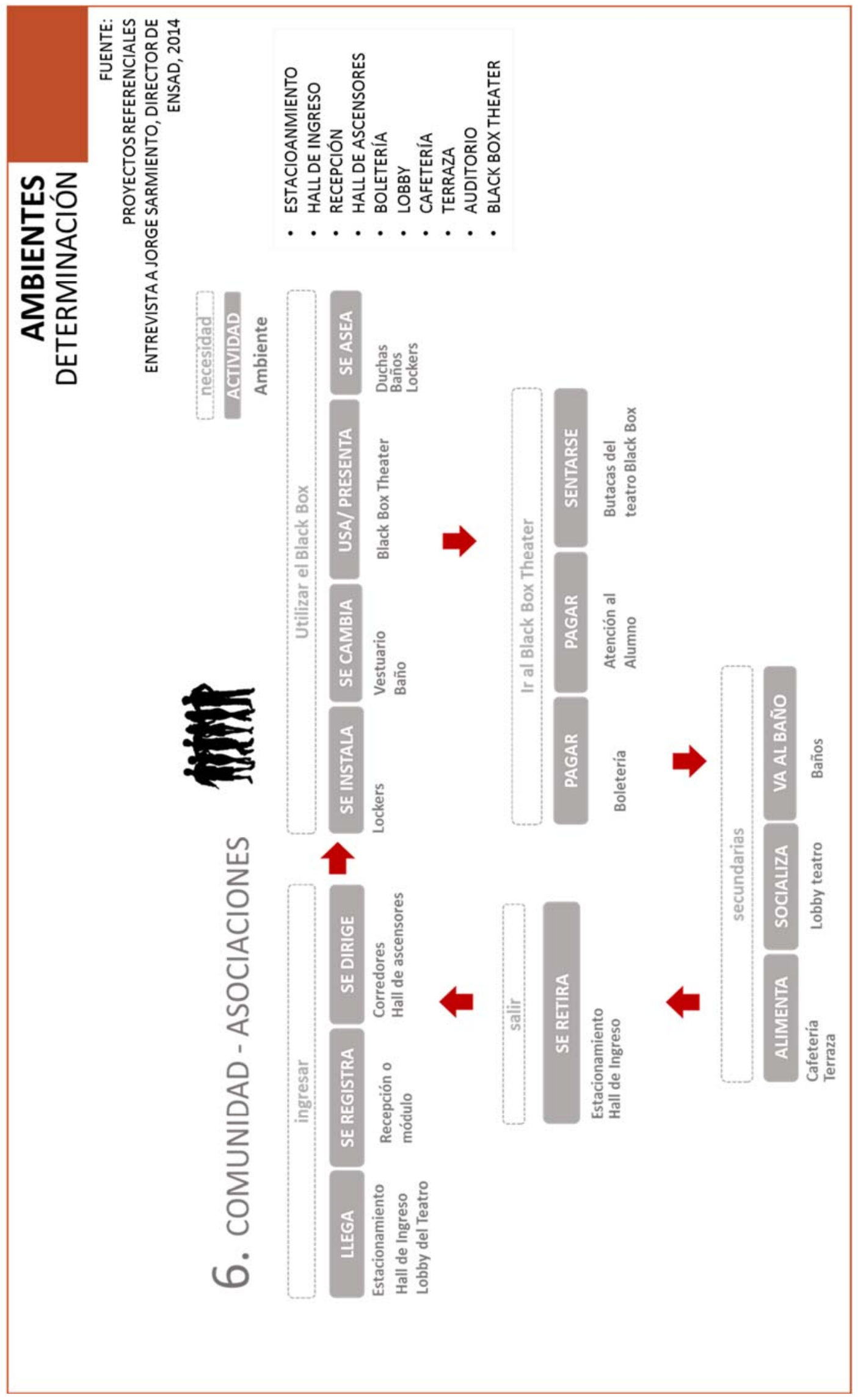

Figura 49. Actividades y Necesidades de Asociaciones de la Comunidad Fuente: Elaboración Propia 


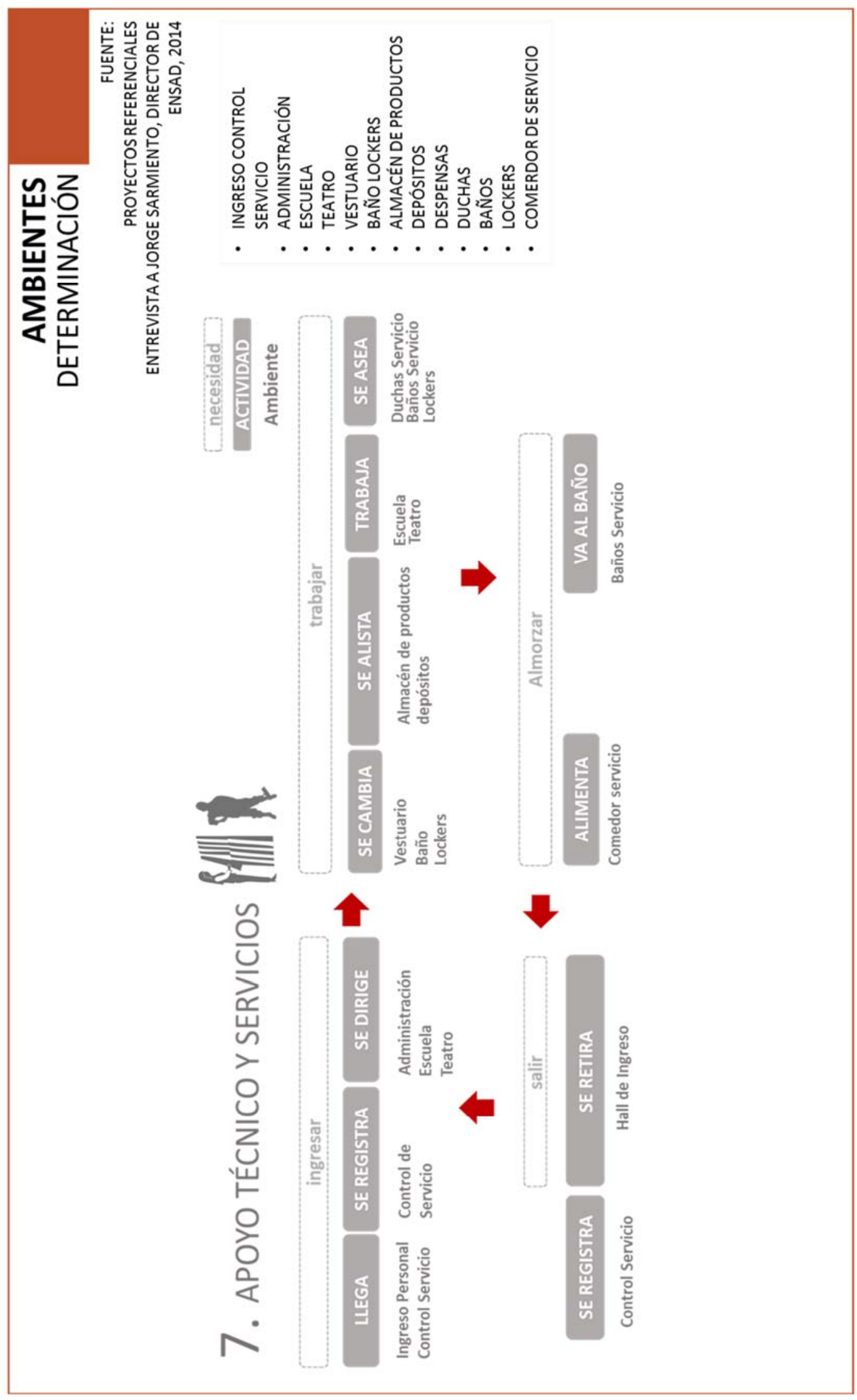

Figura 50. Actividades y Necesidades de Personal de Servicio y Apoyo Técnico Fuente: Elaboración Propia 


\subsection{Determinación de Aspectos Cualitativos y Cuantitativos}

\subsubsection{Determinación de ambientes y elección de 5 ambientes más importantes a desarrollar}

\begin{tabular}{|c|c|c|c|}
\hline UNIDAD & ESPACIO & SUB -ESPACIO & JUSTIFICACIÓN \\
\hline \multirow{11}{*}{ 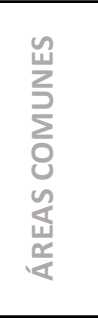 } & \multirow{5}{*}{ INGRESO } & HALL DE INGRESO & \\
\hline & & RECEPCIÓN / INFORMES & \multirow{10}{*}{$\begin{array}{l}\text { Primer Espacio que el usuario observa,y recorre al } \\
\text { ingresar a la Escuela. Su importancia radica en la } \\
\text { escala y la amplitud de este espacio, además es el } \\
\text { punto de partida para el recorrido interior de la } \\
\text { escuela y el encuentro social dentro de la misma. }\end{array}$} \\
\hline & & \begin{tabular}{|l} 
CONTROL Y VIGILANCIA \\
ESCAIERAPRINCIPAI
\end{tabular} & \\
\hline & & \begin{tabular}{|l} 
ESCALERA PRINCIPAL \\
HALL DE ASCENSORES
\end{tabular} & \\
\hline & & SS.HH. PÚBLICO & \\
\hline & \multirow{6}{*}{ CAFETERÍA } & COMEDOR & \\
\hline & & TERRAZA & \\
\hline & & COCINA & \\
\hline & & ALMACÉN & \\
\hline & & CÁMARA FRÍA & \\
\hline & & SS.HH. COMENSALES & \\
\hline \multirow{18}{*}{ 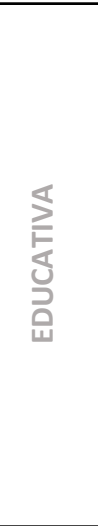 } & \multirow{5}{*}{ AUDITORIO ESCOLAR } & ESCENARIO & \\
\hline & & CABINA & \multirow{6}{*}{$\begin{array}{l}\text { Espacio de demostración de lo aprendido en cada } \\
\text { ciclo de Estudios, tiene varios puntos importantes } \\
\text { a estudiar como: escala, acústica, iluminación y } \\
\text { aforo. }\end{array}$} \\
\hline & & BUTACAS & \\
\hline & & BAÑO Y LOCKERS & \\
\hline & & \begin{tabular}{|l} 
CAMERINOS \\
UTILERÍ́A
\end{tabular} & \\
\hline & \multirow{13}{*}{ AULAS } & AULA TEÓRICA & \\
\hline & & AULA COMPUTO & \\
\hline & & TALLER DE TEATRO & \\
\hline & & TALLER DE ESCENOGRAFÍA & \multirow{13}{*}{$\begin{array}{l}\text { Espacio esencial en la escuela, aula de práctica con } \\
\text { requerimientos técnicos y tecnológicos } \\
\text { importantes de analizar. }\end{array}$} \\
\hline & & SALA POLIVALENTE & \\
\hline & & TALLER DE DIBUJO & \\
\hline & & SALA DE MÚSICA/ENSAYO & \\
\hline & & ALMACÉN & \\
\hline & & TALLER DE DANZA & \\
\hline & & BIBLIOTECA & \\
\hline & & TÓPICO & \\
\hline & & BAÑOS & \\
\hline & & $\begin{array}{l}\text { CAMERINOS } \\
\text { BAÑO DISCAPACITADOS }\end{array}$ & \\
\hline \multirow{13}{*}{$\begin{array}{l}2 \\
\frac{0}{5} \\
\frac{1}{2}\end{array}$} & \multirow{13}{*}{ TEATRO BLACK BOX } & \begin{tabular}{|l} 
BANO DISCAPACITADOS \\
FOYER
\end{tabular} & \\
\hline & & RECEPCIÓN / INFORMES & \\
\hline & & TICKETS & \\
\hline & & CAJA NEGRA & \\
\hline & & BACKSTAGE & \multirow{9}{*}{$\begin{array}{l}\text { Espacio Experimental por excelencia, su estudio } \\
\text { ayudará a dimensionarlo mejor, ver temas de } \\
\text { multifunción y adaptación a la realidad cultural de } \\
\text { Comas. }\end{array}$} \\
\hline & & CAMERINO & \\
\hline & & SS.HH. BACKSTAGE & \\
\hline & & \begin{tabular}{|l} 
UTILERÍA BACKSTAGE \\
\end{tabular} & \\
\hline & & CASILLEROS DAMAS & \\
\hline & & $\begin{array}{l}\text { CASILLEROS HOMBRES } \\
\text { SS.HH. ACTORES }\end{array}$ & \\
\hline & & 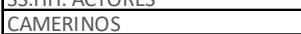 & \\
\hline & & SALA AUDIO E ILUM. & \\
\hline & & DEPÓSITO UTILERÍA & \\
\hline \multirow{15}{*}{ 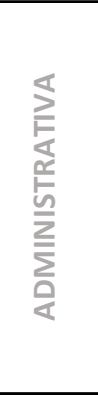 } & & INFORMES & \\
\hline & & SALA DE ESPERA & \\
\hline & ATENCIÓN AL ALUMNO & ATENCIÓN AL ALUMNO & \\
\hline & & ARCHIVADOR & \\
\hline & & SS.HH. & \\
\hline & & SALA DE REUNIONES & \\
\hline & DIRECTIVA Y DOCENTES & SECRETARÍA E INFORMES & \\
\hline & & $\begin{array}{l}\text { SALA DE PROFESORES } \\
\text { OEICINA DEI OIBECTOR }\end{array}$ & \\
\hline & & POOL DE LOGÍSTICA & \\
\hline & & POOL DE ADMINISTRACIÓN & \\
\hline & & OF. PSICOLOGÍA & \\
\hline & ADMINISTRACIÓN & OF.NUTRICIÓN & \\
\hline & & OF. JEFATURA COORD. & \\
\hline & & ARCHIVO & \\
\hline & & SS.HH. & \\
\hline & & DEPÓSITO & \\
\hline & & ÁREA DE MONTACARGA & \\
\hline & & BAÑO CON DUCHAS & Los espacios al aire Libre en las Escuelas de teatro \\
\hline n & SERVICIO & LOCKERS & son interesantes para el estudio debido a que en \\
\hline 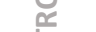 & & COMEDOR & \\
\hline 宸 & & INGRESO Y REGISTRO & estos espacios se realiza la demostración, \\
\hline 0 & & ZONA DE EMBARQUE & experimentación v vida social de los alumnos en \\
\hline & ESTACIONAMIENTO & ESTACIONAMIENTO AUTOS & experime \\
\hline & & ESTACIONAMIENTO BICICLETAS & su etapa de aprendizaje. \\
\hline & AREA LIBRE & EXTERIOR & \\
\hline
\end{tabular}

Figura 51. Cuadro de Ambientes. Elaboración Propia 


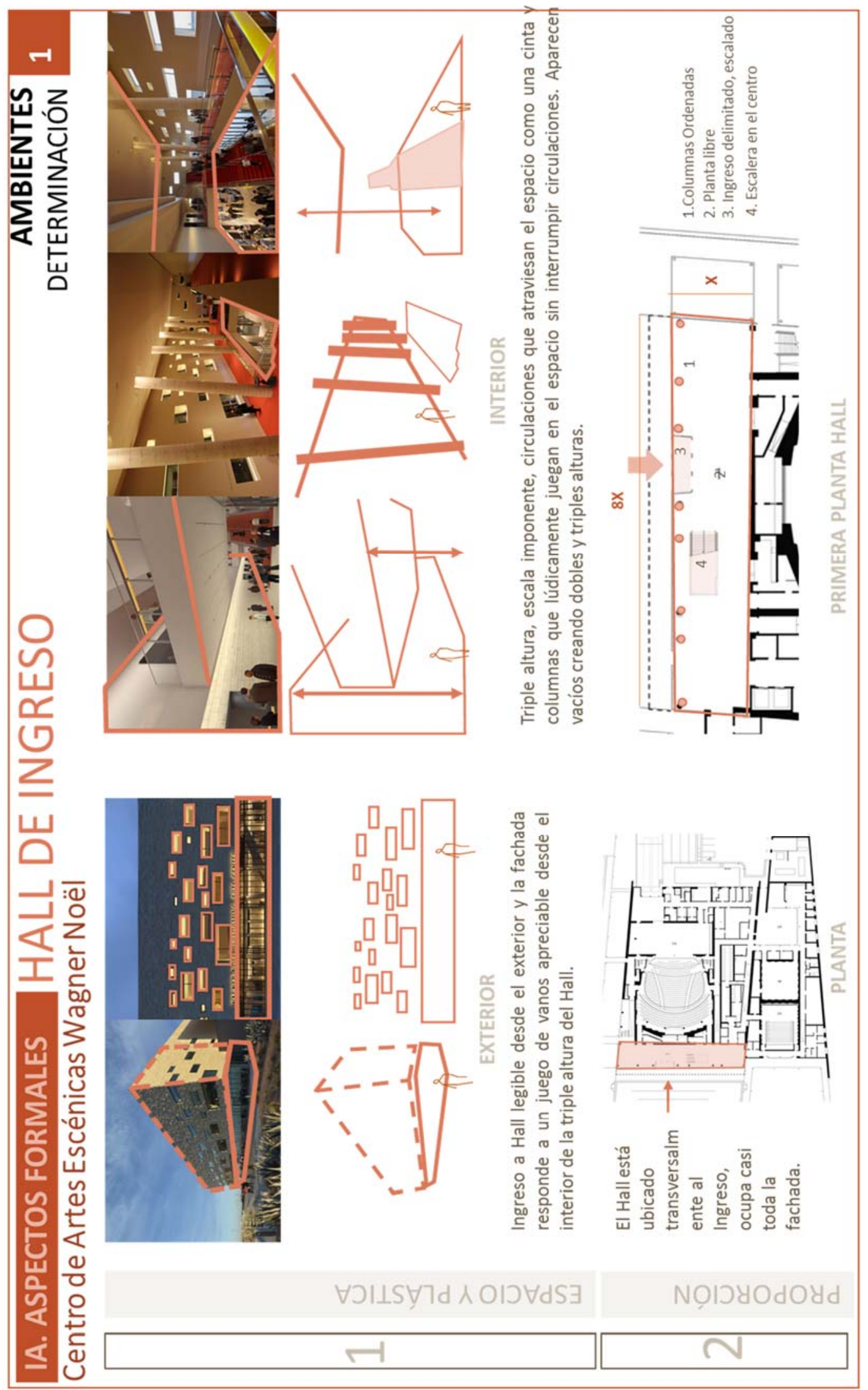

Figura 52. Hall de Ingreso. Elaboración Propia 


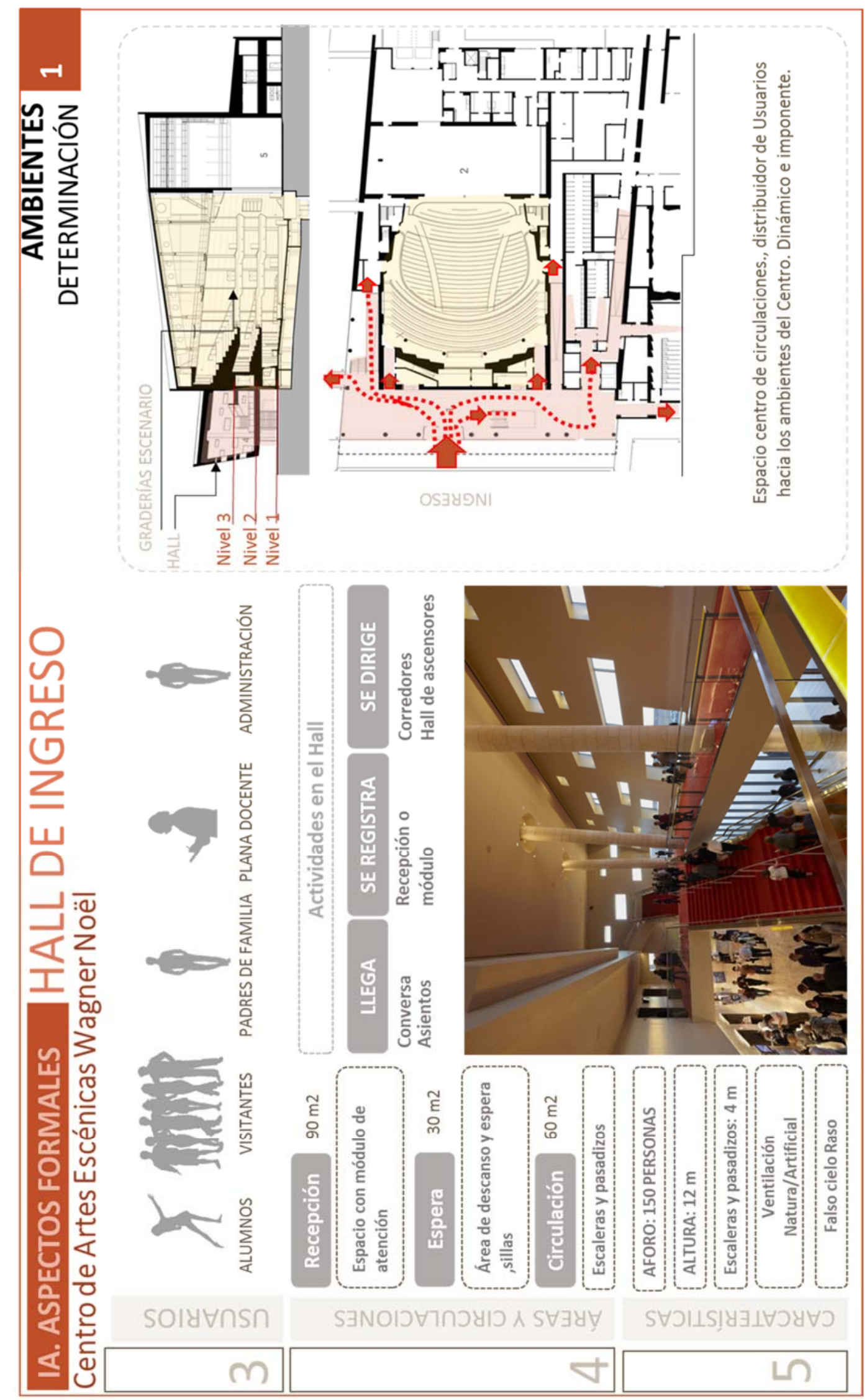

Figura 53. Hall de Ingreso. Elaboración Propia 


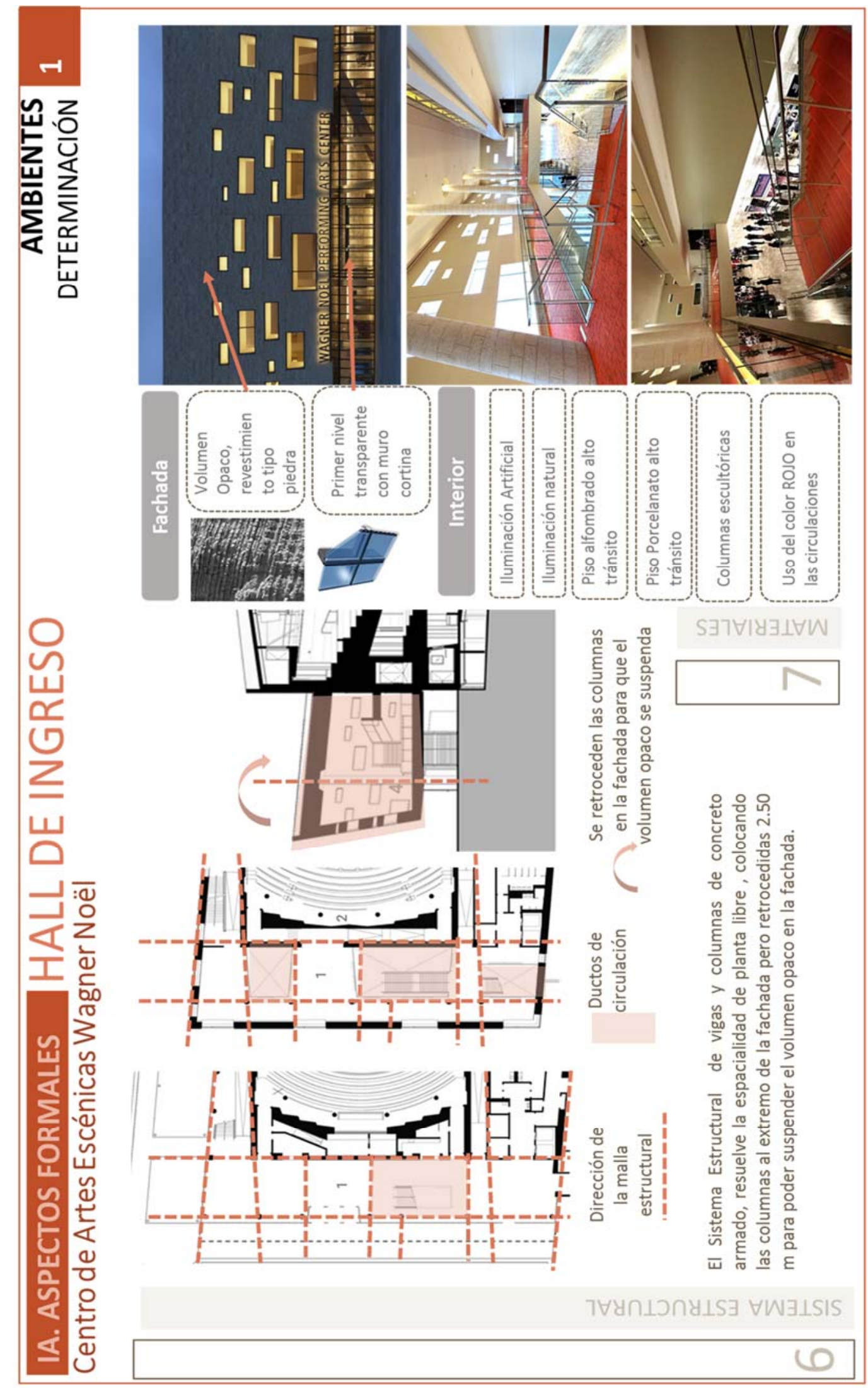

Figura 54. Hall de Ingreso. Elaboración Propia 


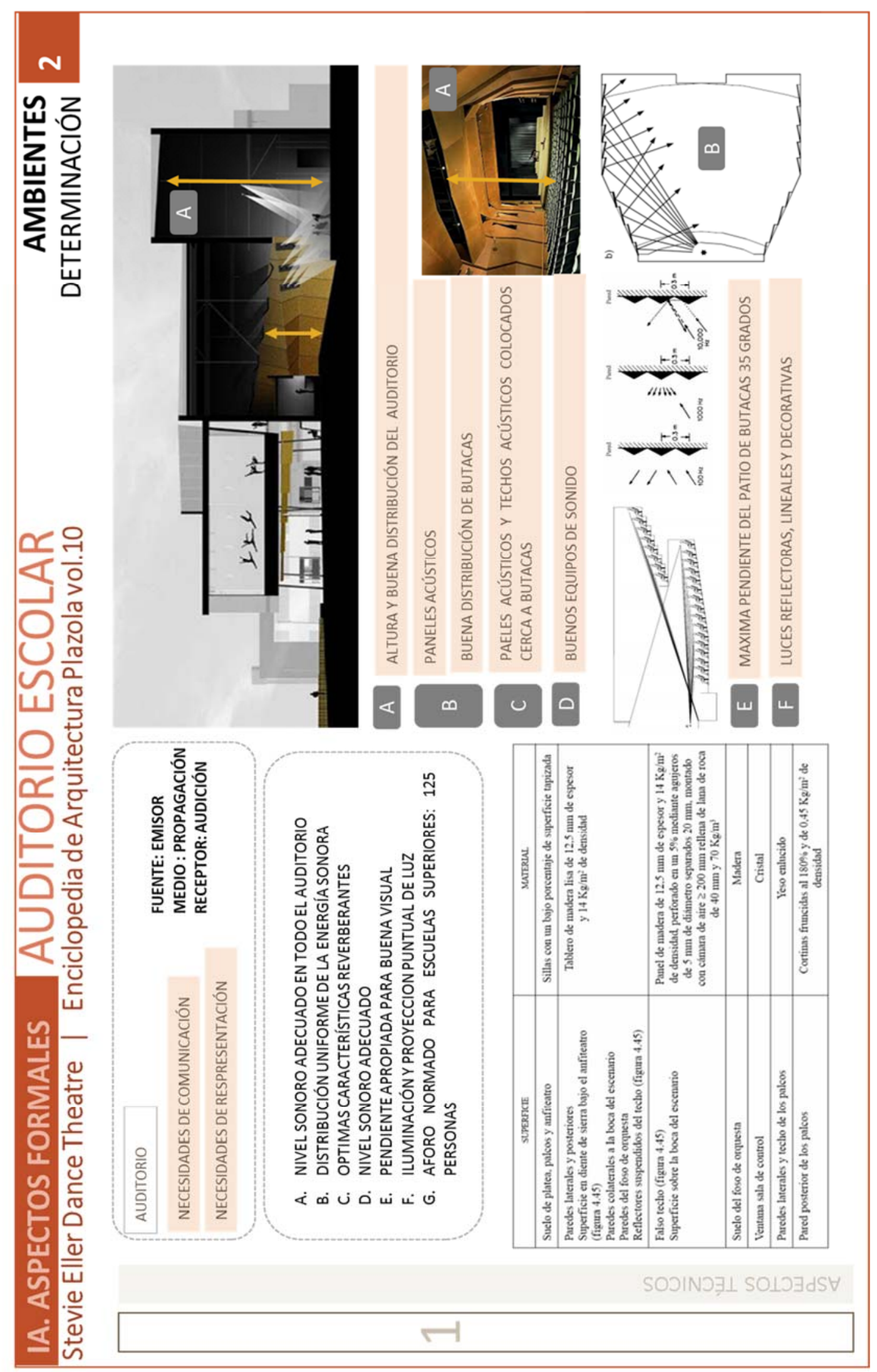

Figura 55. Auditorio Escolar. Elaboración Propia 


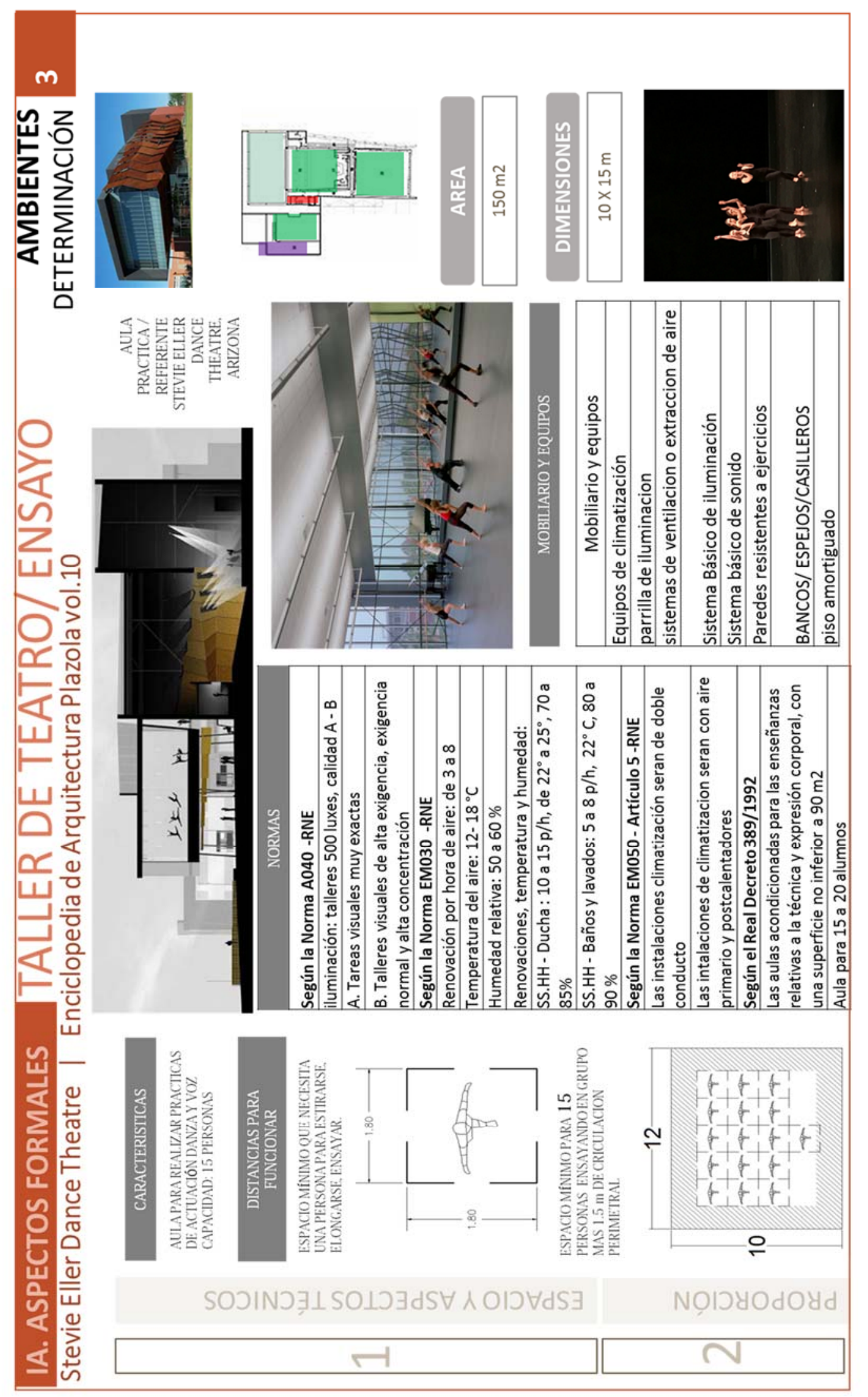

Figura 56. Taller de Teatro. Elaboración Propia 


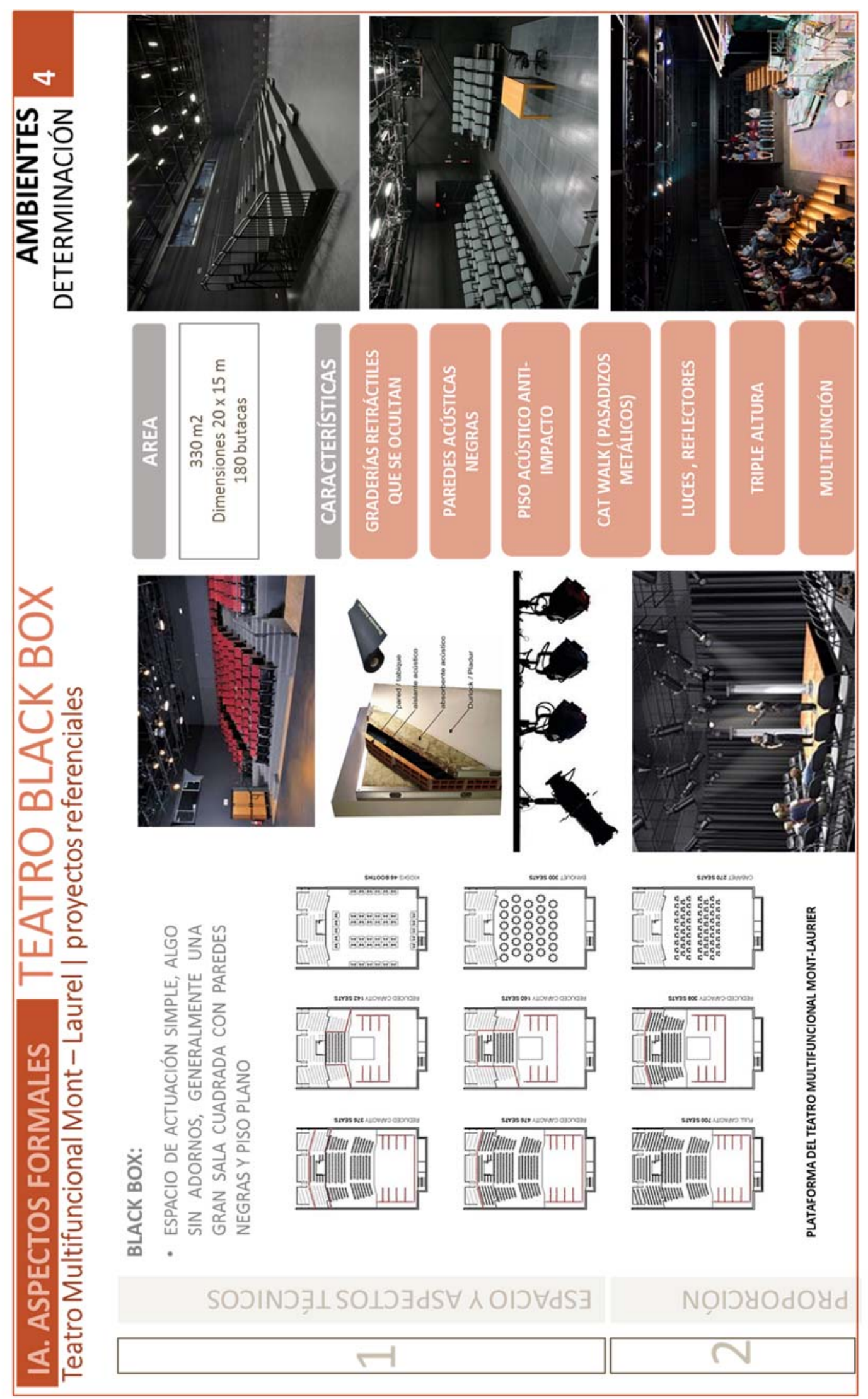

Figura 57. Teatro Black Box. Elaboración Propia 


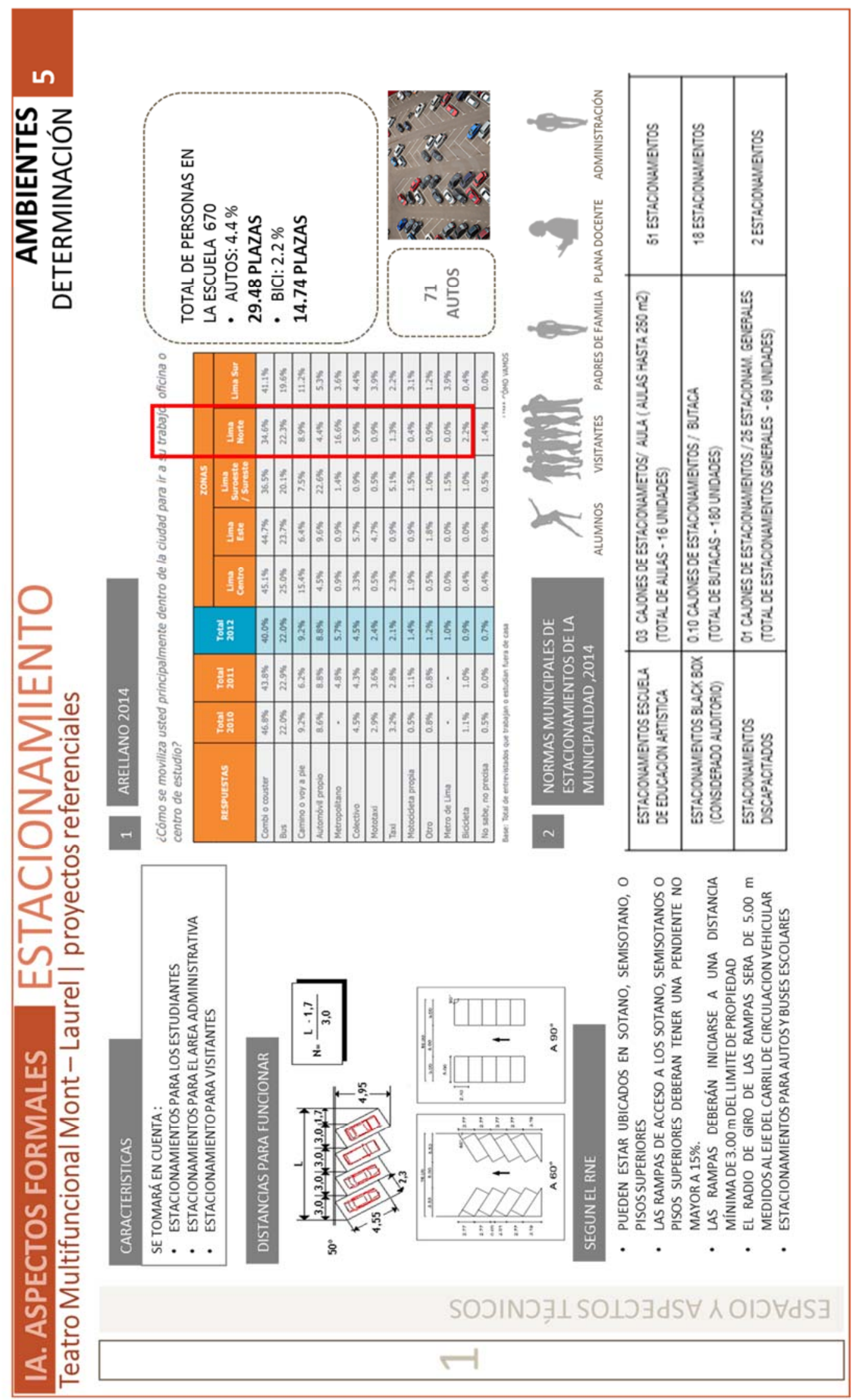

Figura 58. Estacionamiento. Elaboración Propia 


\subsubsection{Interrelaciones funcionales}

\subsubsection{Organigrama}

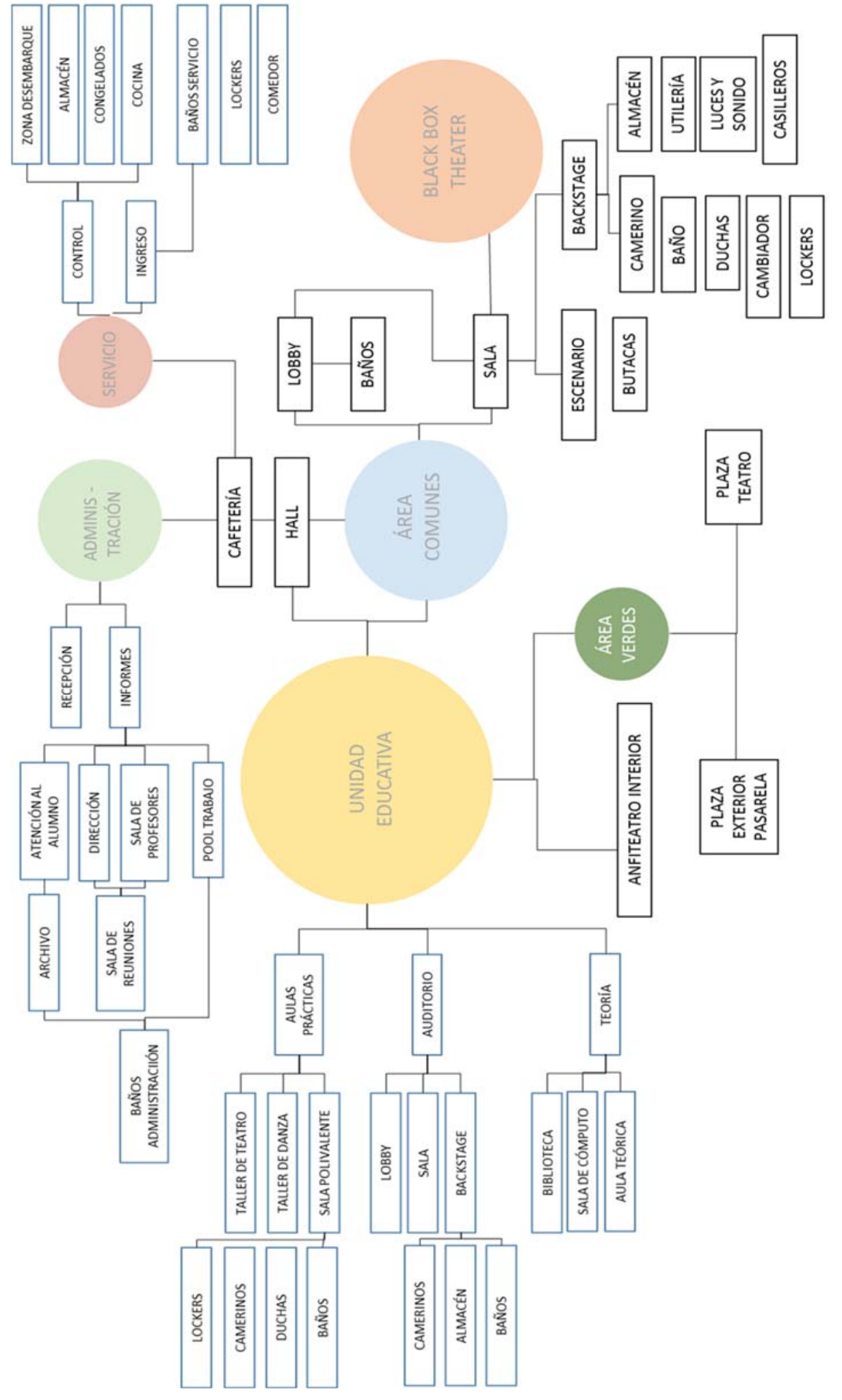

Figura 59. Organigrama. Elaboración Propia 
5.3.2.2. Programa Final

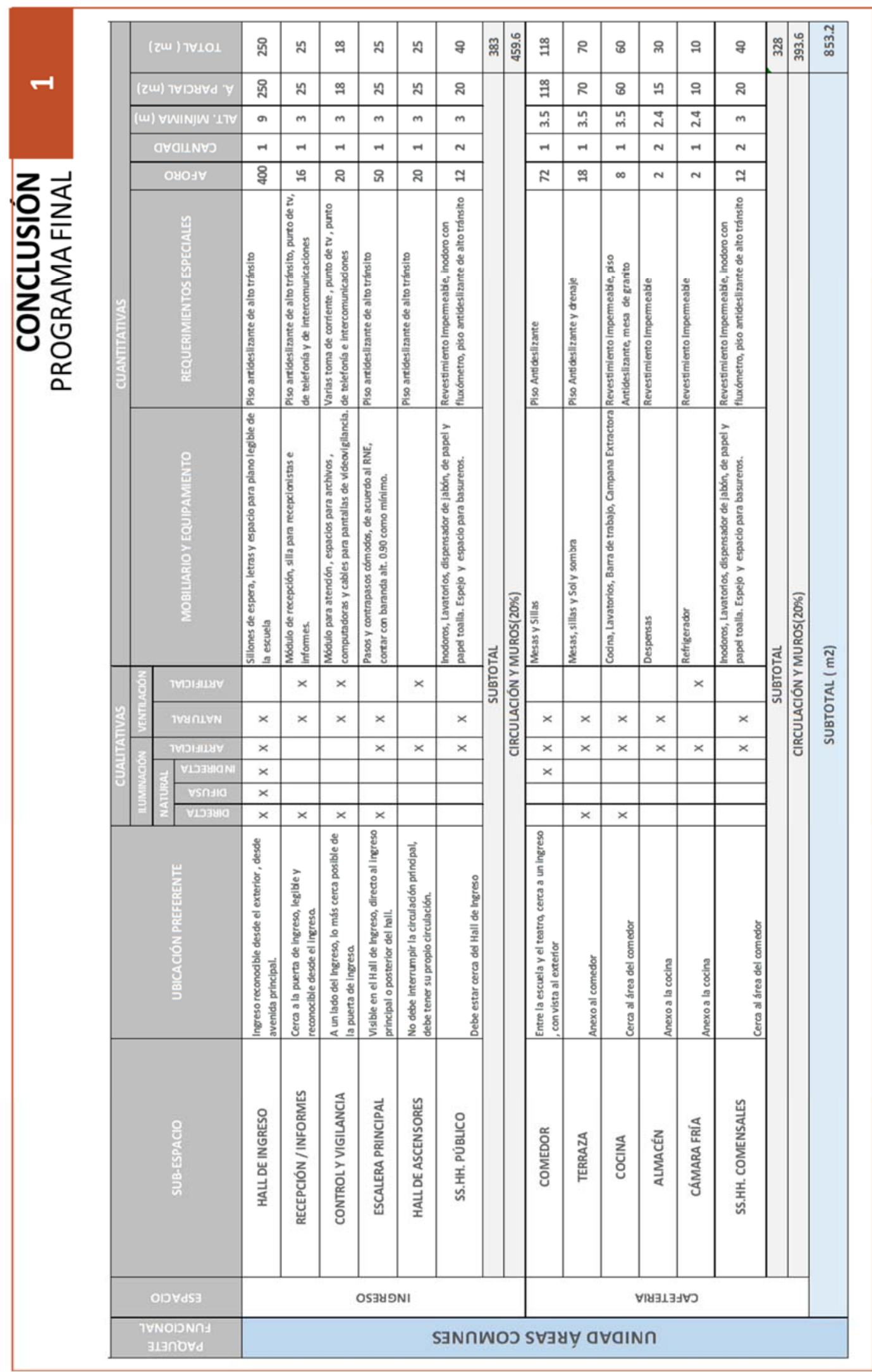

Figura 60. Programa Final. Elaboración Propia 


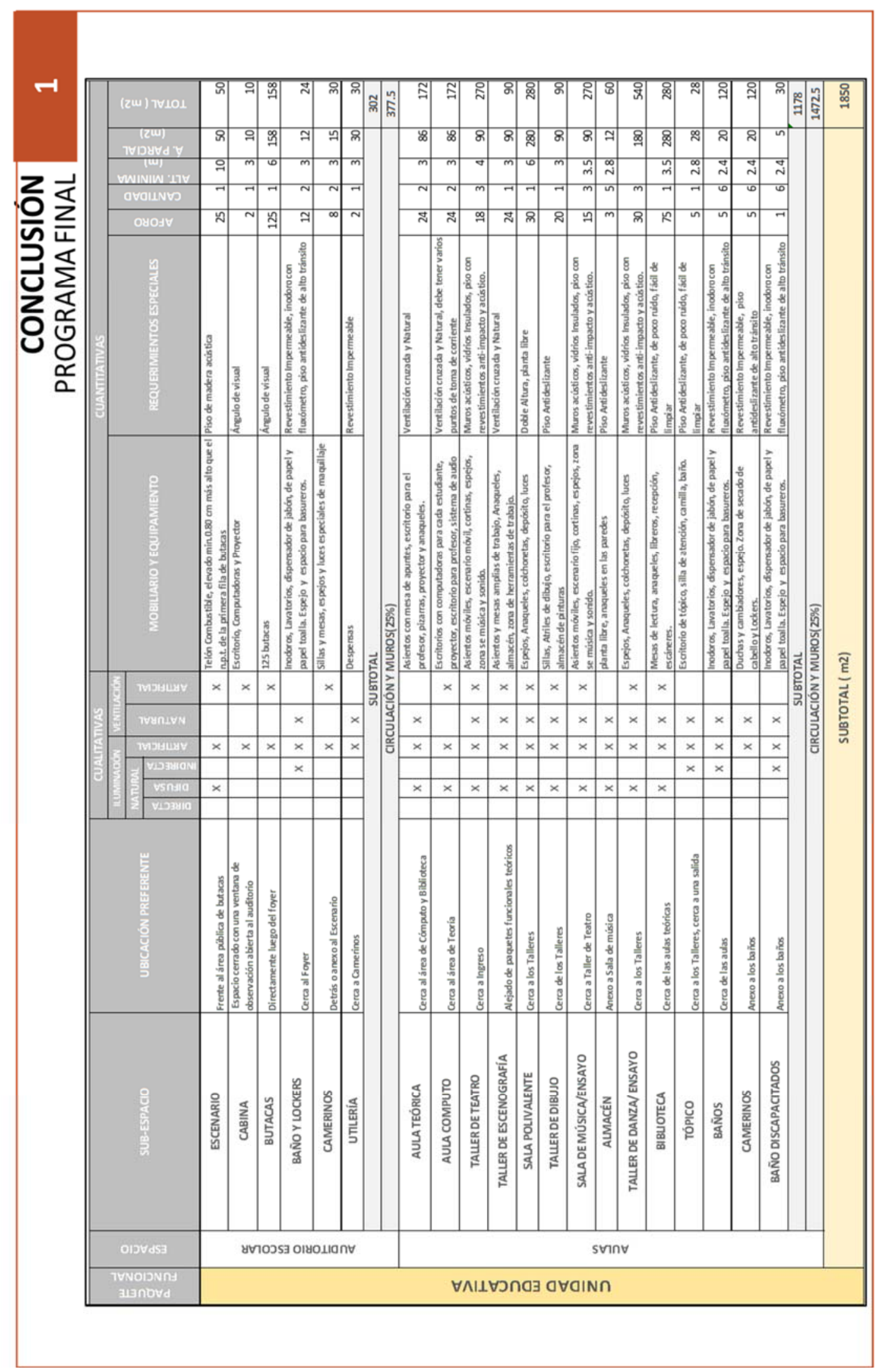

Figura 61. Programa Final. Elaboración Propia 


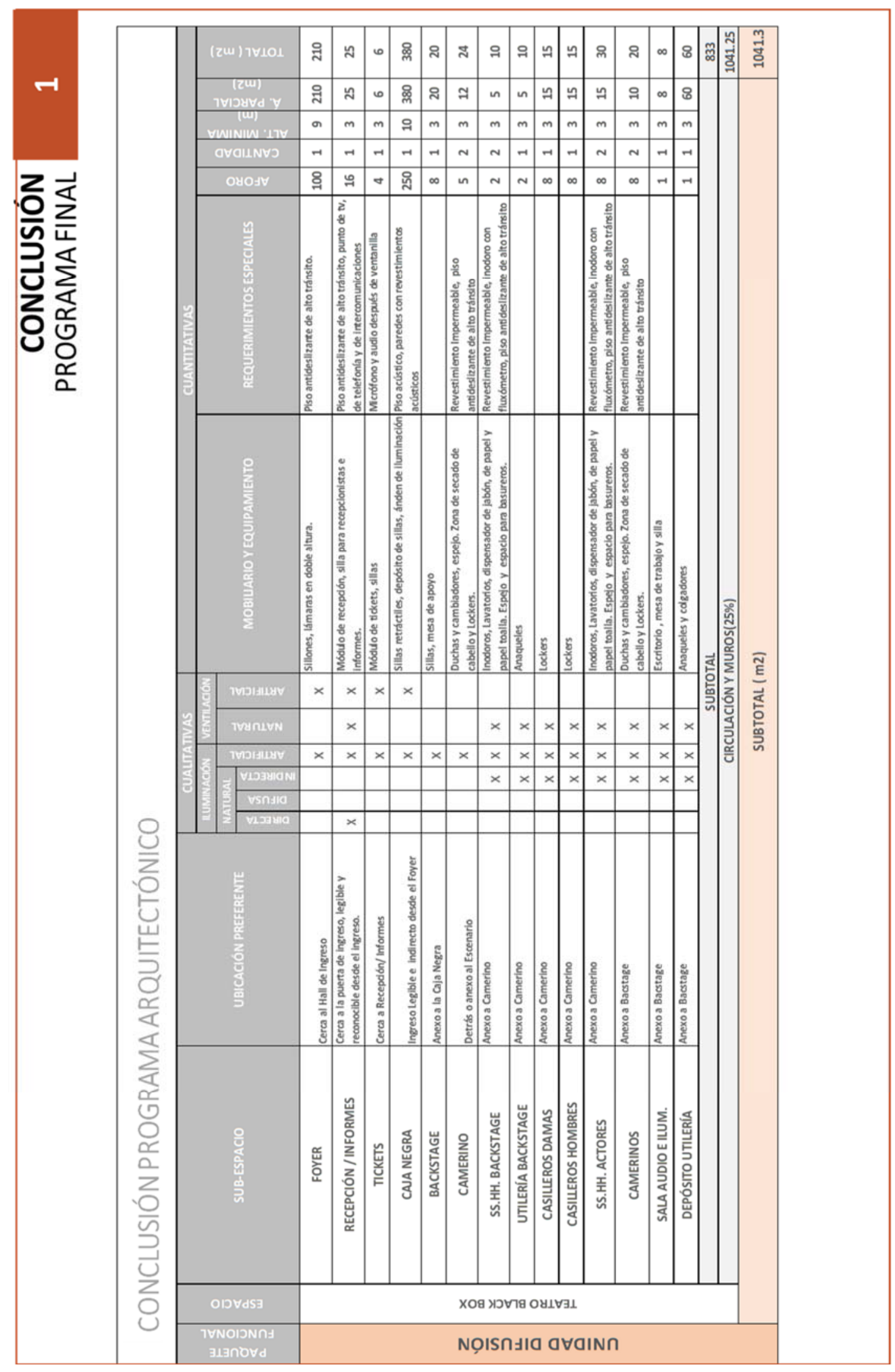

Figura 62. Programa Final. Elaboración Propia 


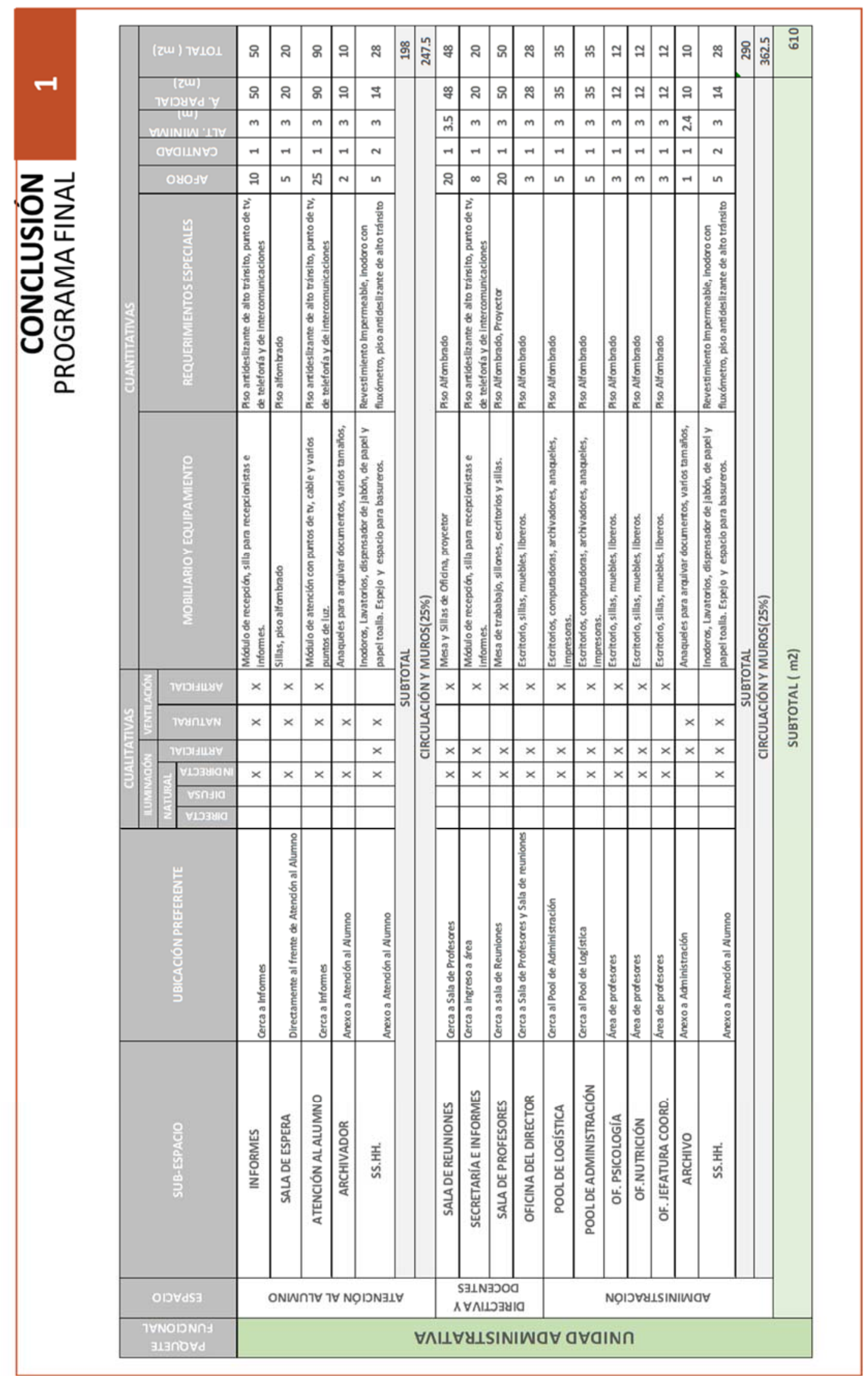

Figura 63. Programa Final. Elaboración Propia 


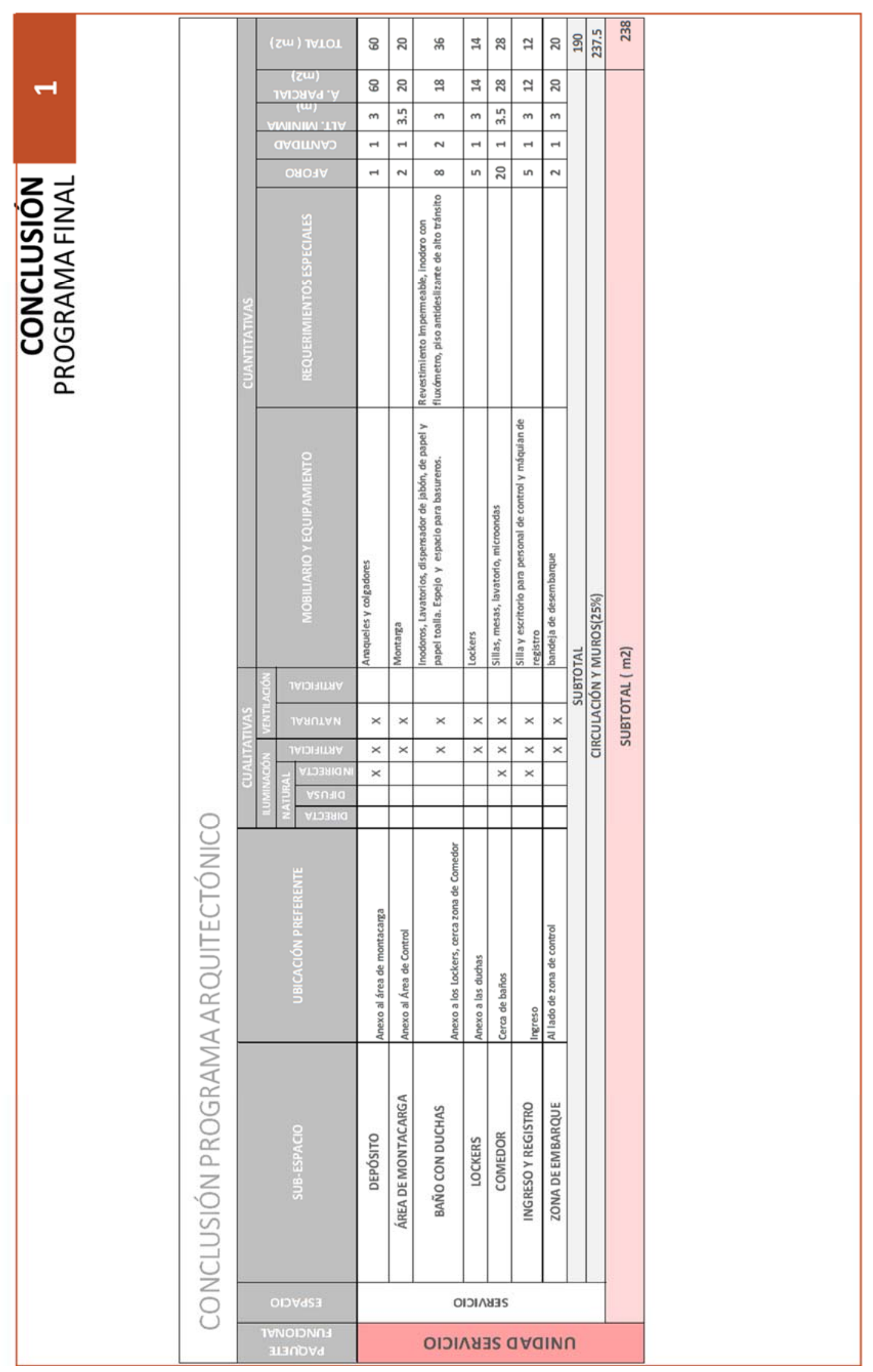

Figura 64. Programa Final. Elaboración Propia 


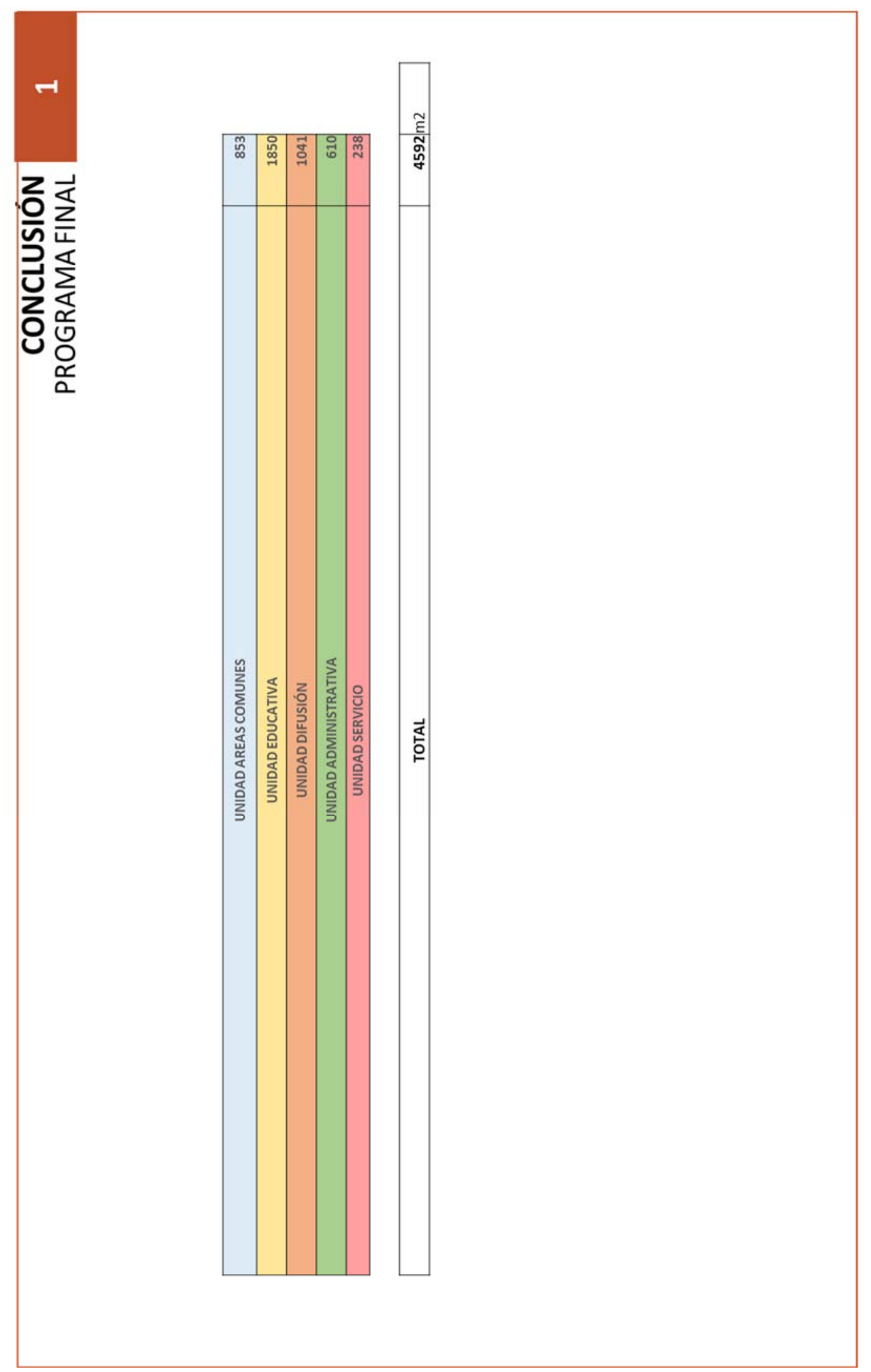

Figura 65. Programa Final. Elaboración Propia 


\section{CAPITULO VI: UBICACIÓN Y DETERMINACIÓN DEL TERRENO}

En esta etapa se justificará la importancia de Comas y su presencia cultural en Lima Norte, una de las nuevas centralidades de Lima metropolitana según el Plan Metropolitano de Desarrollo Urbano de Lima y Callao (PLAM). Así como también se determinará las características del terreno y el terreno donde se situará el proyecto.

\subsection{Las nuevas centralidades en Lima, Lima Norte y Comas}

Los centros y subcentros en Lima son elementos espontáneos que surgen sin la intervención inicial del Gobierno Local. Al contar con la concentración de las actividades económicas condiciona un mayor valor de renta de suelo sin responsabilidad social, generando la especulación mediante la demanda no planificada y el crecimiento excesivo por densificación y extensión. (Lima, 2013) PLAM METROPOLITANO DE LIMA

En la ciudad de Lima el surgimiento de las centralidades se dio por etapas según el diagnóstico técnico participativo del PLAM:

- En los 50's: Casco urbano con dos centros, Lima y Callao.

- En los 60's: Dispersión de ciudad en valles Rímac y Lurín.

- En los 70's: Decadencia del Centro Histórico e inicios de la Policentralidad, surgen los subcentros de Miraflores y San Isidro.

- En los 80's: Abandono de empresas industriales, surgen PYMES. Sin embargo, no se consolidan centros por falta de financiamiento.

- En los 2000's: Aumento poblacional en corredores viales, desborda crecimiento de la ciudad, Aparecen nuevas centralidades, las cuales surgen espontáneamente.

Estos nuevos centros urbanos están constituidos por el conjunto de actividades urbanas que generan excedentes de bienes de acuerdo con el rol y función para atención de un nivel de territorio: 


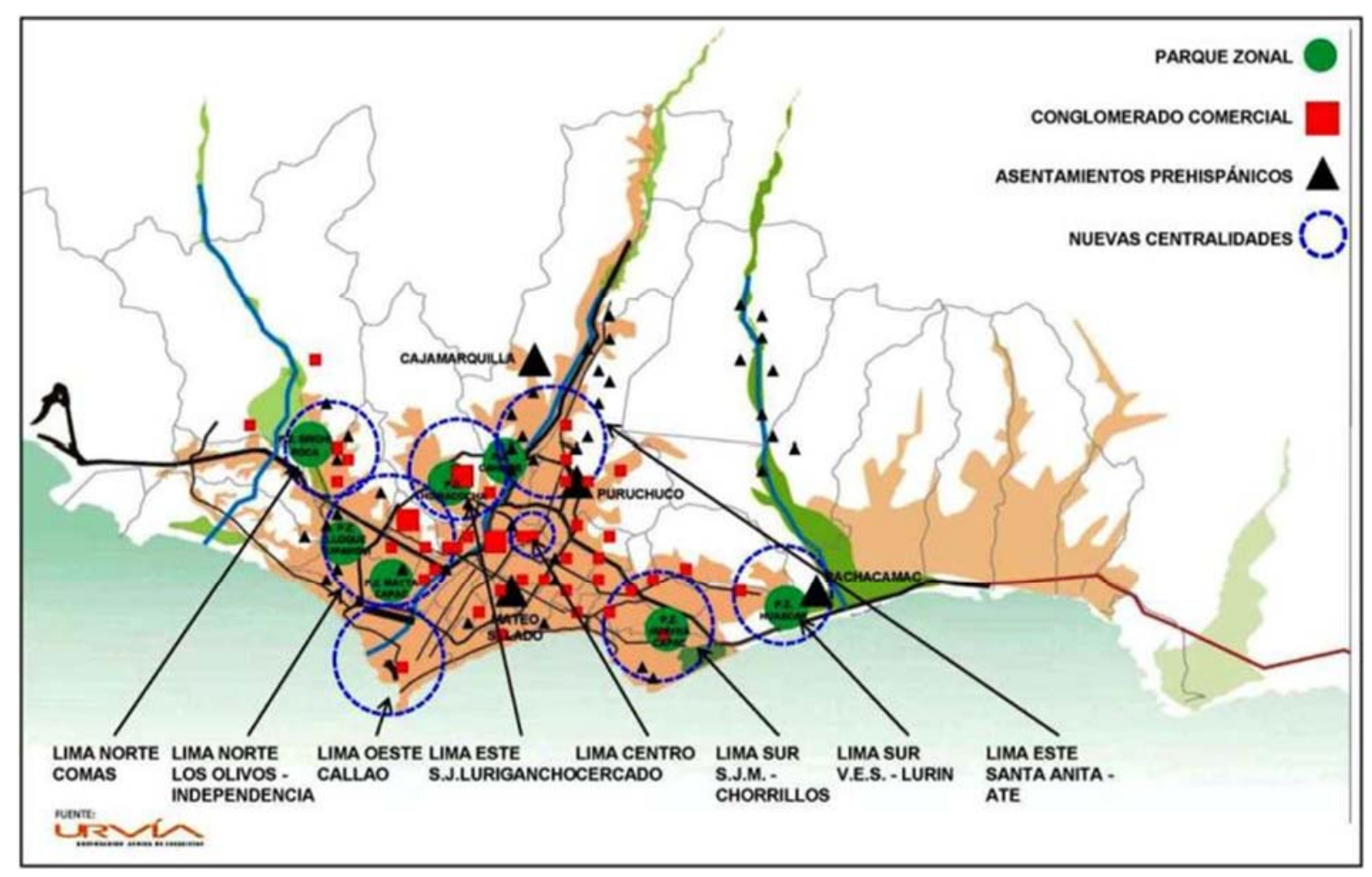

Figura 66. Nuevas centralidades en lima

Fuente: Corporación andina de Urbanistas. http://urvia.blogspot.com/2010/09/lineamientospara-un-mejor-desarrollo.html

Entendiendo la necesidad que tiene cada centralidad de Lima en desarrollar actividades de todo tipo dentro de ellas y la demanda de servicios que abastezcan y promuevan su desarrollo económico, social y cultural, se propone una escuela de teatro en Comas, distrito dentro de Lima norte, cuya demanda de estudiantes de teatro va en aumento según el estudio coyuntural de esta tesis. 


\subsection{Criterios de Selección del Terreno}

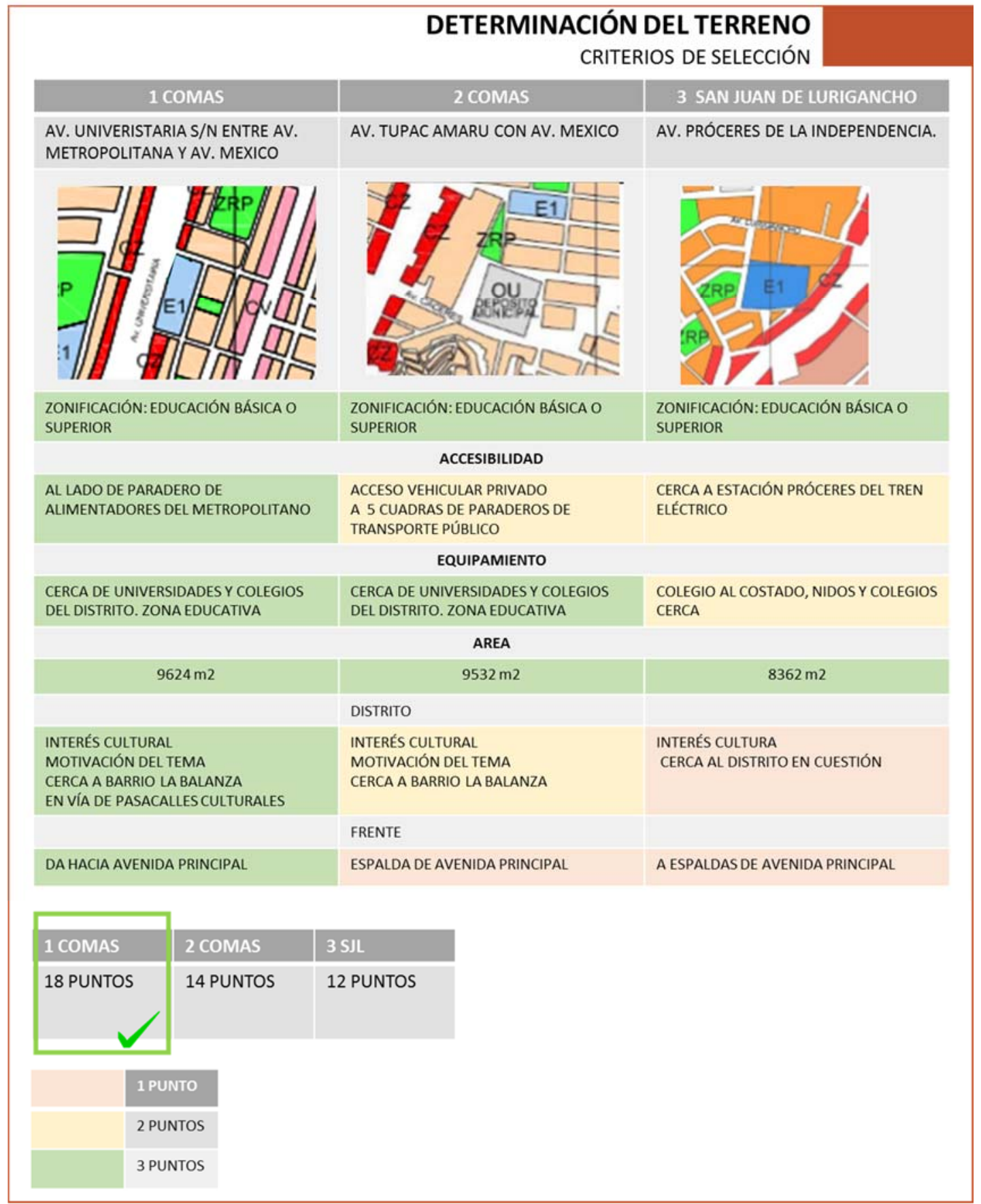

Figura 67. Criterios de Selección del Terreno

Fuente: elaboración propia 


\subsection{Características del Terreno Elegido}

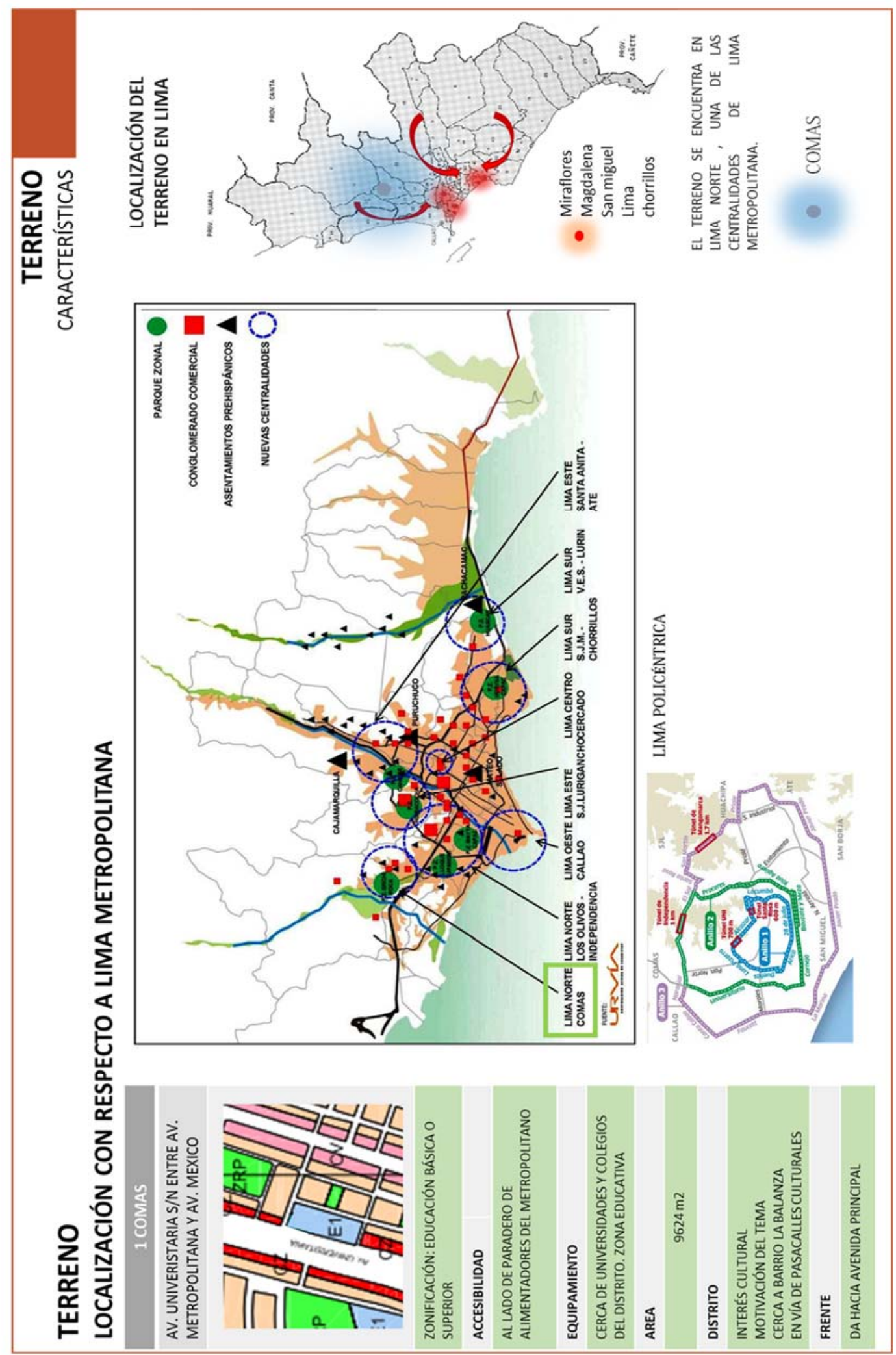

Figura 68. Localización del Terreno 


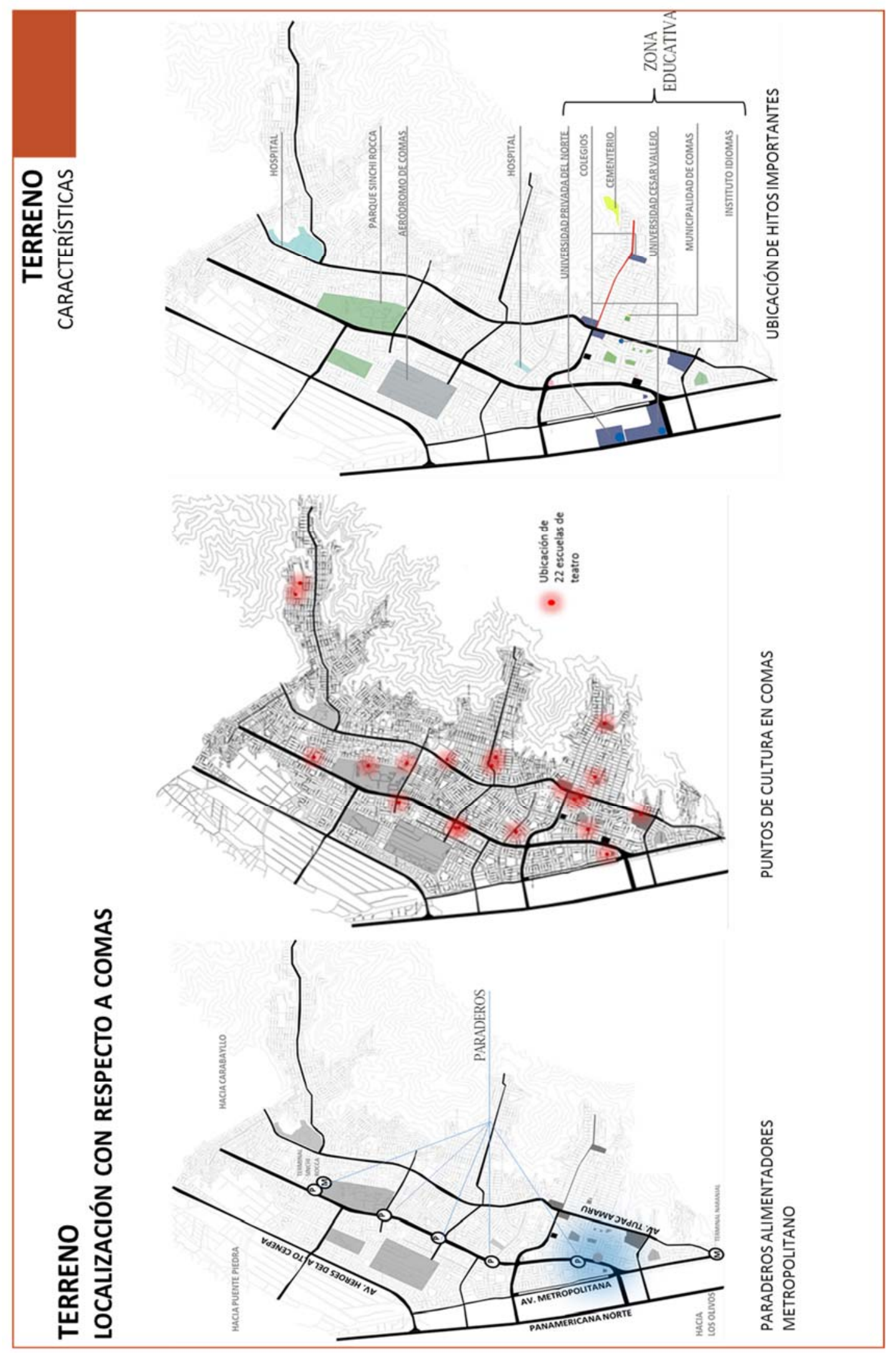

Figura 69. Distrito de Comas. Elaboración Propia 


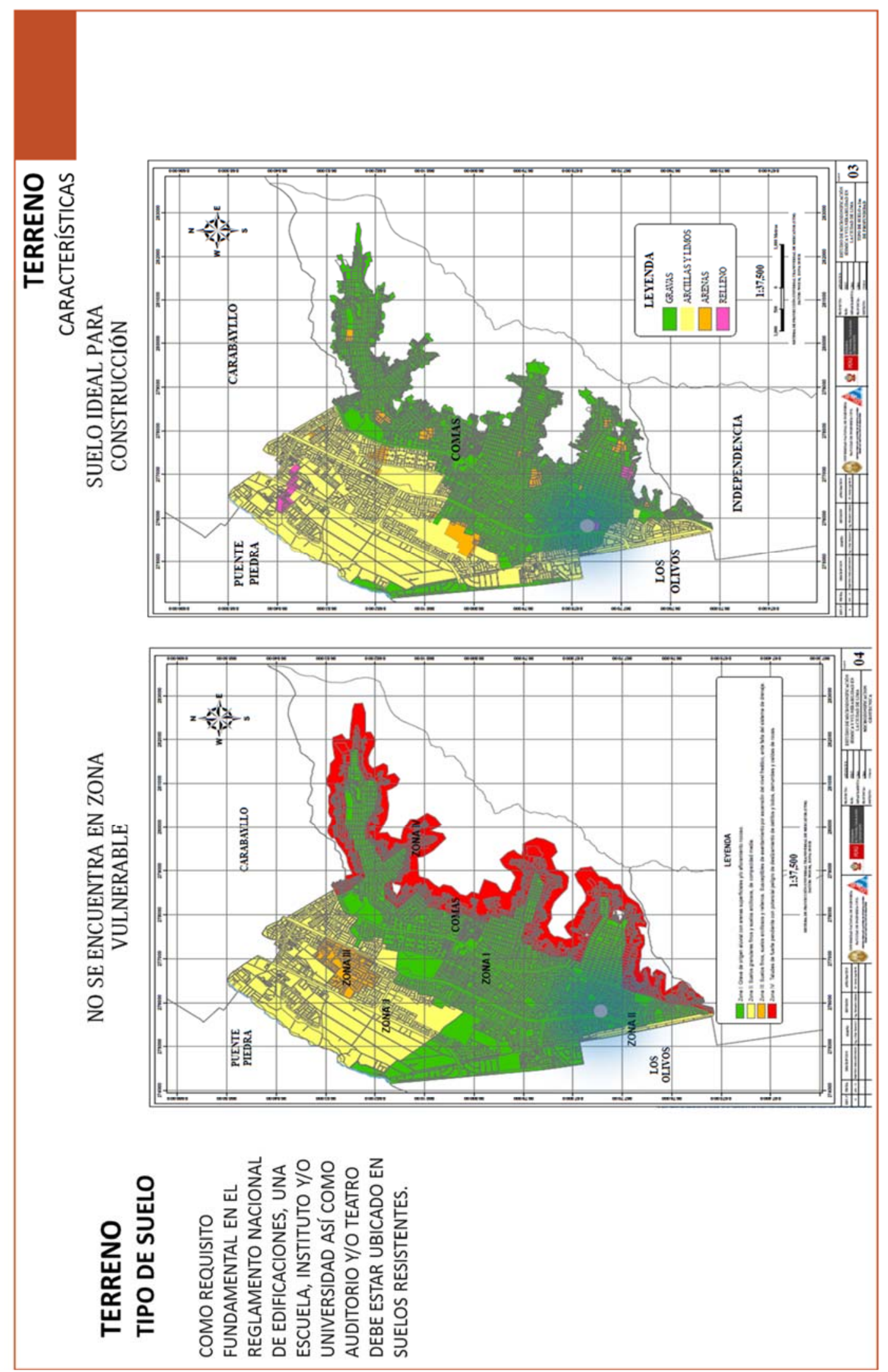

Figura 70. Tipo de Suelo. Elaboración Propia 


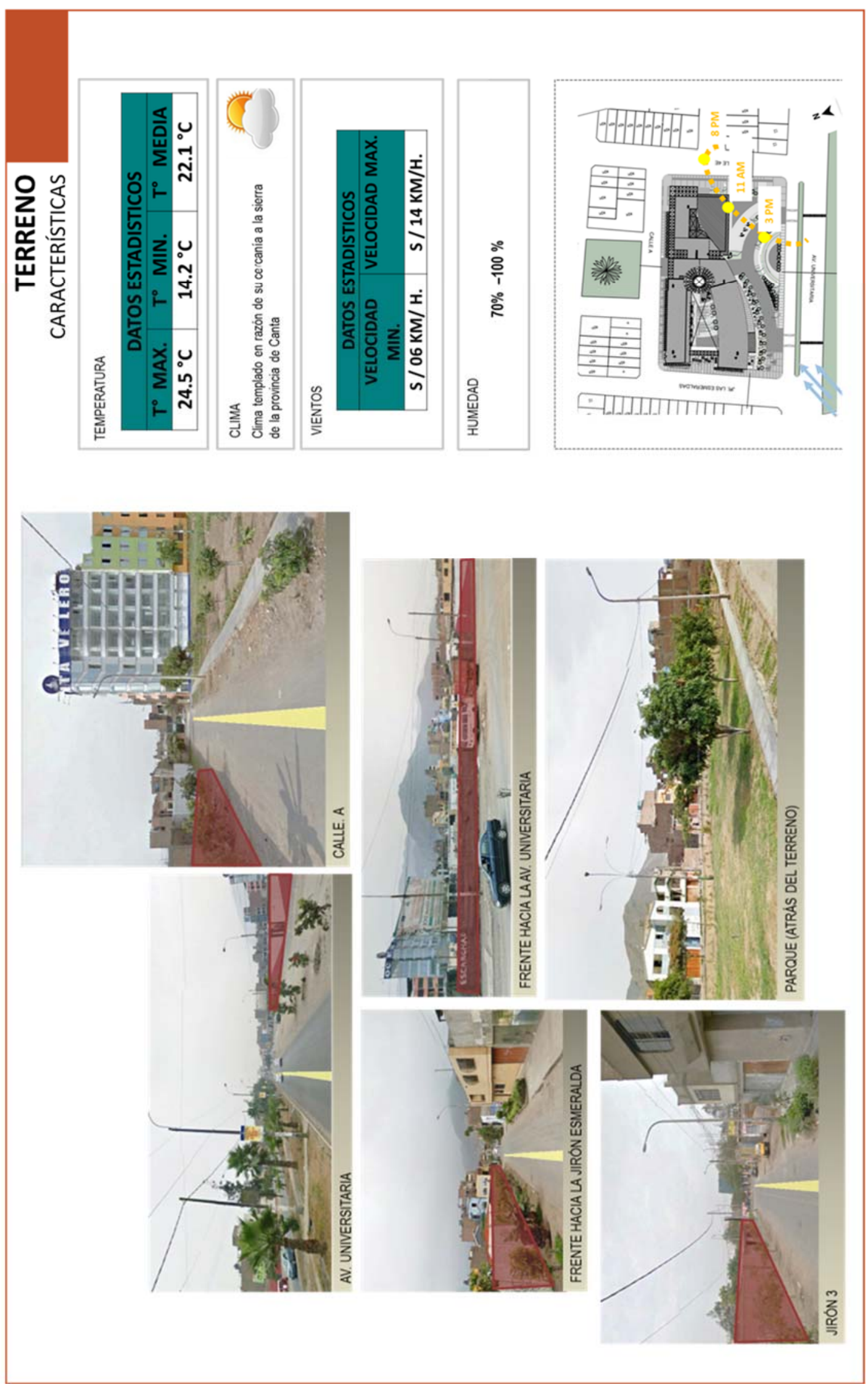

Figura 71. Contexto. Elaboración Propia 


\section{CAPÍTULO VII: PARTIDO ARQUITECTÓNICO}

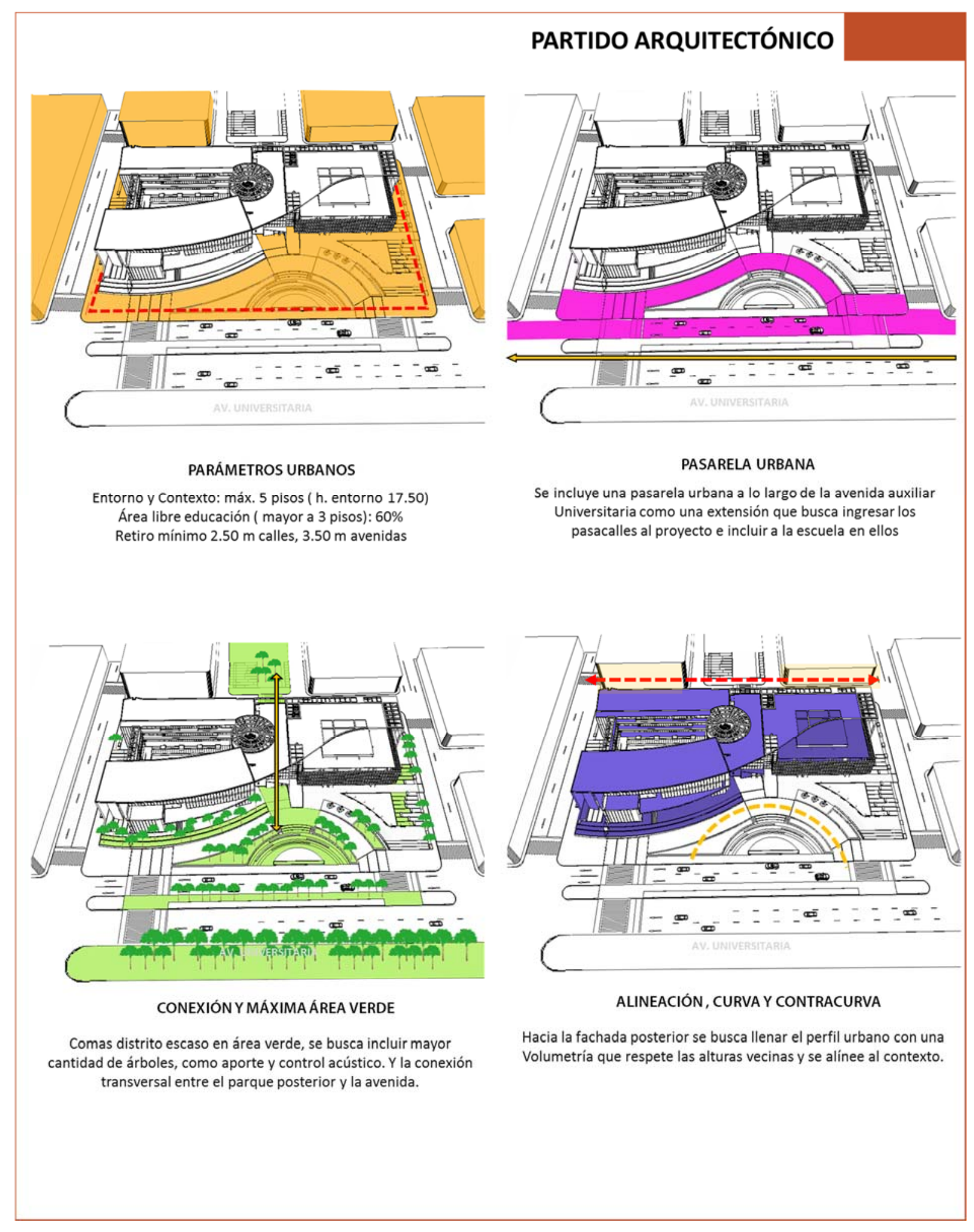

Figura 72. Partido Arquitectónico. Elaboración Propia 


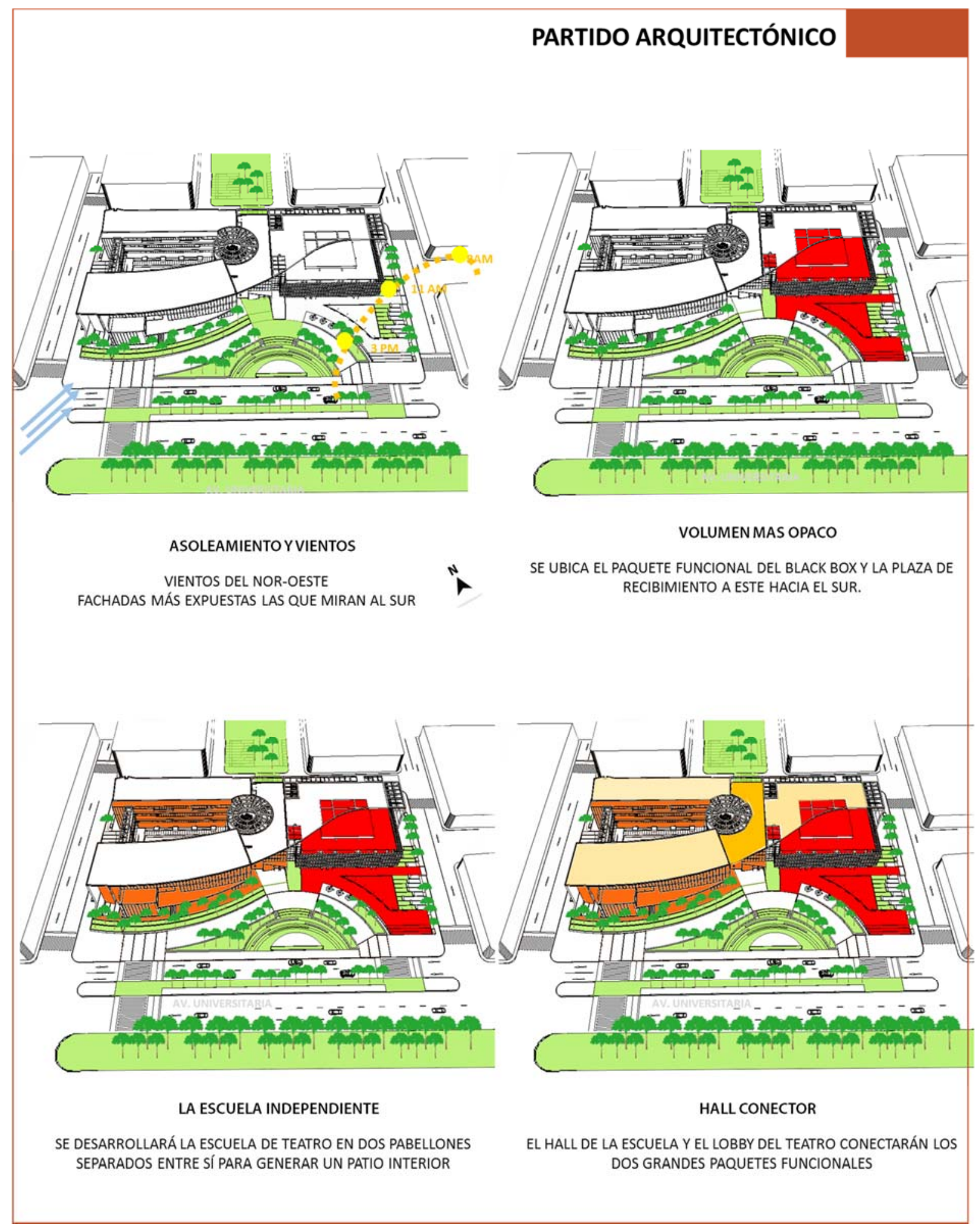

Figura 73. Partido Arquitectónico. Elaboración Propia 


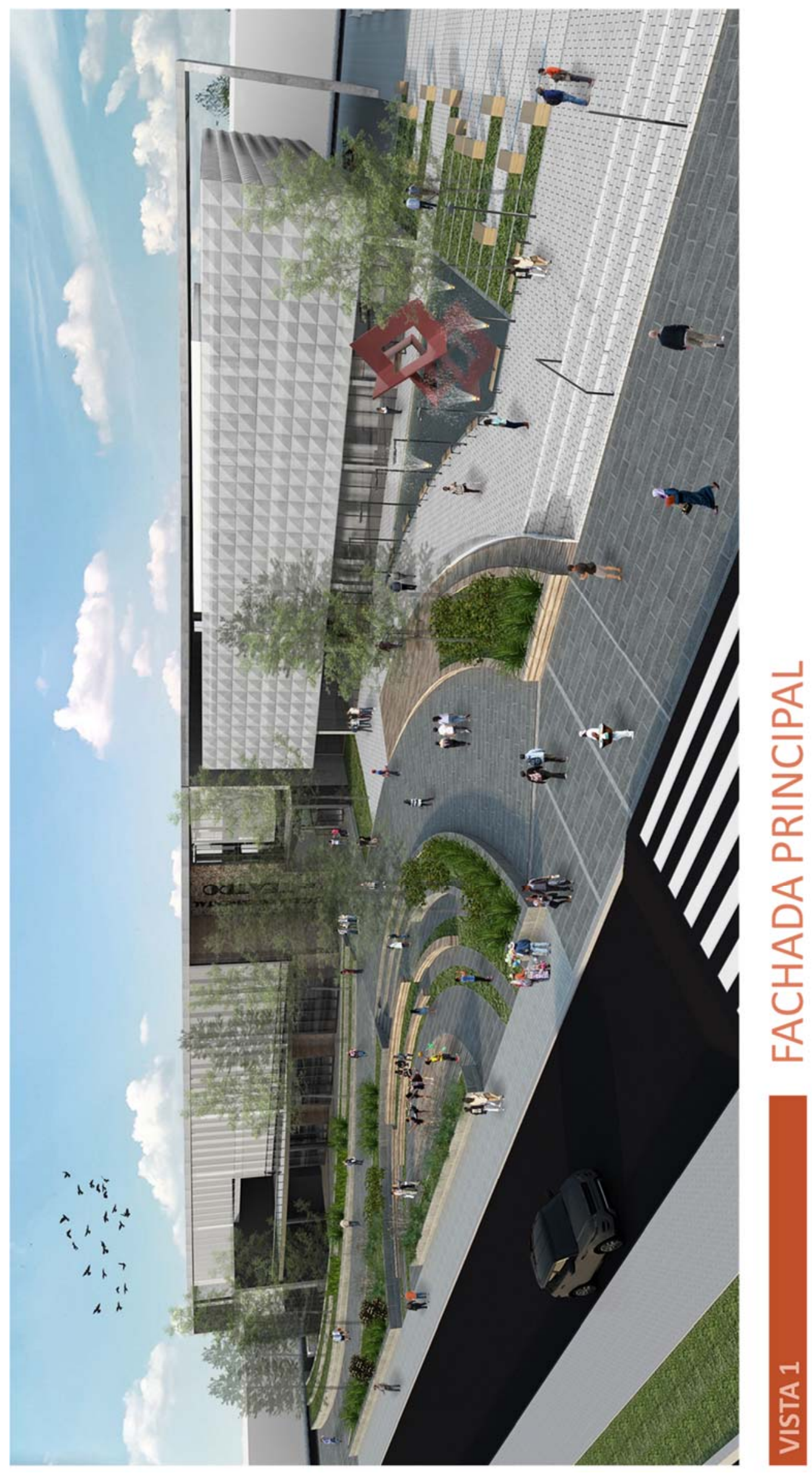

Figura 74. Vista 1. Elaboración Propia 


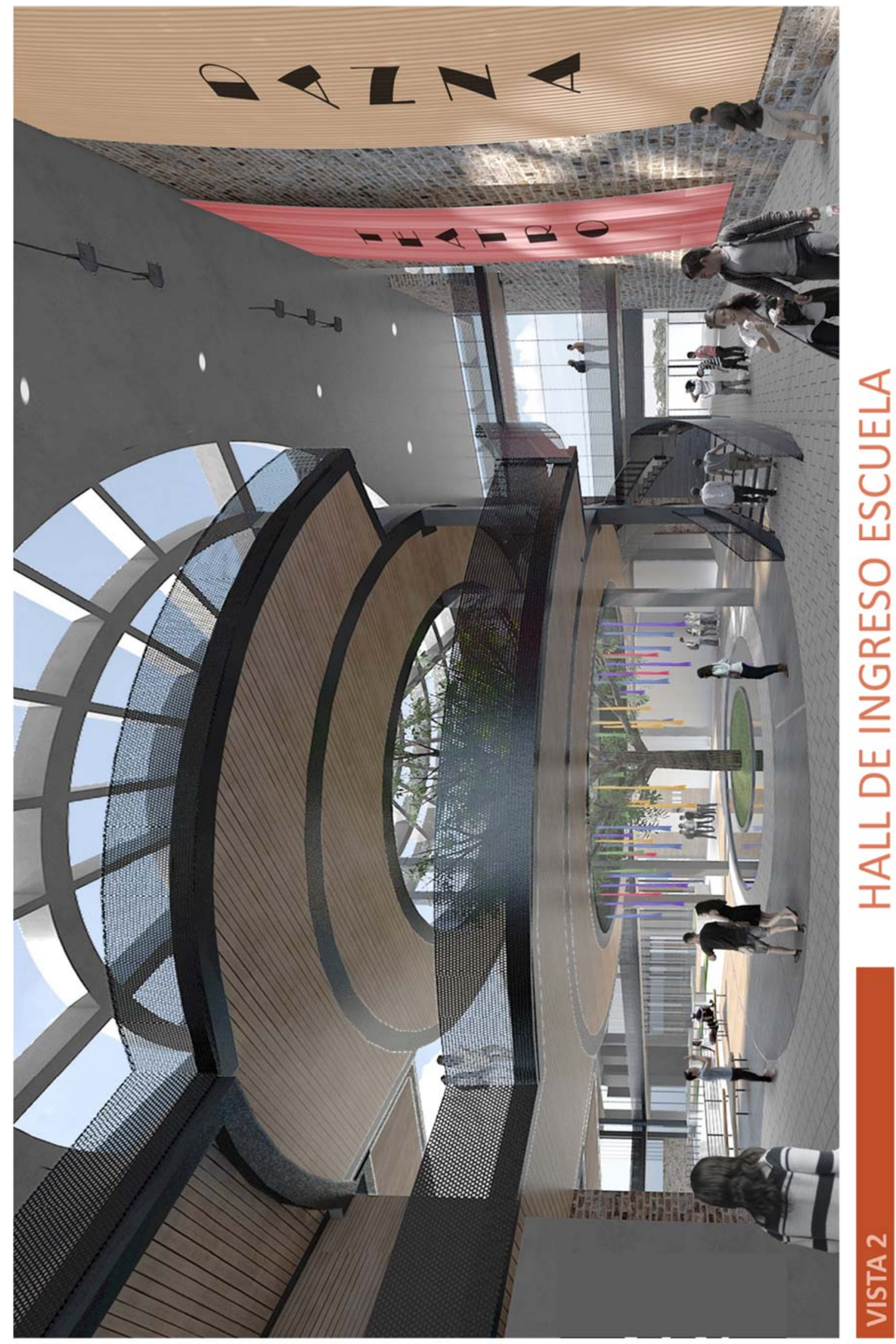

Figura 75. Vista 2. Elaboración Propia 


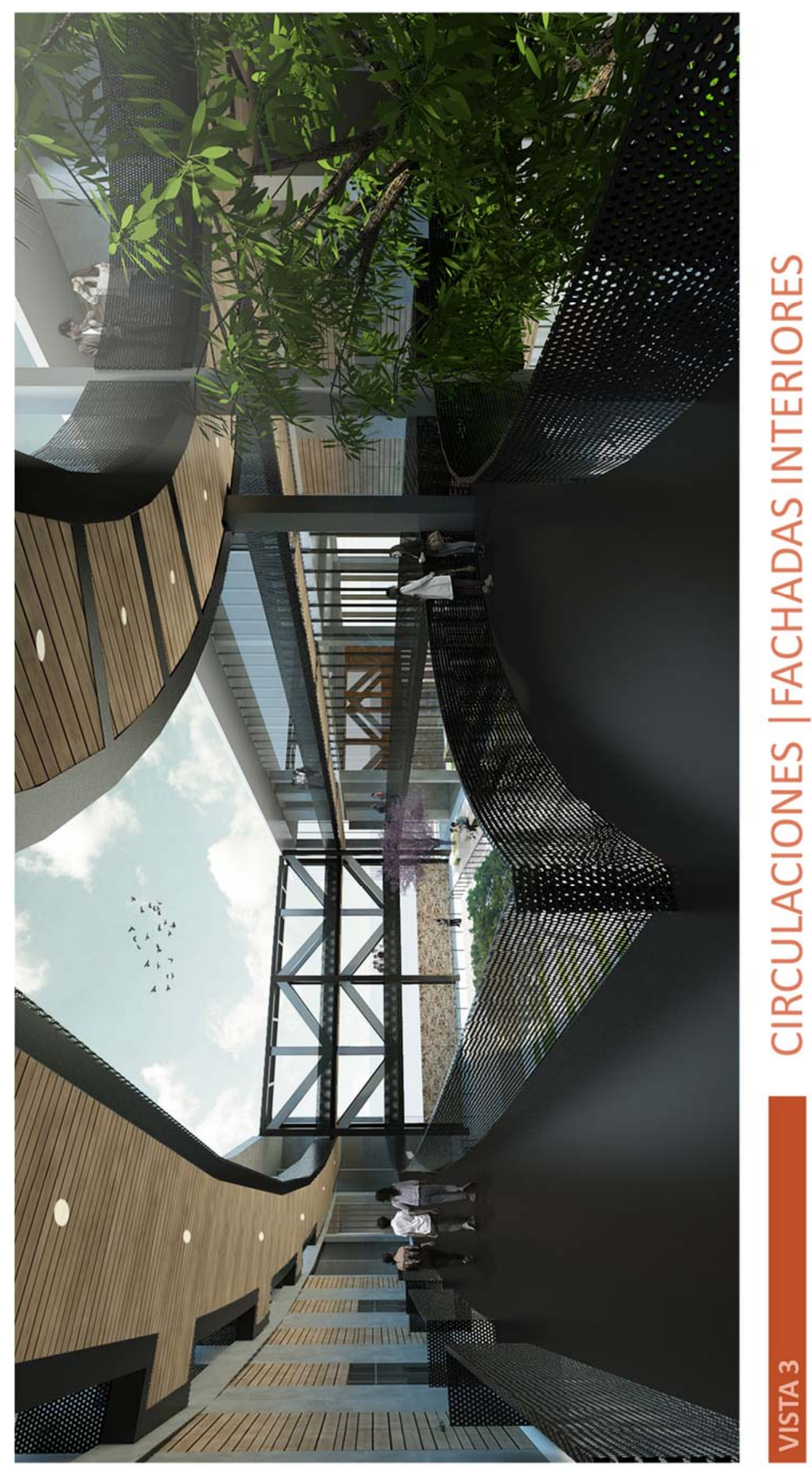

Figura 76. Vista 3. Elaboración Propia 


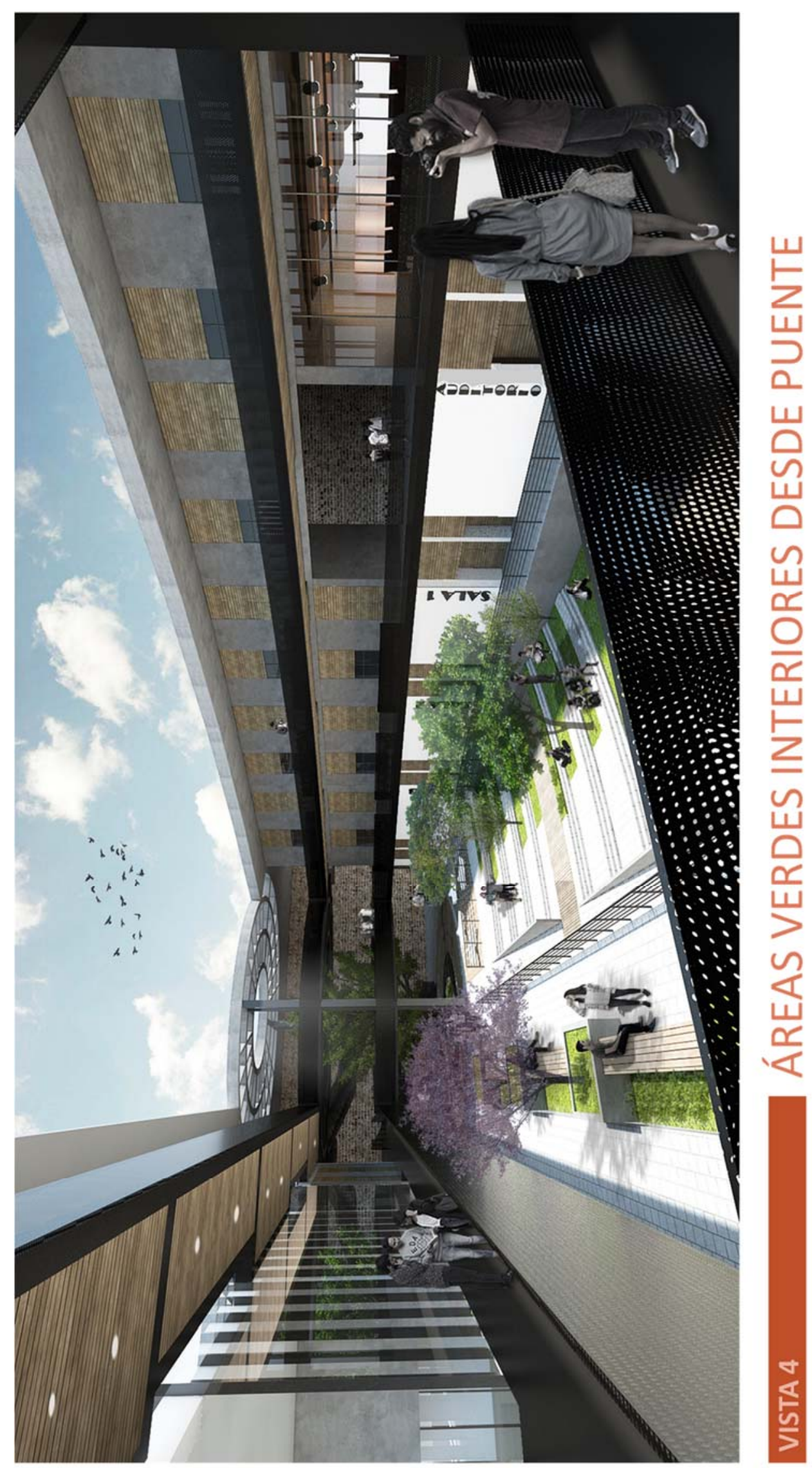

Figura 77. Vista 4. Elaboración Propia 


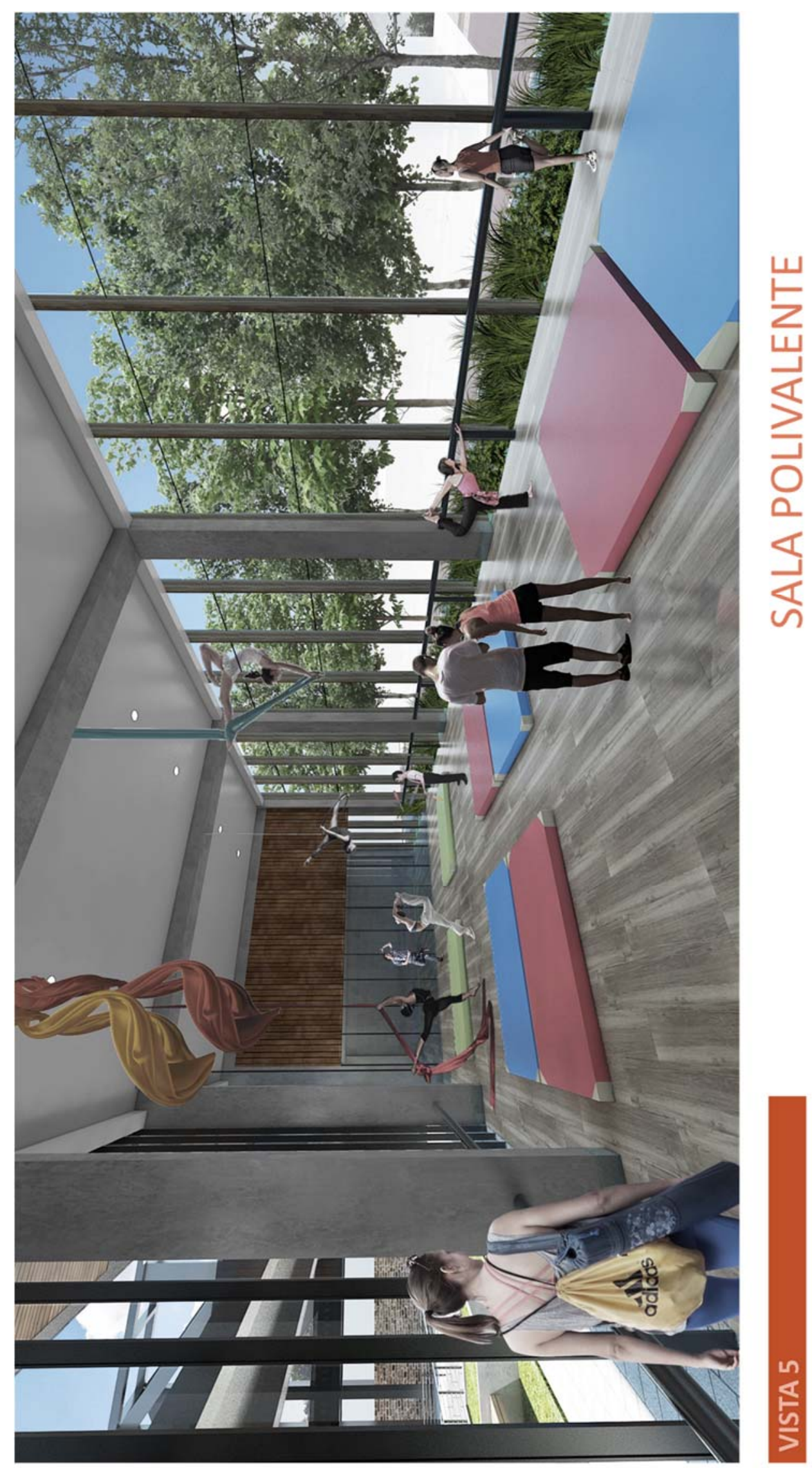

Figura 78. Vista 5. Elaboración Propia 


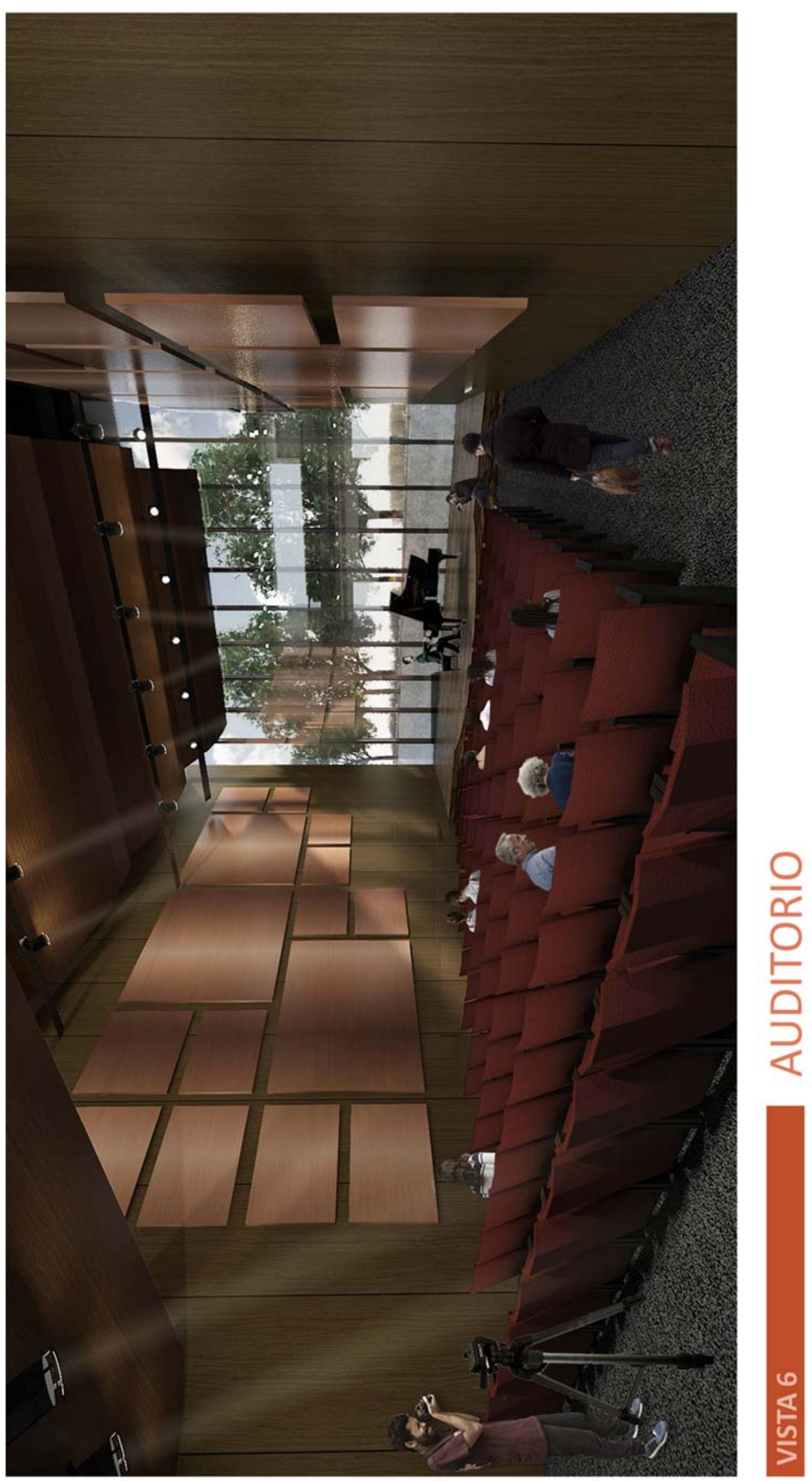

Figura 79. Vista 6. Elaboración Propia 


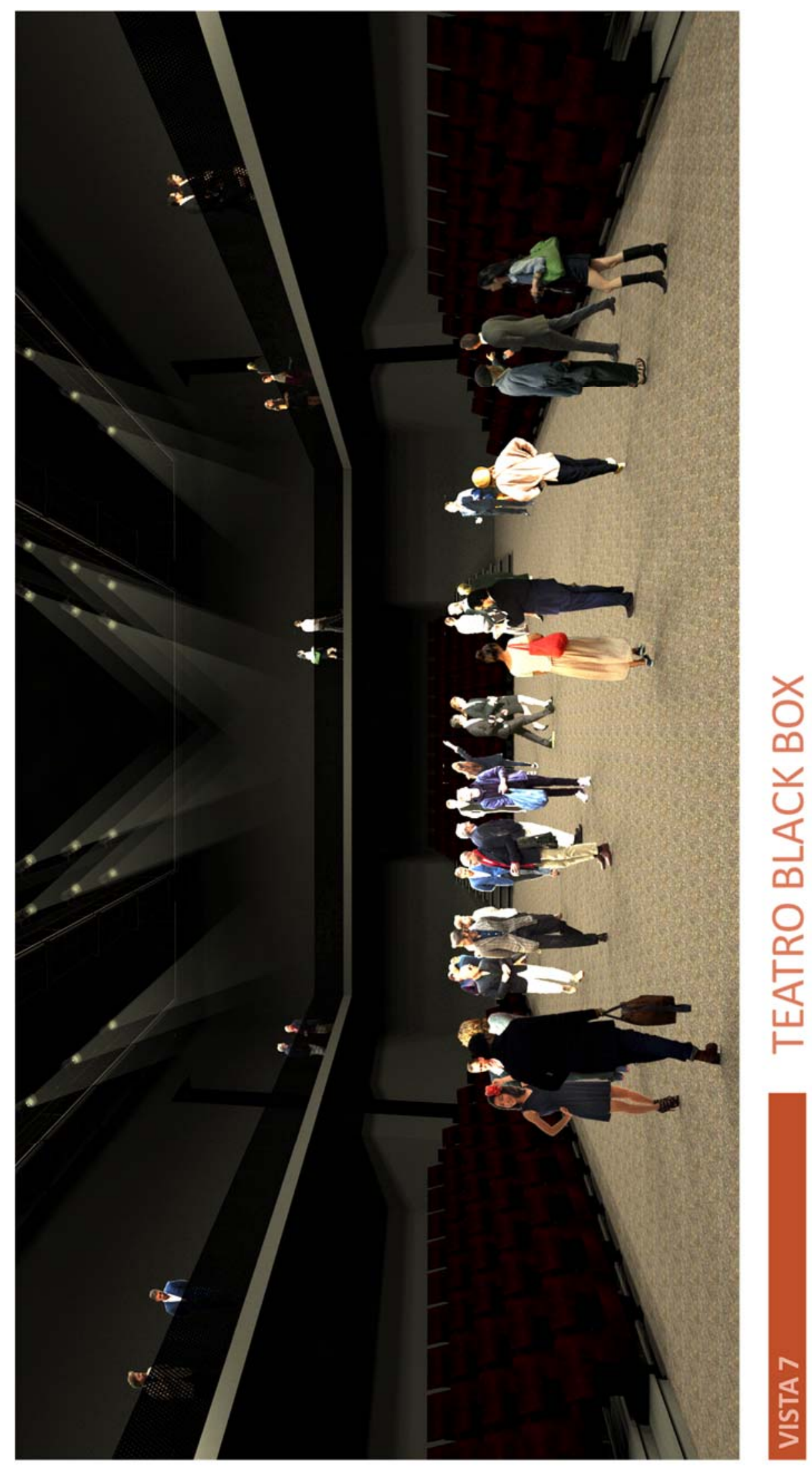

Figura 80. Vista 7. Elaboración Propia 


\section{CAPÍTULO VIII: NORMATIVA}

\subsection{Reglamento Nacional de Edificaciones - Norma A040 Educación}

\subsubsection{Aspectos generales}

Se denomina edificación de uso educativo a toda construcción destinada a prestar servicios de capacitación y educación y sus actividades complementarias.

Tipo de edificación: Centro de educación Superior: Escuela Superior de Arte dramático

\subsubsection{Criterios para seguir en la ejecución}

- Idoneidad de los espacios al uso previsto.

- Las medidas del cuerpo humano en sus diferentes edades.

- Cantidad, dimensiones y distribución del mobiliario necesario para cumplir con la función establecida.

- Flexibilidad para la organización de las actividades educativas, tanto individuales como colectivas.

\subsubsection{Criterios de ubicación en el Plan Urbano}

- Acceso mediante vías que permitan el ingreso de vehículos para la atención de emergencias.

- Posibilidad de uso para la comunidad.

- Capacidad de tener dotación suficiente de servicios de agua y energía.

- Necesidad de expansión futura.

- Topografías con pendientes menores a 5\%

- Impacto negativo del entorno en términos acústicos, respiratorios o de salubridad. 


\subsubsection{Criterios para crear ambientes propicios para el proceso de aprendizaje}

- Orientación y asoleamiento: tomar en cuenta clima predominante, viento y las diferentes estaciones, logrando que se maximice el confort.

- El dimensionamiento de los espacios educativos y mobiliario estará basado en las medidas y proporciones del cuerpo. Humano

- La altura mínima será de $2.50 \mathrm{~m}$

- La ventilación en los recintos educativos debe ser permanente, alta y cruzada.

- La iluminación natural debe estar distribuida de manera uniforme.

- El área de vanos para iluminación deberá tener como mínimo el $20 \%$ de la superficie del recinto

- La distancia entre la ventana única y la pared opuesta a ella será como máximo 2.5 veces la altura del recinto.

- La iluminación artificial deberá tener los siguientes niveles: Aulas (250 luxes), talleres (300 luxes), circulaciones (100 luxes) y servicios higiénicos (75 luxes).

- Las condiciones acústicas:

- Control de interferencias sonoras entre los distintos ambientes o recintos.

- Aislamiento de ruidos recurrentes provenientes del exterior

- Reducción de ruidos generados al interior del recinto.

\subsubsection{Circulaciones: las circulaciones verticales deben estar techadas}

Para el cálculo de las salidas de evacuación, ascensores, ancho y número de escaleras el número de personas se calculará según lo siguiente:

Auditorios - según el número de asientos Salas de Uso Múltiple - 1m2 por persona Salas de clase $-1.5 \mathrm{~m} 2$ por persona Camarines y gimnasios $-4 \mathrm{~m} 2$ por persona

Talleres, Laboratorios, Biblioteca - $5 \mathrm{~m} 2$ por persona Administración - $10 \mathrm{~m} 2$ por persona

\subsubsection{Características de los componentes}

- Pintura debe ser lavable 
- Servicios higiénicos cubiertos con materiales impermeables y de fácil limpieza

- Los pisos serán de materiales antideslizantes, resistentes al tránsito intenso y al agua.

- Las puertas de circulación deben abrir hacia afuera sin interrumpir pasadizos de circulación.

- Ancho mínimo del vano de la puerta será de $1.00 \mathrm{~m}$

- Las escaleras deberán cumplir los siguientes requisitos. Ancho mínimo $1.20 \mathrm{~m}$, deberán tener pasamanos en ambos lados, el cálculo del número y ancho de escaleras se efectuará de acuerdo con el número de ocupantes.

- El número máximo de contrapasos sin descanso será de 16.

\subsubsection{Dotación de Servicios}

Deberá contar para servicios higiénicos de los alumnos, del personal docente, administrativo y de servicio.

Dotación de aparatos:

De 141 a 200 alumnos en hombres (3L, 3U, 31) y en mujeres (3L, 3I), por cada 80 alumnos adicionales (1L, 1u, 1I) y una ducha cada 60 alumnos.

\subsubsection{Dotación de agua}

Educación superior: 25 L x alumno x día 


\section{BIBLIOGRAFÍA}

Berenguer, Á. (2012). La enseñanza del teatro. Redacción para la conferencia de teatro y enseñanza de Angel Berenguer. Alcalá: Universidad de Alcalá. Buenos aires.

Comas, M. d. (2012). Registro Histórico de la Municipalidad de Comas. Lima.

Escuela Nacional de Arte Dramático - ENSAD. (s.f.). Recuperado el abril de 2014, de http://www.ensad.edu.pe/

Española, R. A. (2001). Diccionario de la Lengua Española, 22va Edición. España: Real Academia Española.

Festival Itinerante y encuentro de teatro popular (s.f.) Cultura sin fronteras. Obtenido de: http://fietpo.blogspot.com/

Gehl, J. (2006). La Humanización del Espacio Urbano. Barcelona: Reverte.

Lima Cultura. (abril de 2014). Lima cultura. Obtenido de http://www.limacultura.pe/teatros

Mdu, M. d. (2009). Jornada Internacional de Humanización del espacio Público.

Metropolitana, L. (2013). Diagnóstico Situacional de las y los adolescentes en 9 distritos de Lima Metropolitana. Lima.

Ministerio de Cultura (s.f.) Comas. Recuperado de: http://puntosdecultura.pe/region/comas0 ?page $=1$

Municipalidad Distrital de Comas (2006) Diagnóstico local participativo del consumo de drogas en el distrito de comas 2006. Obtenido de: http://www.cicad.oas.org/fortalecimiento_institucional/savia/PDF/diagnosticofinal/D iagnostico_Final_Comas.pdf.

Perez, R. V. (2012). Danza y teatro: espacio público y privado. Madrid.

Plazola, A. C. (2001). Enciclopedia de Arquitectura Plazola. Plazola Editores.

PUCP (2017) Especialidad de teatro, Plan de Estudios. Facultad de artes escénicas. Obtenido de: http://facultad.pucp.edu.pe/artes-escenicas/especialidades/teatro/plan-de-estudios/

PUCP. (s.f.). Plan de Estudios de la PUCP. Recuperado el Abril de 2014, de http://facultad.pucp.edu.pe/artes-escenicas/especialidades/teatro/plan-de-estudios/

RNE: Reglamento Nacional de Edificaciones del Perú

Rossi, A. (2016) Observatorio de espacios escénicos. Obtenido de: http://espaciosescenicos.org/Cabina-de-control-de-iluminacion 
Sarmiento, J. (22 de setiembre de 2016) GATS. Observatorio de espacios escénicos. Obtenido de: http://teatroclub.pe/portal/entrevistas/perfiles/jorge-sarmiento

Tarumba, L. (s.f.). Grupo Cultural La Tarumba. Recuperado el Mayo de 2014, de www.latarumba.com

UNESCO. (2014). Diccionario Web de la Unesco. Obtenido de http://databases.unesco.org/thessp/

Yuyachkani, G. (2014). http://www.yuyachkani.org. Obtenido de http://www.yuyachkani.org/comunidad.html 